\title{
AGC-2 Irradiation Data Qualification Final Report
}

\author{
Laurence C. Hull
}

July 2012

The INL is a

U.S. Department of Energy

National Laboratory

operated by

Battelle Energy Alliance

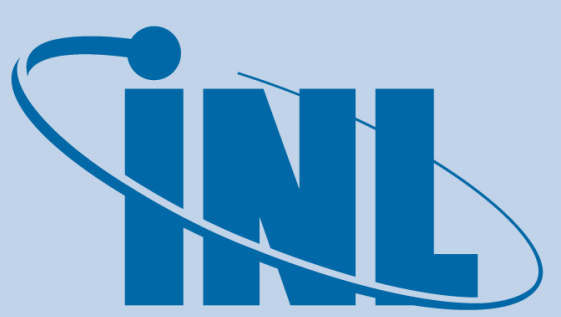

Idaho National Laboratory

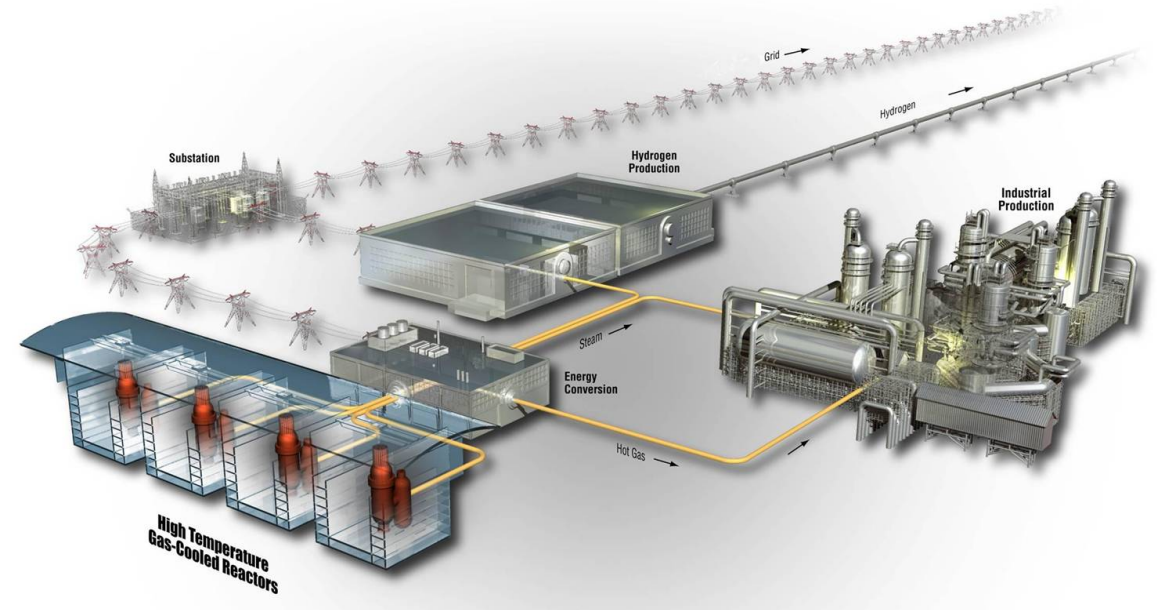




\section{DISCLAIMER}

This information was prepared as an account of work sponsored by an agency of the U.S. Government. Neither the U.S. Government nor any agency thereof, nor any of their employees, makes any warranty, expressed or implied, or assumes any legal liability or responsibility for the accuracy, completeness, or usefulness, of any information, apparatus, product, or process disclosed, or represents that its use would not infringe privately owned rights. References herein to any specific commercial product, process, or service by trade name, trade mark, manufacturer, or otherwise, does not necessarily constitute or imply its endorsement, recommendation, or favoring by the U.S. Government or any agency thereof. The views and opinions of authors expressed herein do not necessarily state or reflect those of the U.S. Government or any agency thereof. 


\title{
AGC-2 Irradiation Data Qualification Final Report
}

\author{
Laurence C. Hull
}

July 2012

\begin{abstract}
Idaho National Laboratory
VHTR Technology Development Office

Idaho Falls, Idaho 83415
\end{abstract}

Prepared for the

U.S. Department of Energy

Office of Nuclear Energy

Under DOE Idaho Operations Office

Contract DE-AC07-05ID14517 

Very High Temperature Reactor Technology Development Office

\title{
AGC-2 Irradiation Data Qualification Final Report
}

\author{
INL/EXT-12-26248
}

July 2012

Approved by:

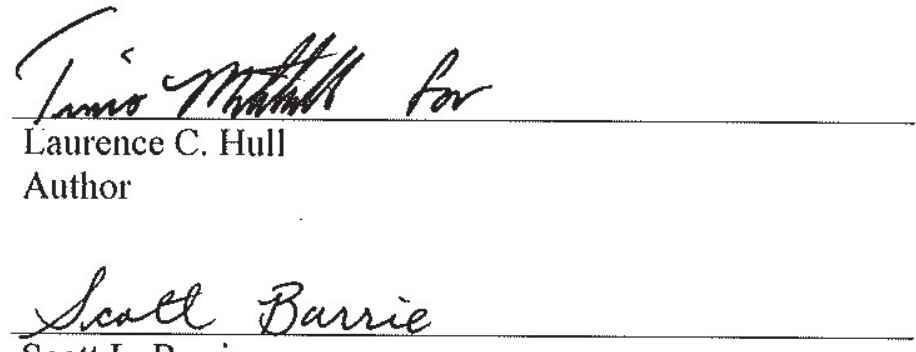

Scott L. Barrie

Independent Technical Reviewer
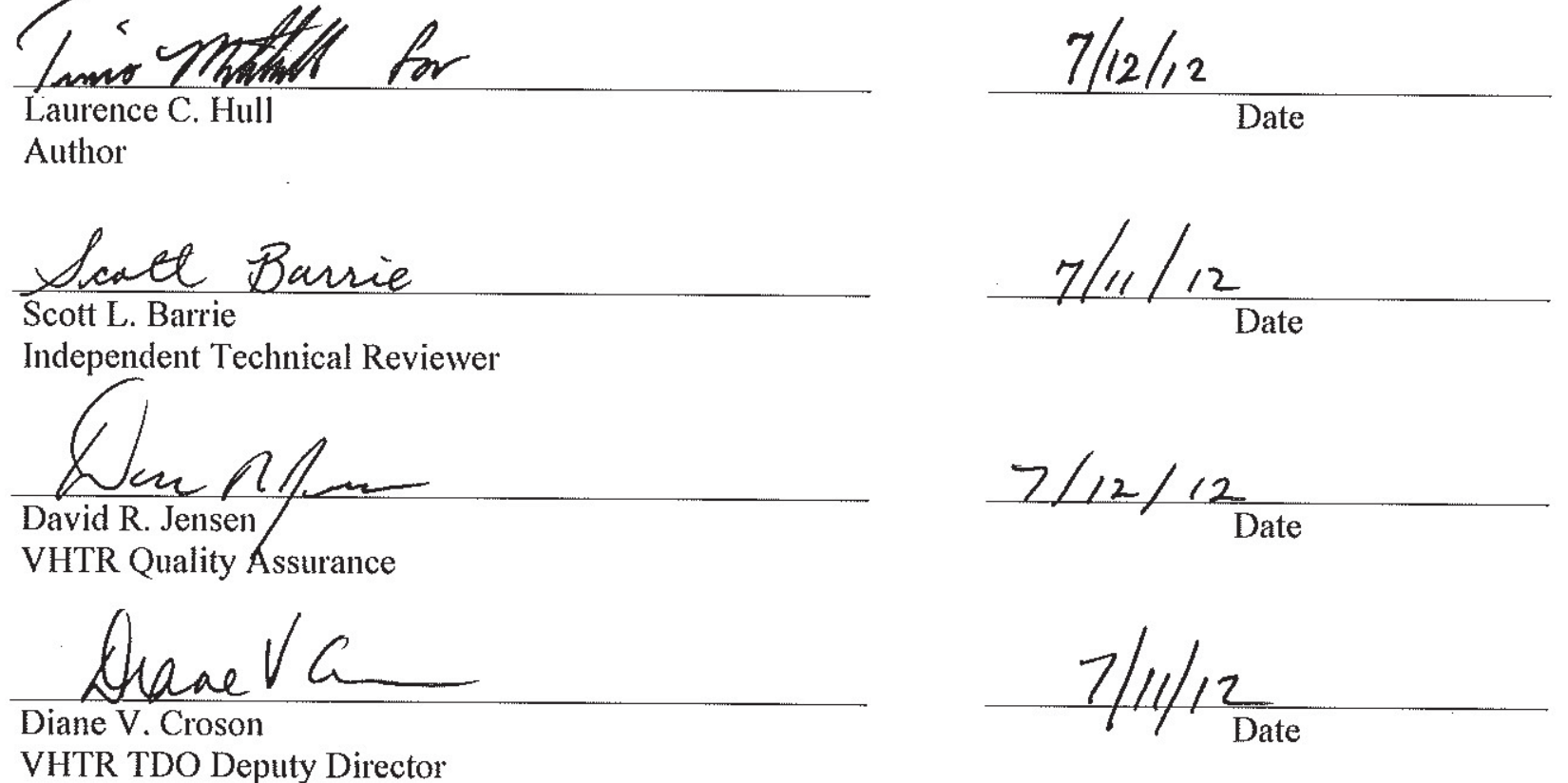



\section{SUMMARY}

The Graphite Technology Development Program will run a series of six experiments to quantify the effects of irradiation on nuclear grade graphite. The second Advanced Graphite Creep (AGC) experiment (AGC-2) began with Advanced Test Reactor (ATR) Cycle 149A on April 12, 2011, and ended with ATR Cycle 151B on May 5, 2012. The purpose of this report is to qualify AGC-2 irradiation monitoring data following Idaho National Laboratory Management and Control Procedure MCP-2691, "Data Qualification." Data that are Qualified meet the requirements for data collection and use as described in the experiment planning and quality assurance documents. Data that do not meet the requirements are Failed. Some data may not quite meet the requirements, but may still provide some useable information. These data are labeled as Trend. No Trend data were identified for the AGC-2 experiment.

All thermocouples functioned throughout the AGC-2 experiment. There was one instance where spurious signals or instrument power interruption resulted in a recorded temperature value being well outside physical reality. This value was identified and labeled as Failed data. All other temperature data are Qualified.

All helium and argon gas flow data are within expected ranges. Total gas flow was approximately $50 \mathrm{sccm}$ through the capsule. Helium gas flow was briefly increased to $100 \mathrm{sccm}$ during reactor shutdowns. All gas flow data are Qualified.

At the start of the experiment, moisture in the outflow gas line increased to 200 ppmv then declined to less than 10 ppmv over a period of 5 days. This increase in moisture coincides with the initial heating of the experiment and drying of the system. Moisture slightly exceeded $10 \mathrm{ppmv}$ three other times during the experiment. While these moisture values exceed the $10 \mathrm{ppmv}$ threshold value, the reported measurements are considered accurate and to reflect moisture conditions in the capsule. All moisture data are Qualified.

Graphite creep specimens were subjected to one of three loads, $393 \mathrm{lbf}$, $491 \mathrm{lbf}$, or $589 \mathrm{lbf}$. Loads were consistently within $5 \%$ of the specified values throughout the experiment. Stack displacement increased consistently throughout the experiment with total displacement ranging from 1 to 1.5 inches. No anomalous values were identified. During reactor outages, a set of pneumatic rams was used to raise the stacks of graphite creep specimens to ensure the specimens had not become stuck within the test train. This stack raising was performed after all cycles when the capsule was in the reactor. All stacks were raised successfully after each cycle. The load and displacement data are Qualified.

Analyses were conducted on correlations between thermocouples, differences between thermocouples, and differences between load cells to look for trends and step changes that might indicate instrument degradation or failure. Correlation analysis is used to identify instances when thermocouples form short circuits, referred to as virtual junctions, which results in thermocouples reporting temperatures from some location in the capsule other than the location where they are intended to read. No evidence was found for virtual junctions. Control charts for differences between thermocouples are used to identify instances when one thermocouple changes its behavior relative to the other thermocouples. No 
instances were found where a thermocouple significantly and uniformly changed behavior relative to the other thermocouples. Control charts for differences between load cells similarly showed no instances where one load cell changed behavior relative to the other load cells.

A total of 3,430,367 response values were recorded from irradiation monitoring of the AGC-2 experiment. Of these data, only one temperature measurement from TC-13 on May 23, 2011, at 10:55, failed to meet the requirements for data collection and accuracy. All other data are Qualified for use by the VHTR TDO Program. 


\section{CONTENTS}

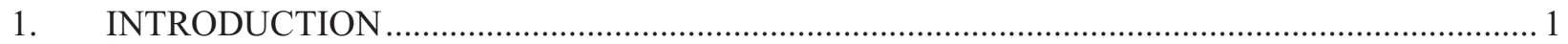

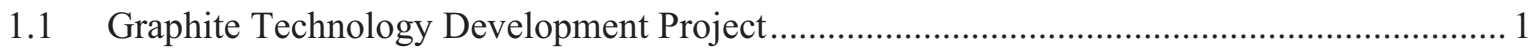

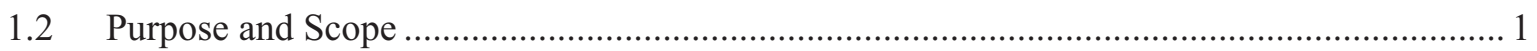

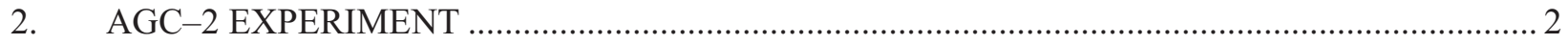

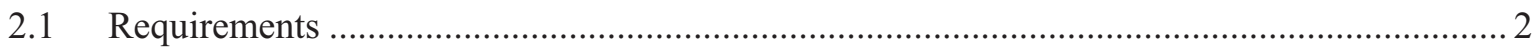

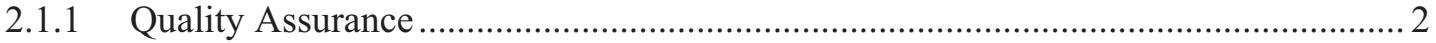

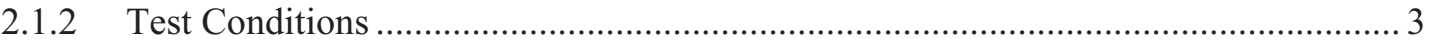

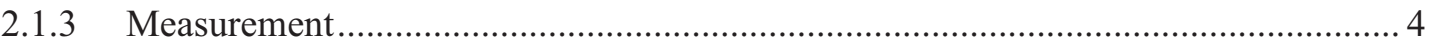

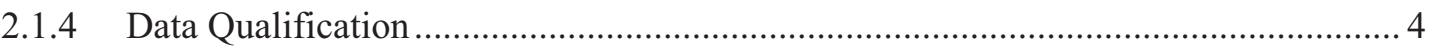

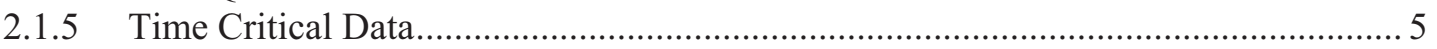

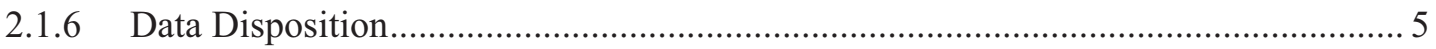

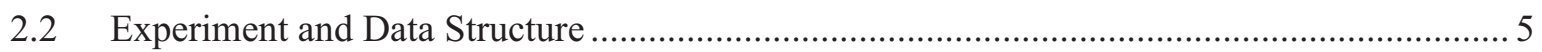

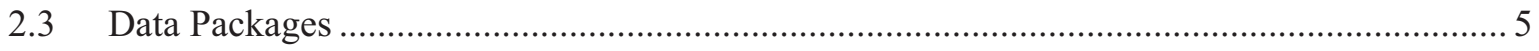

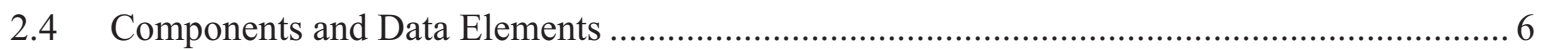

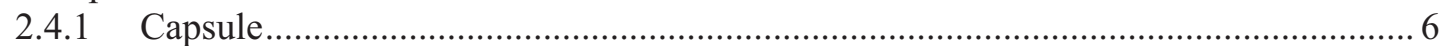

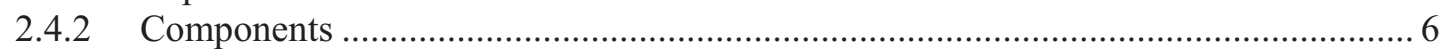

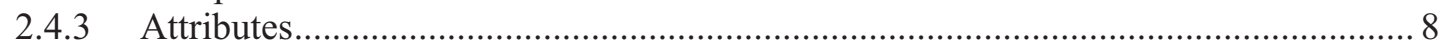

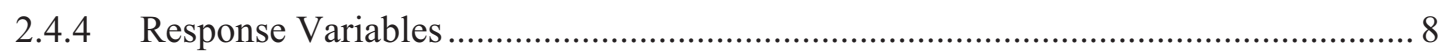

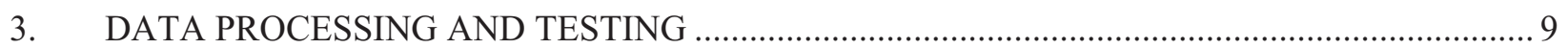

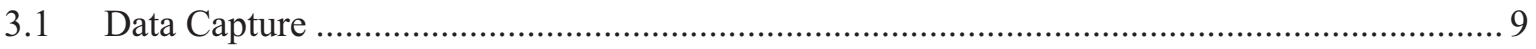

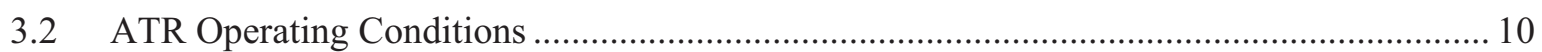

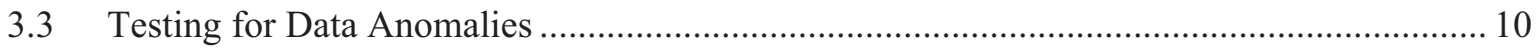

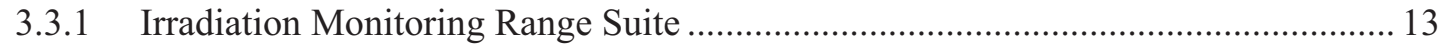

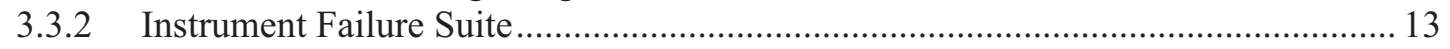

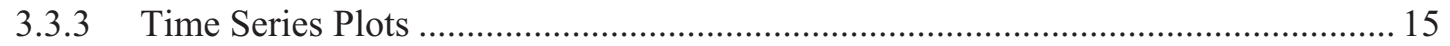

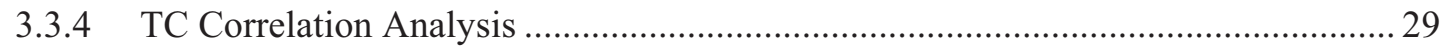

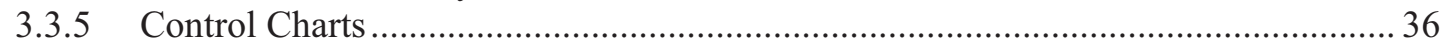

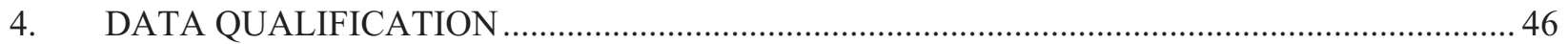

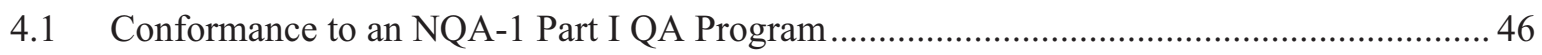

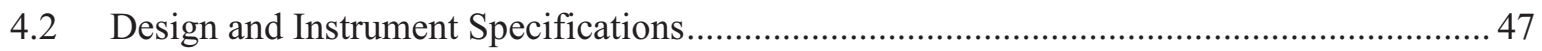

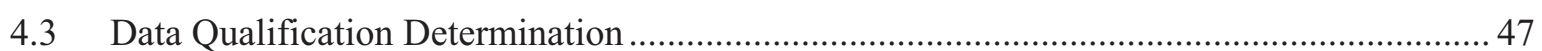

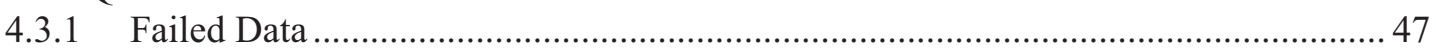

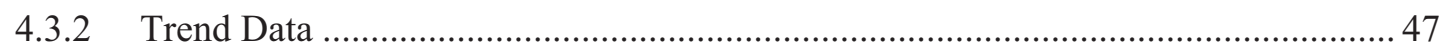

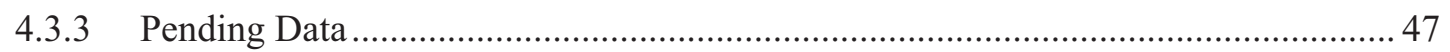

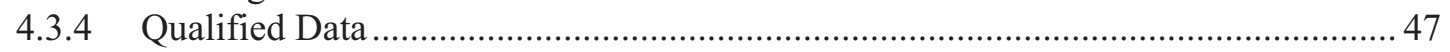

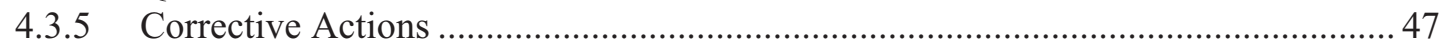

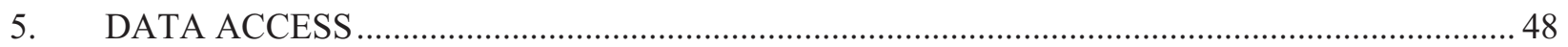

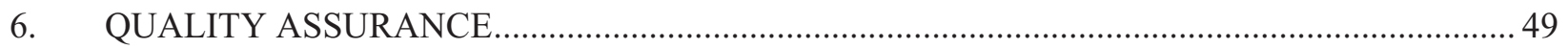

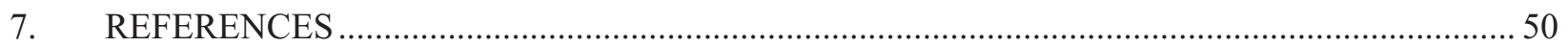




\section{FIGURES}

Figure 1. AGC-2 channel numbers and loads (Burchell 2009) ............................................................... 3

Figure 2. Stages of data processing in NDMAS. ...............................................................................

Figure 3. Effective power at the south flux trap during the AGC-2 experiment....................................... 10

Figure 4. Reported lobe powers in the ATR reactor fluctuate widely during periods of Nitrogen16 system calibration. The reported powers do not reflect actual reactor power during system calibration

Figure 5. Excursion of moisture in the gas outlet line above the 10 ppmv specification occurred four times during AGC-2. Horizontal reference line at 10 ppmv represents the maximum level desired in the capsule. The vertical reference line in $\mathrm{A}$ is the start of the AGC-2 experiment.

Figure 6. Temperature data grouped by distance from the core centerline............................................. 16

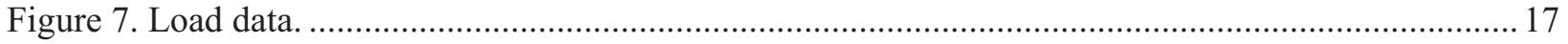

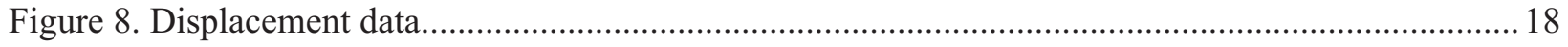

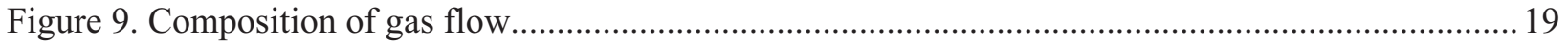

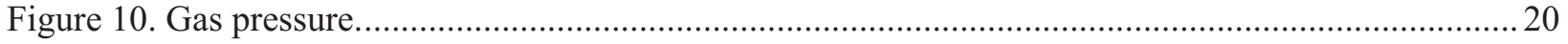

Figure 11. Change in stack position, raise pressure, stack load, and ram gas pressure for stack raising prior to Cycle 149A, immediately after installation of the AGC-2 capsule in the reactor and before irradiation

Figure 12. Change in stack position, raise pressure, stack load, and ram gas pressure for stack raising prior to Cycle 149A. This is a second round of stack raising prior to irradiation.

Figure 13. Change in stack position, raise pressure, stack load, and ram gas pressure for stack raising prior to Cycle 149B

Figure 14. Change in stack position, raise pressure, stack load, and ram gas pressure for stack raising prior to Cycle 150A. This demonstrates that graphite specimens were free prior to the capsule being removed for the high-power Cycle 150A.

Figure 15. Change in stack position, raise pressure, stack load, and ram gas pressure for stack raising prior to Cycle 151A.

Figure 16. Change in stack position, raise pressure, stack load, and ram gas pressure for stack raising on February 12, 2012, prior to Cycle 151B

Figure 17. Change in stack position, raise pressure, stack load, and ram gas pressure for stack raising on March 22, 2012, prior to Cycle 151B.

Figure 18. Change in stack position, raise pressure, stack load, and ram gas pressure for stack raising on March 28, 2012, prior to Cycle 151B.

Figure 19. Change in stack position, raise pressure, stack load, and ram gas pressure for stack raising on May 8 and 9, 2012, prior to Cycle 152A at the end of the AGC-2 experiment........29

Figure 20. The level of the TC with the highest correlation to TC01 at Level $8(45.7 \mathrm{~cm}) \ldots \ldots \ldots \ldots \ldots \ldots \ldots . . . . . . . .30$

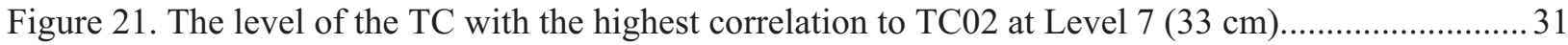




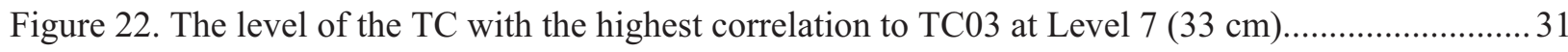

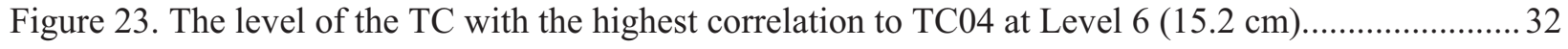

Figure 24. The level of the TC with the highest correlation to TC05 at Level $6(15.2 \mathrm{~cm}) \ldots \ldots \ldots \ldots \ldots \ldots \ldots . . . . . . . .32$

Figure 25. The level of the TC with the highest correlation to TC06 at Level $5(5.1 \mathrm{~cm}) \ldots \ldots \ldots \ldots \ldots \ldots \ldots . . . . . . . . .33$

Figure 26. The level of the TC with the highest correlation to TC07 at Level $4(-15.2 \mathrm{~cm}) \ldots \ldots \ldots \ldots \ldots \ldots . . . . . . .33$

Figure 27. The level of the TC with the highest correlation to TC08 at Level $4(-15.2 \mathrm{~cm})$................... 34

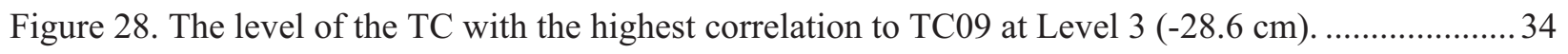

Figure 29. The level of the TC with the highest correlation to TC10 at Level $2(-45.7 \mathrm{~cm}) \ldots \ldots \ldots \ldots \ldots \ldots \ldots . . . . . . .35$

Figure 30. The level of the TC with the highest correlation to TC11 at Level $2(-45.7 \mathrm{~cm}) \ldots \ldots \ldots \ldots \ldots \ldots \ldots . . . . . . .35$

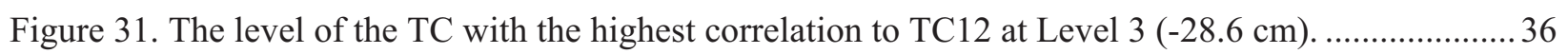

Figure 32. Difference TC01-TC011 has the greatest percent of out-of-control values in the monitoring period for TC01 along with a moderate upward trend and bias.............................. 38

Figure 33. Difference TC02-TC11 has the greatest percent of out-of-control values in the monitoring period for TC02 along with moderate upward trend and bias.

Figure 34. Difference TC03-TC05 has the greatest percent of out-of-control values in the monitoring period for TC03 along with a strong downward trend and bias downward.

Figure 35. Difference TC04-TC11 has the greatest percent of out-of-control values in the monitoring period for TC14 along with a moderate upward trend and bias.

Figure 36. Difference TC05-TC09 has the greatest percent of out-of-control values in the monitoring period for TC05 with a moderate upward trend but not a significant bias.

Figure 37. Difference TC06-TC11 has the greatest percent of out-of-control values in the monitoring period for TC05 with a moderate upward trend and bias

Figure 38. Difference TC07-TC10 has the greatest percent of out-of-control values in the monitoring period for TC07 with a positive bias but no trend.

Figure 39. Difference TC08-TC12 has the greatest percent of out-of-control values in the monitoring period for TC08 with no trend and no bias.

Figure 40. Difference TC09-TC10 shows a strong upward trend and bias with a significant fraction of values out of control.

Figure 41. Difference TC10-TC11 has no out-of-control measurements, but shows a moderate downward trend and bias. .43

Figure 42. Difference TC11-TC12 has no out-of-control measurements with no trend and no bias.........43

Figure 43. Control chart for differences between load cell pair LC01-LC04 ......................................... 44

Figure 44. Control chart for differences between load cell pair LC02-LC05 ........................................45

Figure 45. Control chart for differences between load cell pair LC03-LC06....................................... 45

Figure 46. The AGC-2 irradiation monitoring tab (orange highlight) on the NDMAS webpage provides access to a series of reports and graphs. 


\section{TABLES}

Table 1. Graphite experiments identified in Revision 7 of the VHTR TDO Program Management

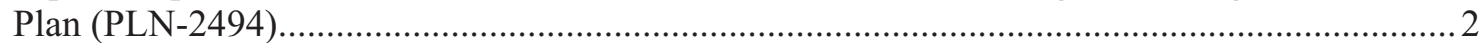

Table 2. Components and response variables monitored for the AGC-2 experiment.............................. 7

Table 3. Tests and test suites defined for evaluating AGC-2 irradiation monitoring data......................... 12

Table 4. Test ranges applied to AGC-2 irradiation monitoring data........................................................... 12 


\section{ACRONYMS}

AGC Advanced Graphite Creep

AGR Advanced Gas Reactor

ATR Advanced Test Reactor

INL Idaho National Laboratory

NDMAS Nuclear Data Management and Analysis System

QA quality assurance

SQL Structured Query Language

TC thermocouple

TDO Technology Development Office

TFR Technical and Functional Requirements

VHTR very high temperature reactor (type) and Very High Temperature Reactor (Program) 


\section{AGC-2 Irradiation Data Qualification Final Report}

\section{INTRODUCTION}

The Very High Temperature Reactor (VHTR) Technology Development Office (TDO) is responsible for research and development activities required to design and license the first VHTR nuclear plant. Materials to be used in the reactor will be tested and characterized to quantify performance in high temperature and high fluence environments. This report presents data qualification for the capsule irradiation monitoring data collected from the second Advanced Graphite Creep (AGC) experiment (AGC-2) during reactor Cycles 149A, 149B, 150B, 151A, and 151B. The capsule was removed from the reactor during Cycle 150A. These cycles spanned the time frame from April 12, 2011, to May 5, 2012.

\subsection{Graphite Technology Development Project}

The Graphite Technology Development Project provides data to support the design of graphite core components within the specific reactor service conditions of the VHTR (Windes et al. 2007). The objectives of the graphite irradiation experiments are to:

- Demonstrate that commercially available nuclear-grade graphite exhibits acceptable nonirradiated and irradiated properties for use in nuclear reactor structural components

- Establish the lifetime under VHTR neutron radiation and temperature regimes for specific graphite types.

To meet these objectives, the Graphite Project has established the following data collection tasks:

- Measure thermophysical properties of graphite specimens before and after irradiation in the Advanced Test Reactor (ATR)

- Measure radiation induced creep at high temperature and high radiation dose.

Data collected during specimen irradiation are used to quantify the temperatures, radiation doses, and compressive stresses experienced by specimens. These data are necessary to develop an understanding of the behavior of graphite in radiation fields.

\subsection{Purpose and Scope}

This report documents whether AGC-2 irradiation monitoring data meet the requirements for data collection as specified in Technical and Functional Requirements (TFR) documents and Quality Assurance (QA) plans. Data handling is described showing how data are passed from the data collection project to the Nuclear Data Management and Analysis System (NDMAS) team. The data structure is described, including data packages, components, attributes, and response variables. The description of the approach to data qualification included the steps taken to qualify data and the specific tests used to verify that data meet requirements. Finally, the current status of data received by NDMAS from the AGC-2 irradiation experiment is presented with summarized information on test results and resolutions. This report addresses all of the irradiation monitoring data collected during the AGC-2 experiment. 


\section{AGC-2 EXPERIMENT}

The AGC Irradiation Test program supports the acquisition of irradiated graphite performance data to assist in selecting the technology to be used for the VHTR. Six irradiation experiments are planned to investigate compressive creep in graphite subjected to a neutron field, and to obtain irradiated mechanical properties of vibrationally molded, extruded, and isomolded graphite for comparison as shown in Table 1. The major objective of AGC-2 is to provide irradiation creep data. This requires matched pairs of stressed and unstressed specimens to be irradiated. This is achieved using the axial flux symmetry in ATR, with a stressed specimen above the symmetry plane matched to an unstressed specimen placed below the symmetry plane. This arrangement is used in six channels around the periphery of a graphite experiment capsule with a center channel used for additional unstressed specimens.

The AGC-2 experiment follows the design of AGC-1 very closely, and so AGC-1 planning documents also describe the AGC-2 experiment. AGC-1 is described in two reports: AGC-1 Irradiation Experiment Test Plan (Bratton 2006), and A Revised AGC-1 Creep Capsule Layout (Burchell 2009). The AGC-2 experiment was irradiated in the south flux trap of ATR to a peak irradiation dose of about 3 dpa (displacements per atom) at an intended irradiation temperature of $600^{\circ} \mathrm{C}$. The irradiation had a planned duration of 280 effective-full-power days with an estimated actual irradiation of 240 effective-full-power days. The capsule was removed from the reactor during Cycle 150A. At the beginning of the experiment, Channel 1 was oriented north, facing core center. Between Cycles 150B and 151A, the AGC-2 experiment capsule was rotated 180 degrees to more evenly distribute radiation dose.

Table 1. Graphite experiments identified in Revision 7 of the VHTR TDO Program Management Plan (PLN2494).

\begin{tabular}{cll}
\hline Experiment Name & $\begin{array}{c}\text { Experiment } \\
\text { Abbreviation }\end{array}$ & \multicolumn{1}{c}{ Experiment Description } \\
\hline Advanced Graphite Capsule 1 & AGC-1 & $600^{\circ} \mathrm{C}$ and 3-6 dpa. \\
Advanced Graphite Capsule 2 & AGC-2 & $600^{\circ} \mathrm{C}$ and $0.5-3 \mathrm{dpa}$. \\
Advanced Graphite Capsule 3 & AGC-3 & $900^{\circ} \mathrm{C}$ and $0.5-3 \mathrm{dpa}$. \\
Advanced Graphite Capsule 4 & AGC-4 & $900^{\circ} \mathrm{C}$ and 3-6 dpa. \\
Advanced Graphite Capsule 5 & AGC-5 & $1200^{\circ} \mathrm{C}$ and $0.5-3 \mathrm{dpa}$. \\
Advanced Graphite Capsule 6 & AGC-6 & $1200^{\circ} \mathrm{C}$ and 3-6 dpa. \\
\hline
\end{tabular}

\subsection{Requirements}

Requirements for the AGC-2 capsule irradiation monitoring are presented in three INL TFRs: "Advanced Graphite Capsule AGC-2 Experimental Test Train" (TFR-645), "Advanced Graphite Capsule Temperature Control System" (TFR-509), and "Advanced Graphite Capsule Compressive Load Control Gas System" (TFR-510). Temperature control and compressive load systems are unchanged from the AGC-1 experiment and use the same TFRs.

\subsubsection{Quality Assurance}

The AGC-2 graphite irradiation experiment was conducted within an NQA-1, Part I, compliant QA program as implemented in the "Very-High-Temperature-Gas Reactor Technology Development Office Quality Assurance Program Plan" (PLN-2690) 


\subsubsection{Test Conditions}

\subsubsection{Temperature}

The experiment maximized the number of specimens at a temperature of $600^{\circ} \mathrm{C}$ along the $1.22-\mathrm{m}$ length of the core. Since the flux decreases rapidly at the ends of the capsule, maintaining a uniform axial temperature profile in the test would require additional design complexity. Thus, the graphite samples at the ends of the test would see lower temperatures than $600^{\circ} \mathrm{C}$. The instantaneous peak temperature for each specimen was not to exceed $650^{\circ} \mathrm{C}$, nor was each specimen's time and volume average minimum temperature to be less than $550^{\circ} \mathrm{C}$.

\subsubsection{Load}

To evenly balance the stresses on the graphite body within the capsule, each pair of opposing channels were stressed to one of three stress levels as shown in Figure 1: $13.8 \mathrm{MPa}$ (393 lbf, $2 \mathrm{ksi}$ ), 17.3 MPa (491 lbf, $2.5 \mathrm{ksi}$ ), or $20.7 \mathrm{MPa}$ (589 lbf, $3 \mathrm{ksi}$ ) (Burchell 2009). The central channel was not stressed. The load was generated by six pneumatic rams located in the 5-inch pressure boundary. Graphite pushrods transmitted the force of the ram's piston onto the graphite columns. The loading system had the capability to compensate for thermal expansion and expected graphite shrinkage during the experiment. This was accomplished by using administrative feedback from in-line load cells (determining pressure response) between the pneumatic rams and pushrods to maintain the correct loading on the columns via the correct pressure in the cylinders.

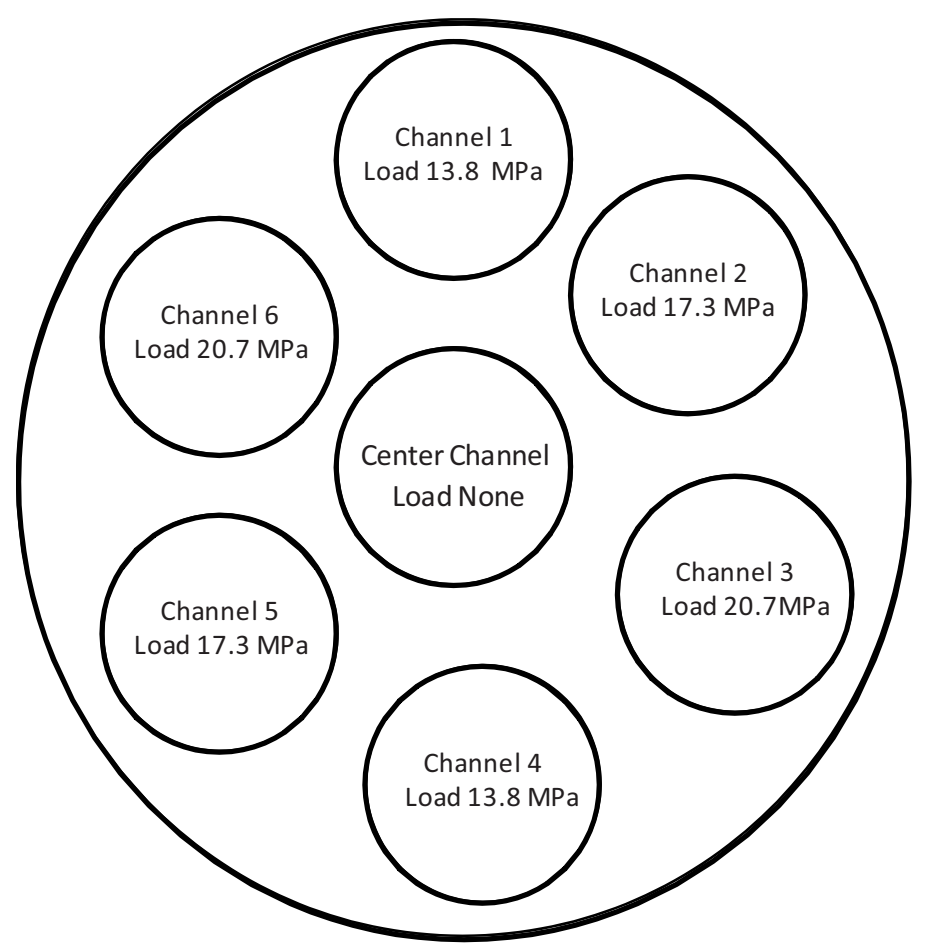

Figure 1. AGC-2 channel numbers and loads (Burchell 2009).

\subsubsection{Fluence}

Specimens were exposed to fast neutron fluence $(\mathrm{E}>0.1 \mathrm{MeV})$ between $0.5 \mathrm{E}+21 \mathrm{n} / \mathrm{cm}^{2}$ and $5.5 \mathrm{E}+21 \mathrm{n} / \mathrm{cm}^{2}$. The fluence difference between graphite specimens at equal distances above and below 
the core centerline was not to exceed $10 \%$. Fluence, determined by computer modeling of reactor physics, will be verified by flux wires installed in the AGC-2 capsule.

\subsubsection{Measurement}

\subsubsection{Temperature}

Thermocouples (TCs) used to record capsule temperatures were selected based on operating range and the ability to withstand the effects of the high neutron fluences planned for this irradiation. Temperature was measured at 12 locations throughout the vertical extent of the capsule.

\subsubsection{Temperature Control and Sweep Gas}

All sweep gases entering the capsule were to be filtered to remove oxygen and moisture. The sweep gas was to contain less than 5 ppmv $\mathrm{O}_{2}$ and less than $10 \mathrm{ppmv}$ moisture prior to entering the experiment. The sweep gas was a mixture of helium and argon or 100\% helium. Gas flow rates, line pressures, and outlet moisture were recorded at one-minute intervals. Gas mixtures were to be recorded every 10 seconds.

\subsubsection{Load}

The pneumatic rams used to apply stress to the six stacks of graphite specimens were controlled by applying the desired load within $\pm 5 \%$. The load cells have a maximum load rating of $\pm 1,000 \mathrm{lbf}$ with no more than a $\pm 5 \%$ error in load measurement. During reactor outages, the compressive load from the upper pneumatic rams was removed and the specimen stacks were raised by lower pneumatic rams to ensure that the graphite stack was not lodged or jammed in the graphite holder. Experiment data were recorded at 1-minute intervals.

\subsubsection{ATR Operating Conditions}

ATR data that described the core neutronics and thermal-hydraulics environment were gathered. These data will be used to assist the physics analysis necessary for the final test report. Data provided include individual lobe powers and shim cylinder positions. These data were recorded and backed up on a separate storage device once every minute.

\subsubsection{Neutron Dosimetry}

The volume average fast neutron fluence for the graphite specimens were inferred from physics calculations normalized by the flux wire measurements performed after capsule disassembly. The flux wires were chosen to measure the fast spectrum greater than $0.1 \mathrm{MeV}$.

\subsubsection{Data Qualification}

All electronically recorded data will be evaluated for validation and qualified against data collection requirements. The following parameters were qualified for use, and therefore identified as Type $A^{\text {a }}$ data: TC temperatures, pneumatic ram pressures, load cell output, stack position, constituent sweep gas flow rates and pressure, and outlet moisture.

a. Type $A$ - data collected within an NQA-1 QA program that are collected to meet specific requirements with independent verification that those requirements were met. 


\subsubsection{Time Critical Data}

Technical staff needed to have access to the capsule monitoring data to evaluate whether experimental parameters were within specifications, determine whether instruments functioned as planned, and assess the experiments progress. TC temperatures, pneumatic ram gas pressures, load cell output, stack position, constituent sweep gas flow rates and pressure, and measured sweep gas outlet species were displayed on the Web and made accessible during the experiment.

\subsubsection{Data Disposition}

Irradiation monitoring data consisting of TC temperatures, pneumatic ram pressures, load cell output, stack position, constituent sweep gas flow rates and pressure, and measured sweep gas inlet and outlet species were archived in NDMAS. INL Form 435.77, "The Next Generation Nuclear Plant Project Information Input Sheet," covering the irradiation monitoring data was filed with VHTR Records Management in accordance with the "Records Management Plan for the VHTR Technology Development Office" (PLN-3319).

\subsection{Experiment and Data Structure}

The design of the graphite experimental program data storage structure was based on a hierarchy of Experiment

Data stream

Data package

Data element.

This section expands on this hierarchy by explaining these four levels and the types of information collected for them. Six experiments have been planned in the graphite irradiation program (Table 1). The AGC-2 experiment consisted of four data streams: preirradiation characterization, irradiation monitoring, post-irradiation examination, and thermal and neutronics calculations. This report addresses qualification of the irradiation monitoring data stream of the AGC-2 experiment.

\subsection{Data Packages}

AGC-2 irradiation monitoring data were received by NDMAS approximately every week. Each batch of data received is termed a data package. Data were transmitted in comma-separated values (csv) text files, each containing data from a 1-week period of time. Each file contains date and time in the first two columns followed by response variable data in columns. Column headers in the first row identify the data contained in that column. Data are provided as time-average values. The averaging time varied over the experiment from a low of 1 minute to a high of 10 minutes. Most of the data were collected as 5-minute average values.

The files were placed on the $\backslash \backslash$ fsisc 1 server by ATR operations then copied to NDMAS archive server IIisasapp, with operating system verification of the copy process. Once on the NDMAS server, the files were added to the subversion system, which provides configuration control for archived files. SAS ${ }^{\circledR}$ Enterprise Guide projects were then used to read data from the csv files. 


\subsection{Components and Data Elements}

The data element is the recorded single variable value that provides information about the system or object being measured. Data elements are divided into response and attribute elements. Simply defined, response elements are numeric values that describe the response of the object or system such as pressure, temperature, and elastic modulus. Attribute elements generally describe the object or system being measured, or provide category or spatial information about the object such as graphite grade or irradiation position.

Both response and attribute values are associated with a component - the generic name for the object or system being measured. Examples of components are capsule, outer gas annulus, or TC. Component attributes provide additional information about the components. The components established for the AGC-2 irradiation monitoring data stream are listed in Table 2. Multiple response variables can be associated with a single component.

\subsubsection{Capsule}

The AGC-2 irradiation capsule is approximately $1.22 \mathrm{~m}$ long and contains seven channels that are loaded with stacks of graphite specimens. The six peripheral channels contain stressed creep specimens in the upper housing and paired unstressed graphite specimens in the lower housing (Bratton 2006;

TFR-645). The apparent irradiation creep strain will be determined from the difference in the dimensional changes between stressed and unstressed specimens irradiated at the same temperature and to the same neutron damage dose. In addition to the unstressed creep control specimens, each specimen stack also contains a number of smaller piggy back specimens of other VHTR-relevant graphite. The central channel contains unstressed piggy back specimens and a few specimens of highly oriented pyrolytic graphite.

\subsubsection{Components}

The highest level component in the component-assembly tree is the capsule. For AGC experiments, there is only one capsule. Components are selected to represent the physical system collecting the data. The components consist of: one capsule, seven channels, 13 TCs, a gas annulus inside the heat shield, a gas annulus outside the heat shield, and an outlet gas line (Table 2). The vertical positions of TCs 12 and 13 were changed between AGC-1 and AGC-2. TC-12 was brought closer to the core center line, and TC13 was raised to be further above the core. 
Table 2. Components and response variables monitored for the AGC-2 experiment.

\begin{tabular}{|c|c|c|}
\hline Component & Component Attribute & Response Variables \\
\hline AGC-2 Capsule & & Raise pressure (psig) \\
\hline \multicolumn{3}{|l|}{ Reference TC } \\
\hline TC01 & $45.7 \mathrm{~cm}$ above reactor center line & Temperature $\left({ }^{\circ} \mathrm{C}\right)$ \\
\hline TC02 & $33.0 \mathrm{~cm}$ above reactor center line & Temperature $\left({ }^{\circ} \mathrm{C}\right)$ \\
\hline TC03 & $33.0 \mathrm{~cm}$ above reactor center line & Temperature $\left({ }^{\circ} \mathrm{C}\right)$ \\
\hline $\mathrm{TC} 04$ & $15.2 \mathrm{~cm}$ above reactor center line & Temperature $\left({ }^{\circ} \mathrm{C}\right)$ \\
\hline TC05 & $15.2 \mathrm{~cm}$ above reactor center line & Temperature $\left({ }^{\circ} \mathrm{C}\right)$ \\
\hline $\mathrm{TC} 06$ & $5.1 \mathrm{~cm}$ above reactor center line & Temperature $\left({ }^{\circ} \mathrm{C}\right)$ \\
\hline TC07 & $15.2 \mathrm{~cm}$ below reactor center line & Temperature $\left({ }^{\circ} \mathrm{C}\right)$ \\
\hline TC08 & $15.2 \mathrm{~cm}$ below reactor center line & Temperature $\left({ }^{\circ} \mathrm{C}\right)$ \\
\hline TC09 & $28.6 \mathrm{~cm}$ below reactor center line & Temperature $\left({ }^{\circ} \mathrm{C}\right)$ \\
\hline TC10 & $45.7 \mathrm{~cm}$ below reactor center line & Temperature $\left({ }^{\circ} \mathrm{C}\right)$ \\
\hline TC11 & $45.7 \mathrm{~cm}$ below reactor center line & Temperature $\left({ }^{\circ} \mathrm{C}\right)$ \\
\hline TC12 & $28.6 \mathrm{~cm}$ below reactor center line & Temperature $\left({ }^{\circ} \mathrm{C}\right)$ \\
\hline TC13 & $358.6 \mathrm{~cm}$ above reactor center line & Temperature $\left({ }^{\circ} \mathrm{C}\right)$ \\
\hline Channel 1 & - & $\begin{array}{l}\text { Ram gas pressure (psig) } \\
\text { Load (lbf) } \\
\text { Specimen position (in) }\end{array}$ \\
\hline Channel 2 & - & $\begin{array}{l}\text { Ram gas pressure (psig) } \\
\text { Load (lbf) } \\
\text { Specimen position (in) }\end{array}$ \\
\hline Channel 3 & - & $\begin{array}{l}\text { Ram gas pressure (psig) } \\
\text { Load (lbf) } \\
\text { Specimen position (in) }\end{array}$ \\
\hline Channel 4 & - & $\begin{array}{l}\text { Ram gas pressure (psig) } \\
\text { Load (lbf) } \\
\text { Specimen position (in) }\end{array}$ \\
\hline Channel 5 & - & $\begin{array}{l}\text { Ram gas pressure (psig) } \\
\text { Load (lbf) } \\
\text { Specimen position (in) }\end{array}$ \\
\hline Channel 6 & - & $\begin{array}{l}\text { Ram gas pressure (psig) } \\
\text { Load (lbf) } \\
\text { Specimen position (in) }\end{array}$ \\
\hline \multicolumn{3}{|l|}{ Center Channel } \\
\hline $\begin{array}{l}\text { Gas annulus inside } \\
\text { shield }\end{array}$ & - & $\begin{array}{l}\text { Helium gas flow }(\mathrm{sccm}) \\
\text { Argon gas flow }(\mathrm{sccm}) \\
\text { Total gas flow }(\mathrm{sccm}) \\
\text { Gas pressure (psia) }\end{array}$ \\
\hline $\begin{array}{l}\text { Gas annulus } \\
\text { outside shield }\end{array}$ & - & $\begin{array}{l}\text { Helium gas flow }(\mathrm{sccm}) \\
\text { Argon gas flow }(\mathrm{sccm}) \\
\text { Total gas flow }(\mathrm{sccm}) \\
\text { Gas pressure (psia) }\end{array}$ \\
\hline Outlet gas line & - & $\begin{array}{l}\text { Moisture content (ppmv) } \\
\text { Gas composition (ppmv) }\left[\mathrm{CO}_{2}, \mathrm{CO}\right] \\
\text { Gas pressure (psia) }\end{array}$ \\
\hline
\end{tabular}




\subsubsection{Attributes}

TCs are the only component for which attributes have been defined. TC attributes identify the position of the TC in the graphite capsule.

\subsubsection{Response Variables}

Capsule monitoring parameters are also specified in Table 2. Pneumatic rams provide the compressive load on the stressed specimens in the six specimen stacks (TFR-510). The upper rams and lower bellows are located away from the high neutron and gamma fields of the ATR core. The force exerted on the specimens is transmitted by stainless-steel pushrods in the leadout to graphite pushrods inside the high temperature graphite holder. An in-line load cell, located above the reactor core and between the pneumatic rams and the push bars, was used to monitor the force on the graphite specimens in each stack. The position of the pushrod is monitored to record the compression of the graphite specimens.

Twelve TCs are distributed between the specimen stacks and arranged throughout the height of the capsule to monitor temperature during irradiation. The TCs are installed as deemed appropriate to monitor and control the specimen temperatures during irradiation.

The temperature inside the capsule is controlled by altering the thermal conductivity of gas in the annulus around the capsule. Temperature readings from the TCs are used by the gas flow control system to control the experiment temperature by adjusting the argon-to-helium gas ratio in the annulus of the experiment capsule (TFR-509). The helium and argon gas flow rates, total gas flow, and gas pressure are monitored.

The fast neutron fluence $(\mathrm{E}>0.1 \mathrm{MeV})$ will be measured by flux wires located within the six peripheral channels. Physics calculations were also performed to estimate temperatures and dose to graphite specimens. The composition of the gas stream will be used in heat transport simulations to calculate the average temperature at the specimen locations. 


\section{DATA PROCESSING AND TESTING}

Data generated by the AGC-2 experiment must be qualified for use, stored in a readily accessible electronic form, and controlled to ensure the correct data are used. The graphite data are stored in NDMAS to address these requirements. NDMAS provides a controlled and secure electronic data storage environment, supports data qualification, identifies the qualification status of data, provides data analysis and modeling products, and makes data available for use to the program (PLN-2709). The data delivery portal is Web-based so program members can: access the system and review the data; obtain analysis results, including statistics and graphics; create slide presentations; and download data for advanced analysis. By performing these roles, the NDMAS assures the correct data are used by the project and data of known quality are available to support future licensing.

Data received from the AGC-2 experiment are archived on the NDMAS server as shown in Figure 2. The native files are then read and the data captured to the NDMAS Microsoft Structured Query Language $\left(\mathrm{SQL}^{\circledR}\right) 2008$ database (aka "the vault"). Details of data handling and storage are given in the "VeryHigh-Temperature-Reactor Program Data Management and Analysis Plan” (PLN-2709).

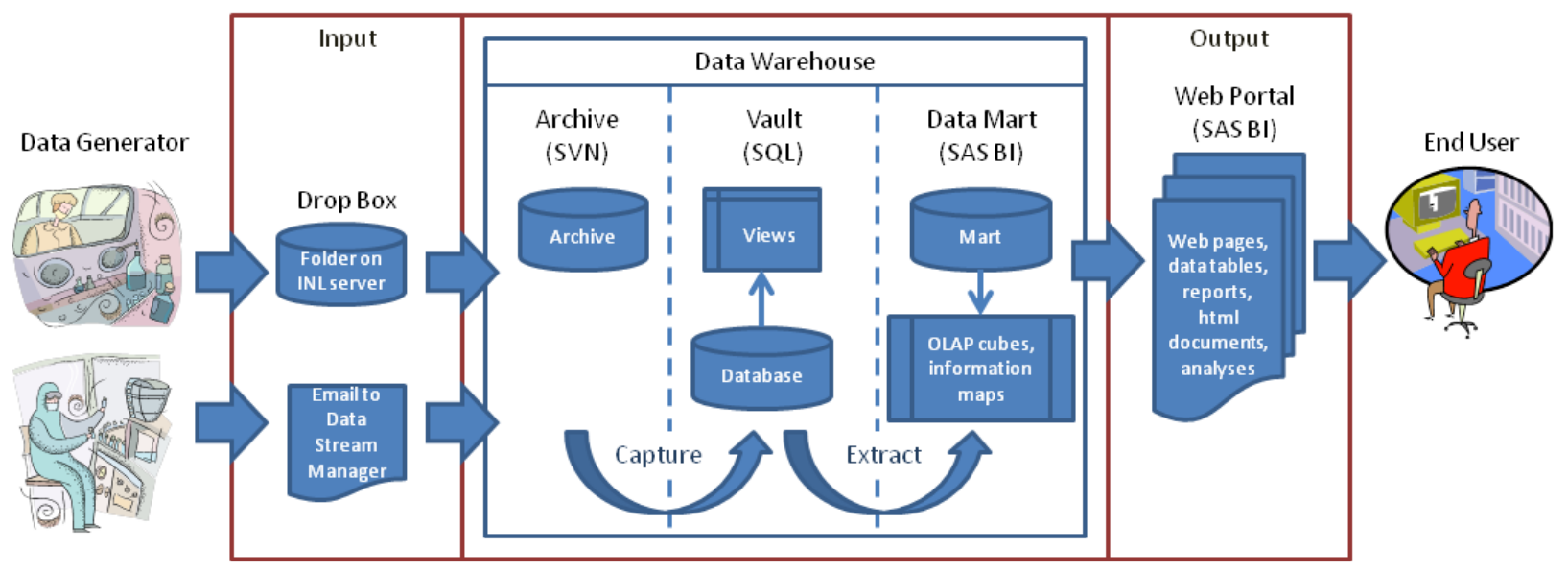

Figure 2. Stages of data processing in NDMAS.

\subsection{Data Capture}

Data to be displayed on the Web were captured from the native csv files and stored in a common electronic format that can be used to feed webpage reports. A SAS ${ }^{\circledR}$ Enterprise Guide Project was used to read the csv files, convert date/time values to Mountain Standard Time, change measurement units to standard units, remove duplicate values, and create a SAS ${ }^{\circledR}$ dataset. The SAS ${ }^{\circledR}$ dataset was then appended to data in the Microsoft SQL ${ }^{\circledR} 2008$ NDMAS database. When data are first appended to the database, they are assigned a Data_State_ID flag of 1, indicating the data have not been verified.

Data are captured using SAS ${ }^{\circledR}$ Enterprise Guide Projects. Data capture is verified in two ways. First, by manually comparing data pulled from the NDMAS database to the original data in the native csv files. A stratified random sample of the data is taken to assure that all parameters from all types of csv files are read correctly. This verification process is used to test and verify that the Enterprise Guide Project correctly captures the data into the vault and that the data pulled from the vault match the data pushed into the vault. Once the Enterprise Guide Project has been verified by manual inspection, subsequent data capture events are verified using an automated comparison between data pulled from the vault and data pushed into the vault. When changes are made to the Enterprise Guide Project used to capture the data, 
the manual verification is performed again. The verified Enterprise Guide Project is stored under configuration control to assure the same verified project is used to capture subsequent csv files.

If errors are detected in the capture process, the process is reviewed to identify the source of the error, and corrections are made. It may be necessary to delete some or all of the captured records from the database and repeat the process. In other cases, the database can be corrected. Once the capture of the data is verified, the Data_State_ID is changed from 1 (raw) to 3 (capture passed).

\subsection{ATR Operating Conditions}

ATR operating conditions data are collected under an NQA-1 QA program maintained by ATR operations, and are not qualified by the VHTR program. Effective power at the south flux trap is calculated as the average of the lobe powers at the southeast, southwest, and center lobe. Effective power averaged 23.4 MW during capsule irradiation as shown in Figure 3. The capsule was removed from the reactor during Cycle 150A because the reactor was run at elevated power during that cycle (Figure 3).

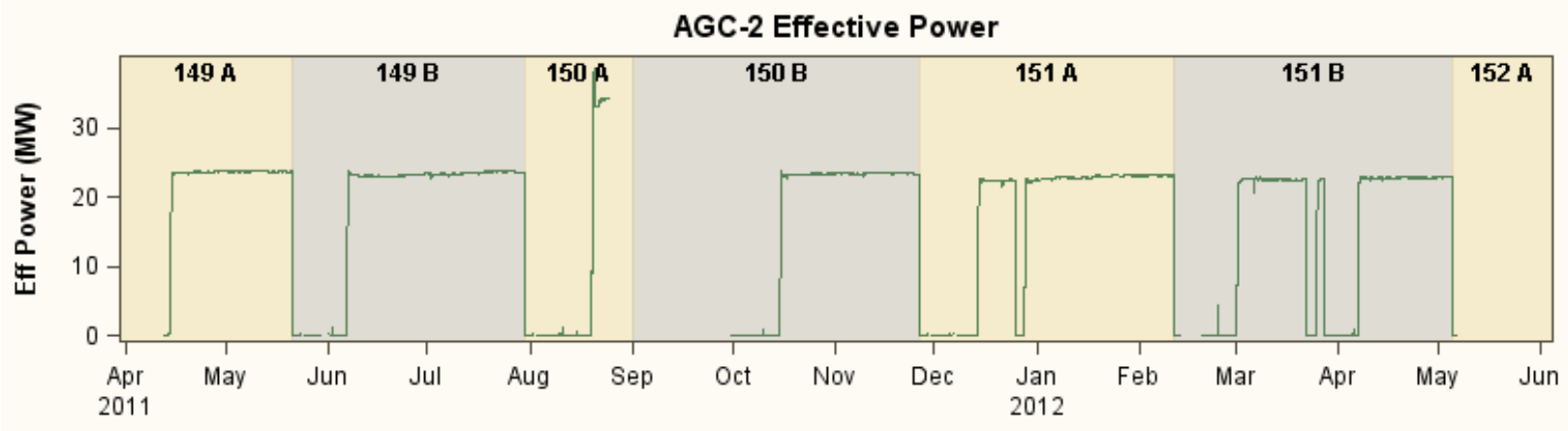

Figure 3. Effective power at the south flux trap during the AGC-2 experiment.

Periodically, ATR calibrates the Nitrogen-16 system in the reactor. These episodes are delineated by a flag variable (N16D) in the data set being set to 1. During these periods, reported reactor power fluctuates widely, as shown in Figure 4, because the Nitrogen-16 system is used in the calculation of reactor power. NDMAS fails reactor power data during calibration of the Nitrogen-16 system because the reported reactor powers do not reflect actual conditions in the reactor core.

\subsection{Testing for Data Anomalies}

Once the irradiation data are captured into the NDMAS database, a number of tests are run to examine the data for anomalies. Anomalies are data with values outside the range of expected behaviors. Some of these may be errors and some may be transient events that produced real data outside of normal ranges. The anomalies are reviewed as part of the data qualification process. This section discusses the tests and basis for the tests and presents the results of the testing. Qualification decisions based on the results of the tests are presented in Section 4.

Tests developed to verify data are listed in Table 3. The tests are grouped into test suites. Most tracking of data testing in NDMAS is done at the test suite and data package level. However, errors and error resolutions are tracked at the data element level. 

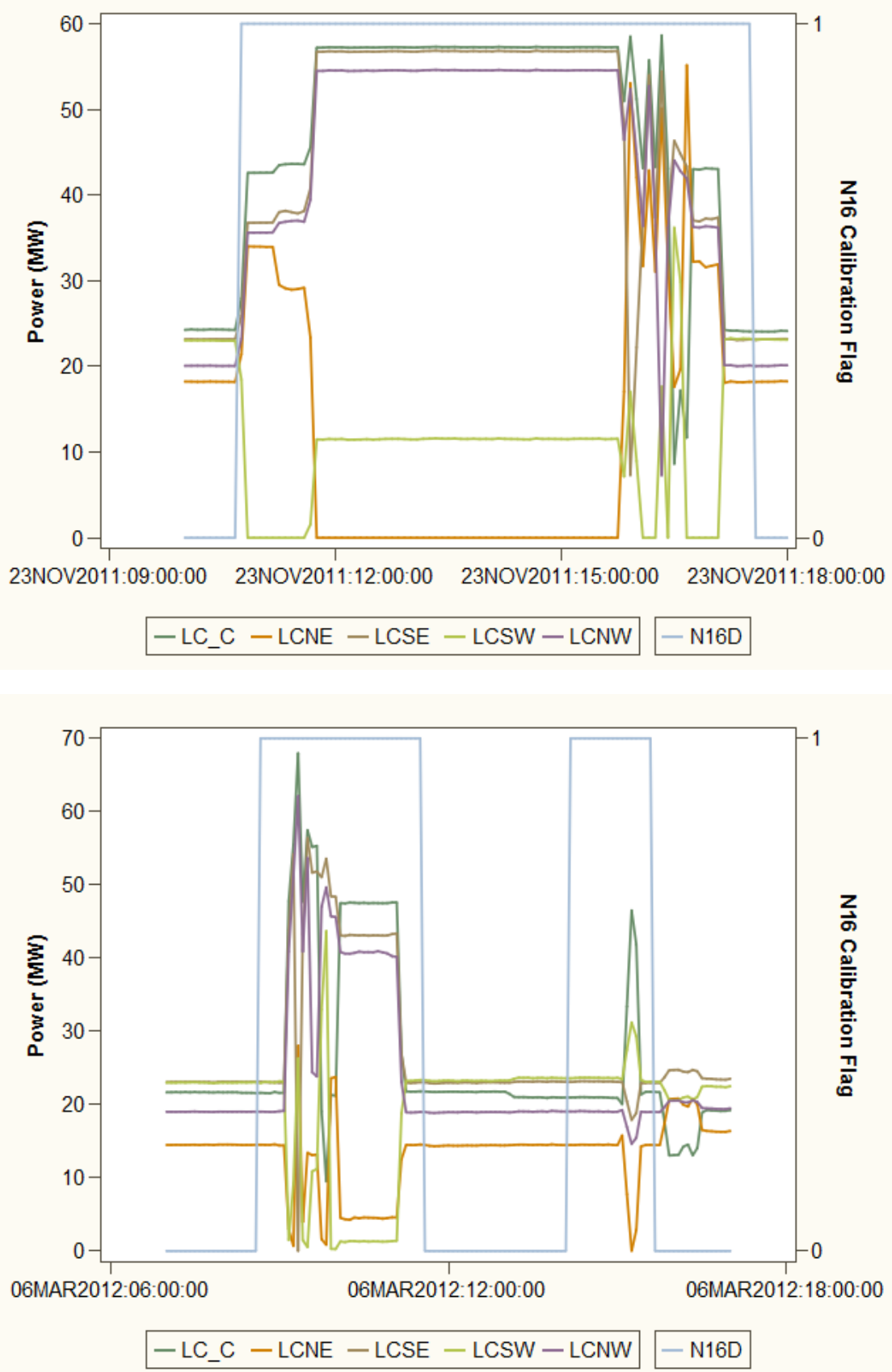

Figure 4. Reported lobe powers in the ATR reactor (left scale) fluctuate widely during periods of Nitrogen-16 system calibration, indicated by the N16D calibration flag being set to 1 (right scale). The reported powers do not reflect actual reactor power during system calibration. 
Table 3. Tests and test suites defined for evaluating AGC-2 irradiation monitoring data.

\begin{tabular}{|c|c|c|c|}
\hline Test Type & Test Name & Test Description & Applied to \\
\hline \multirow[t]{2}{*}{ Accuracy } & $\begin{array}{l}\text { Irradiation } \\
\text { Monitoring } \\
\text { Range }\end{array}$ & $\begin{array}{l}\text { Compares response values to anticipated } \\
\text { acceptable ranges from the experiment. } \\
\text { Identifies as anomalous values that fall } \\
\text { outside the expected range. }\end{array}$ & $\begin{array}{l}\text { Temperature, gas flow, gas } \\
\text { pressure, humidity, upper ram } \\
\text { gas pressure, compressive load, } \\
\text { and specimen position }\end{array}$ \\
\hline & $\begin{array}{l}\text { Instrument } \\
\text { Failure }\end{array}$ & $\begin{array}{l}\text { Used to fail data collected from an } \\
\text { instrument that has been deemed to no } \\
\text { longer be providing reliable data. }\end{array}$ & $\begin{array}{l}\text { All response variables as } \\
\text { needed }\end{array}$ \\
\hline \multirow[t]{3}{*}{ Analysis } & $\begin{array}{l}\text { TC Spatial } \\
\text { Correlation }\end{array}$ & $\begin{array}{l}\text { Calculates correlations between daily } \\
\text { average temperatures. TCs adjacent to } \\
\text { each other should be more highly } \\
\text { correlated than TCs at different } \\
\text { elevations. }\end{array}$ & TCs 1 through 12. \\
\hline & $\begin{array}{l}\text { TC Difference } \\
\text { Control Charts }\end{array}$ & $\begin{array}{l}\text { The temperature difference between TCs } \\
\text { should be similar over time. Trends and } \\
\text { discontinuities in the data suggest that } \\
\text { one of the TCs is drifting or failing. }\end{array}$ & TCs 1 through 12. \\
\hline & $\begin{array}{l}\text { Load Cell } \\
\text { Difference } \\
\text { Control Charts }\end{array}$ & $\begin{array}{l}\text { The load difference between channels } \\
\text { should be similar over time. Trends and } \\
\text { discontinuities suggest that a load cell is } \\
\text { drifting or failing. }\end{array}$ & Load cells for Channels 1 to 6 . \\
\hline
\end{tabular}

Table 4. Test ranges applied to AGC-2 irradiation monitoring data.

\begin{tabular}{|c|c|c|}
\hline Response Variable & Expected Range & Comments \\
\hline Temperature & 0 to $1200^{\circ} \mathrm{C}$ & $\begin{array}{l}\text { The minimum temperature for TCs should be the ambient reactor } \\
\text { coolant temperature, which is on the order of } 30^{\circ} \mathrm{C} \text {. However, } \\
\text { TCs designed for high temperatures may have some bias at low } \\
\text { temperatures, so the lower limit is set lower than } 30^{\circ} \mathrm{C} \text {. This test } \\
\text { does not implement the requirement that time and volume } \\
\text { average temperatures must be } 600 \pm 50^{\circ} \mathrm{C} \text {, because the test is } \\
\text { applied to } 10 \text { min average point data. }\end{array}$ \\
\hline Gas flow & -2 to $100 \mathrm{sccm}$ & $\begin{array}{l}\text { Gas flows for temperature control normally fall between } 0 \text { and } \\
50 \mathrm{sccm} \text {. During reactor shutdown, the He gas flow is increased } \\
\text { to } 100 \mathrm{sccm} \text {. }\end{array}$ \\
\hline Gas pressure & 10 to 25 psia & Gas pressure is specified to be 14.7 psia or less. \\
\hline Moisture & 0 to $10 \mathrm{ppmv}$ & $\begin{array}{l}\text { The upper limit is set to the specification for moisture of } \\
10 \text { ppmv. }\end{array}$ \\
\hline Ram gas pressure & -10 to 300 psig & $\begin{array}{l}\text { This test looks for excursions well above the highest expected } \\
\text { ram gas pressure of } 250 \text { psig. }\end{array}$ \\
\hline Load cell & -15 to $700 \mathrm{lbf}$ & $\begin{array}{l}\text { This test looks for excursions well above the highest expected } \\
\text { load of } 600 \mathrm{lbf} \text {. }\end{array}$ \\
\hline Stack position & 1.0 to -3.0 in & $\begin{array}{l}\text { This range test simply looks to see if stack position is outside the } \\
\text { expected range. }\end{array}$ \\
\hline
\end{tabular}




\subsubsection{Irradiation Monitoring Range Suite}

The range tests evaluate whether instrument readings fall within an expected range of values. The expected ranges for instruments are listed in Table 4. Range tests do not necessarily test for conformance to specifications so the range values listed generally do not match specifications for test parameters.

\subsubsection{Temperature}

One temperature measurement fell well outside the range of expected values. The reported temperature for TC-13 on May 23, 2011, at 10:55 was $-3,365,498^{\circ} \mathrm{C}$, which cannot represent actual temperatures in the AGC-2 capsule. All other temperature values were within the anticipated range.

\subsubsection{Moisture}

There were four periods when moisture values exceeded $10 \mathrm{ppmv}$ as shown in Figure 5. These occurred:

- Between April 12, 2011 and April 25, 2011

- On October 16, 2011

- On April 242012

- On April 25, 2012.

The AGC-2 experiment began with reactor Cycle 149A, which went to full power on April 14, 2011. As can be seen in Figure 5A, the rise in temperature in the capsule was accompanied by a flushing of moisture from the capsule over a period of about 5 days. While these moisture conditions are well above the 10 ppmv specification, they represent a transient condition that existed while the capsule dried out. The AGC-2 capsule was removed from the reactor during Cycle 150A, and returned for Cycle 150B, which went to full power on October 16, 2011. There was a brief period of elevated moisture in the capsule outlet for about 2.5 hours on October 16 as shown in Figure 5B. The capsule apparently picked up a small amount of moisture when it was out of the reactor. In April 2012, the moisture content in the outlet gas line was cycling with a 24 hour period, peaking during the early morning hours between 2 and 6 a.m. as shown in Figure 5C. During two of those cycles, the moisture content exceeded the $10 \mathrm{ppmv}$ specification by less than $1 \mathrm{ppmv}$ for a few minutes. In all of these instances, the measured values represent actual moisture conditions in the capsule outflow gas line.

\subsubsection{Sweep Gas Chemical Constituents}

No data on gas-phase chemical contaminants $\mathrm{CO}_{2}$ and $\mathrm{CO}$ have been identified.

\subsubsection{Instrument Failure Suite}

This test suite applies data qualification decisions to monitoring data. When an instrument has failed and this failure is verified during the data qualification process, all future data collected from the instrument will be failed. This test applies a Failed data flag to all future data collected from that instrument. No instruments failed during the AGC-2 experiment. 

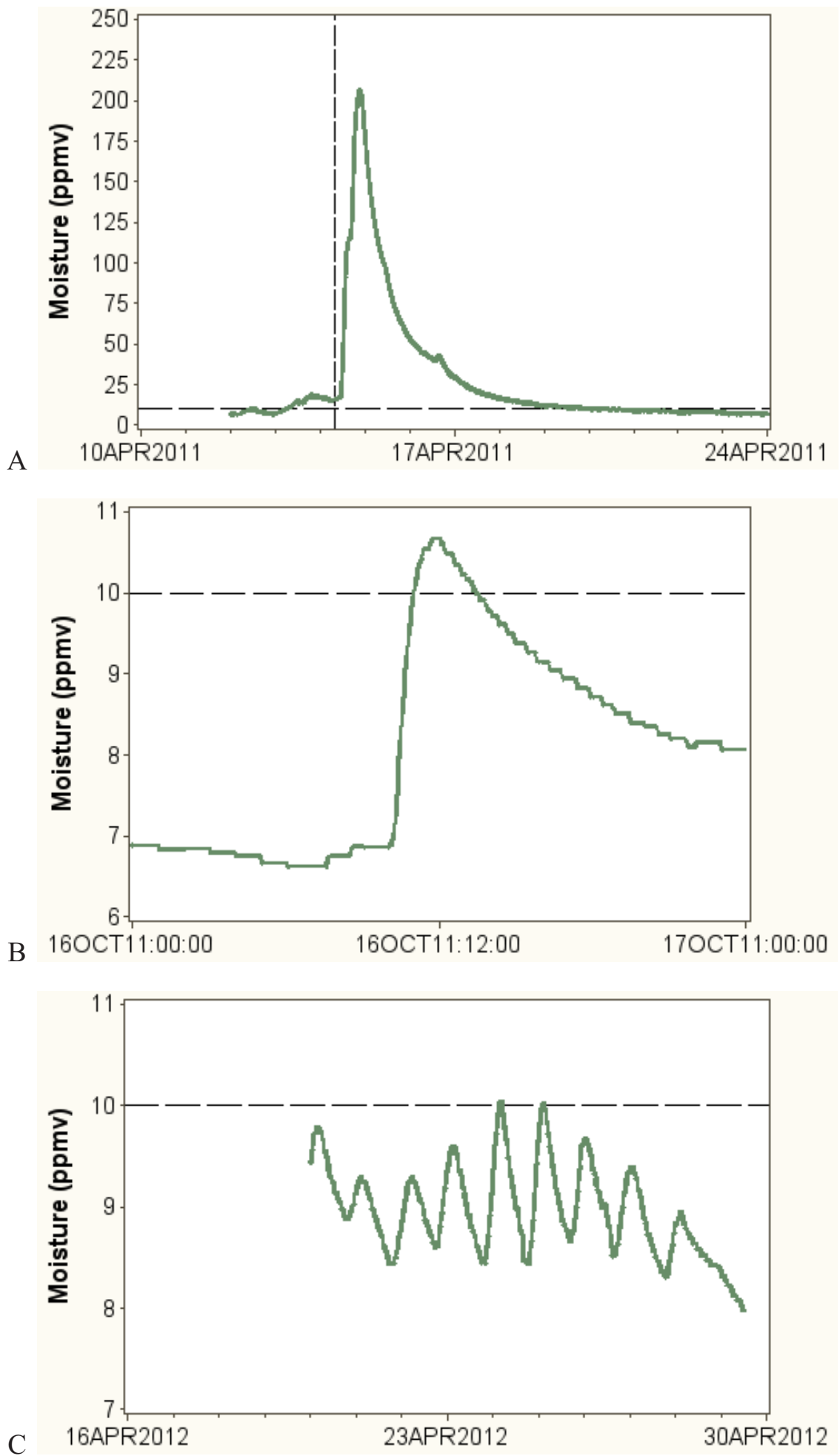

Figure 5. Excursion of moisture in the gas outlet line above the $10 \mathrm{ppmv}$ specification occurred four times during AGC-2. Horizontal reference line at 10 ppmv represents the maximum level desired in the capsule. The vertical reference line in A is the start of the AGC-2 experiment. 


\subsubsection{Time Series Plots}

The temperature and compression load at which specimens are to be irradiated is specified in the test plan (TFR-645). The temperature specification is based on a time and volume average temperature, which can only be determined from thermal calculations. It is therefore not possible to directly compare measured temperatures to design specifications. Creep specimen loads have a design specification, but no tolerance specified on the load, only on instrument precision. This section compares measured temperature and load data to bounds derived from the design specifications. These plots are provided for information and to assist in interpretation of the correlation plots and control charts in the next section. Decisions regarding whether data met specifications for the experiment will be included in data application reports written after the experiment is complete, and are not part of this data qualification process.

Based on experiment requirements, each stack of stressed graphite specimens must be raised from below during each reactor outage to ensure that the stacks are not stuck in the channels. Time series plots of the stack raising activity during AGC-2 are shown.

\subsubsection{Temperature Data}

Temperatures in the graphite capsule are specified to be $600 \pm 50^{\circ} \mathrm{C}$. The temperature profile through the core is stronger than expected prior to the experiment. Temperatures near the centerline of the core generally exceed $650^{\circ} \mathrm{C}$. Temperatures near the top and bottom of the core generally fall around the $600^{\circ} \mathrm{C}$ specification. Figure 6 displays temperature data for each TC along with temperature specifications grouped by distance from the core centerline. 


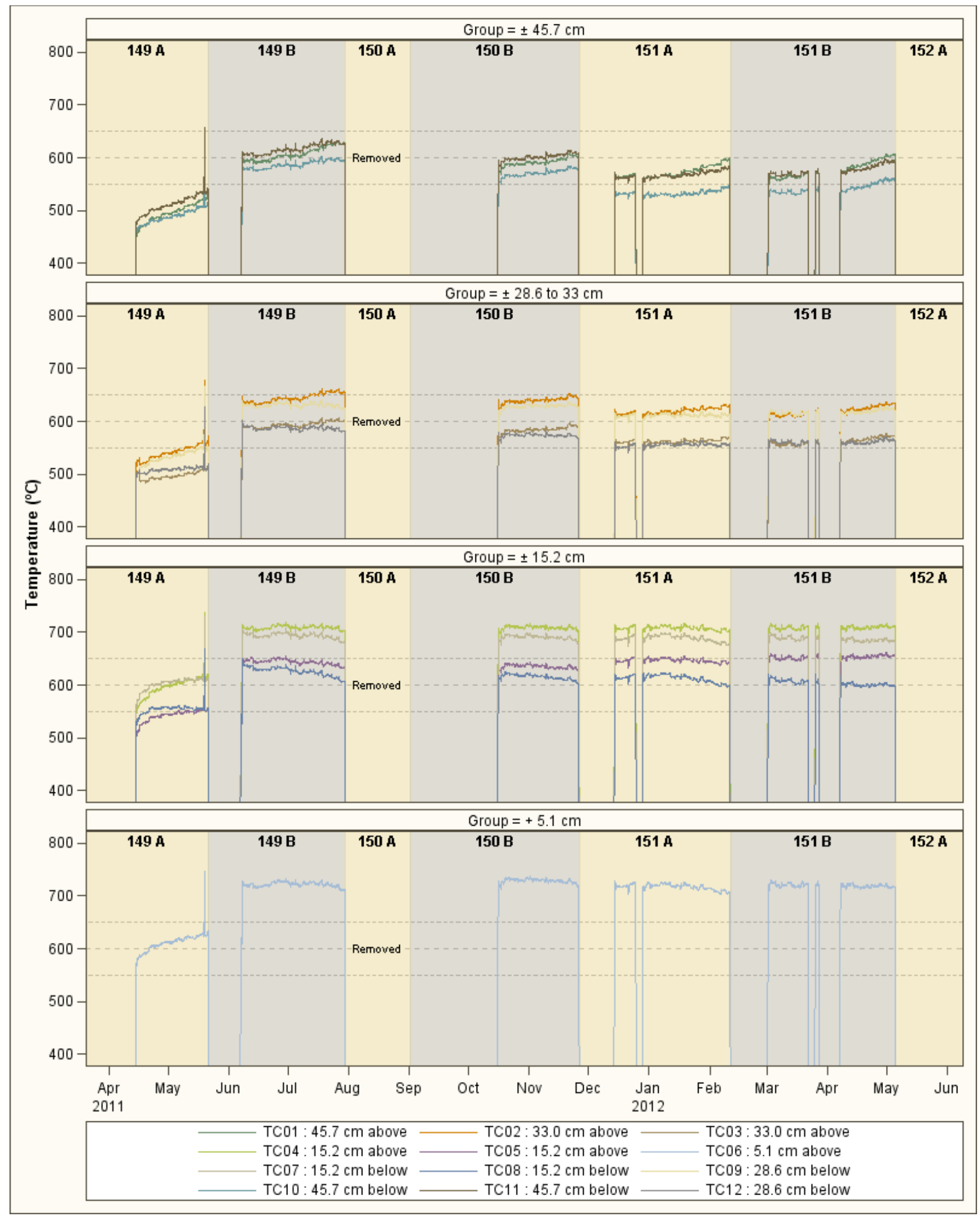

Figure 6. Temperature data grouped by distance from the core centerline. 


\subsubsection{Load Cell and Displacement Data}

Graphite specimens are loaded to one of three specified loads, depending on the channel in which they are installed. Channels 1 and 4 are loaded to $393 \mathrm{lbf}(2 \mathrm{ksi})$, Channels 2 and 5 are loaded to $491 \mathrm{lbf}$ ( $2.5 \mathrm{ksi})$, and Channels 3 and 6 are loaded to $589 \mathrm{lbf}$ ( $3 \mathrm{ksi})$. Measurement errors are specified at $\pm 5 \%$. The measured loads are plotted in Figure 7. Load data are generally within 5\% of the specified load. Loads to the paired stacks are very similar for the first three experiment cycles (149A, 149B, and 150B), but show greater differences in the last two cycles (151A and 151B). This change coincides with the rotation of the capsule between Cycles 150B and 151A. The load values fall within the tolerance limits of the experiment plan.

Specimen displacement is continuous throughout the experiment as shown in Figure 8.

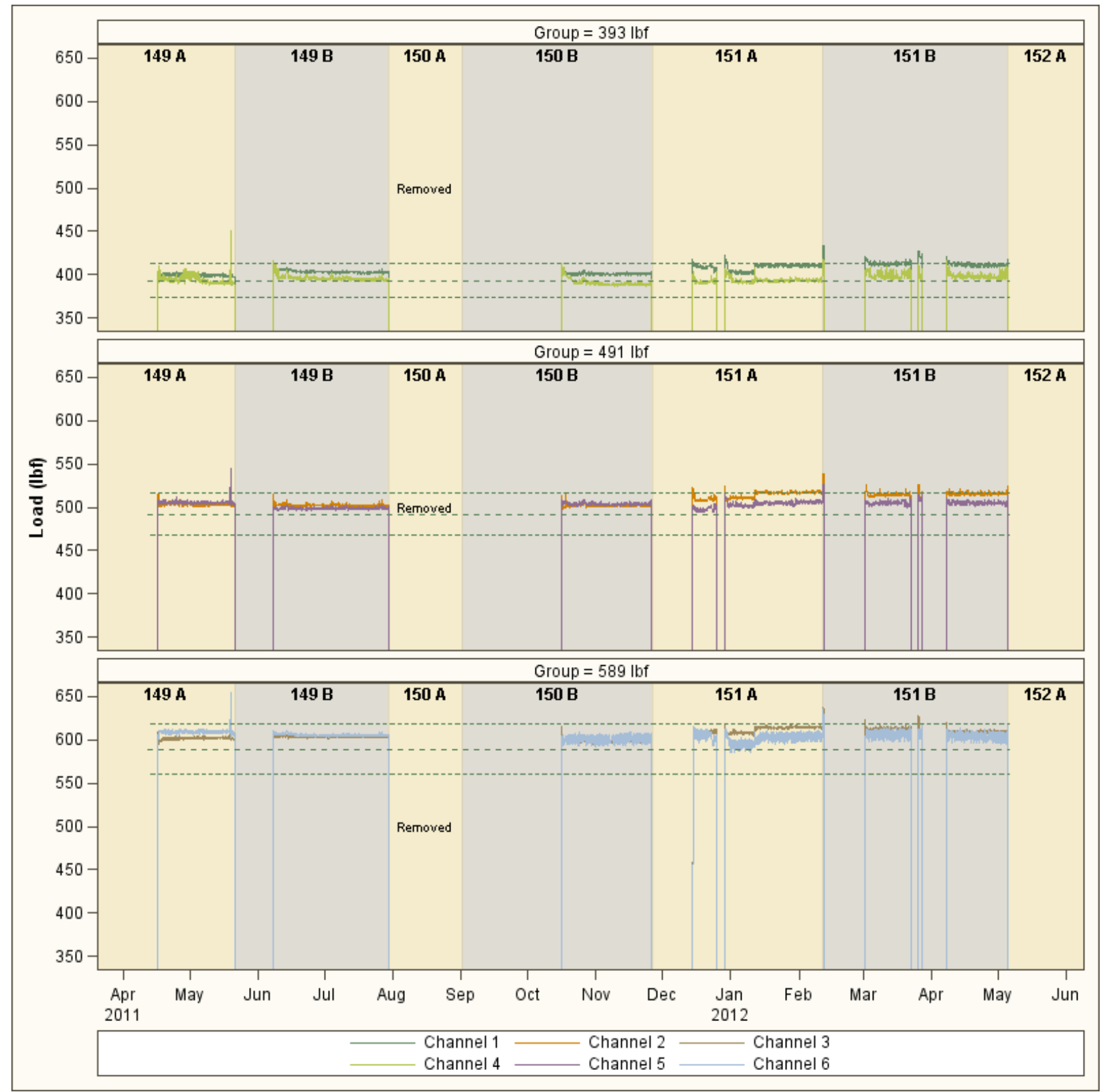

Figure 7. Load data. 


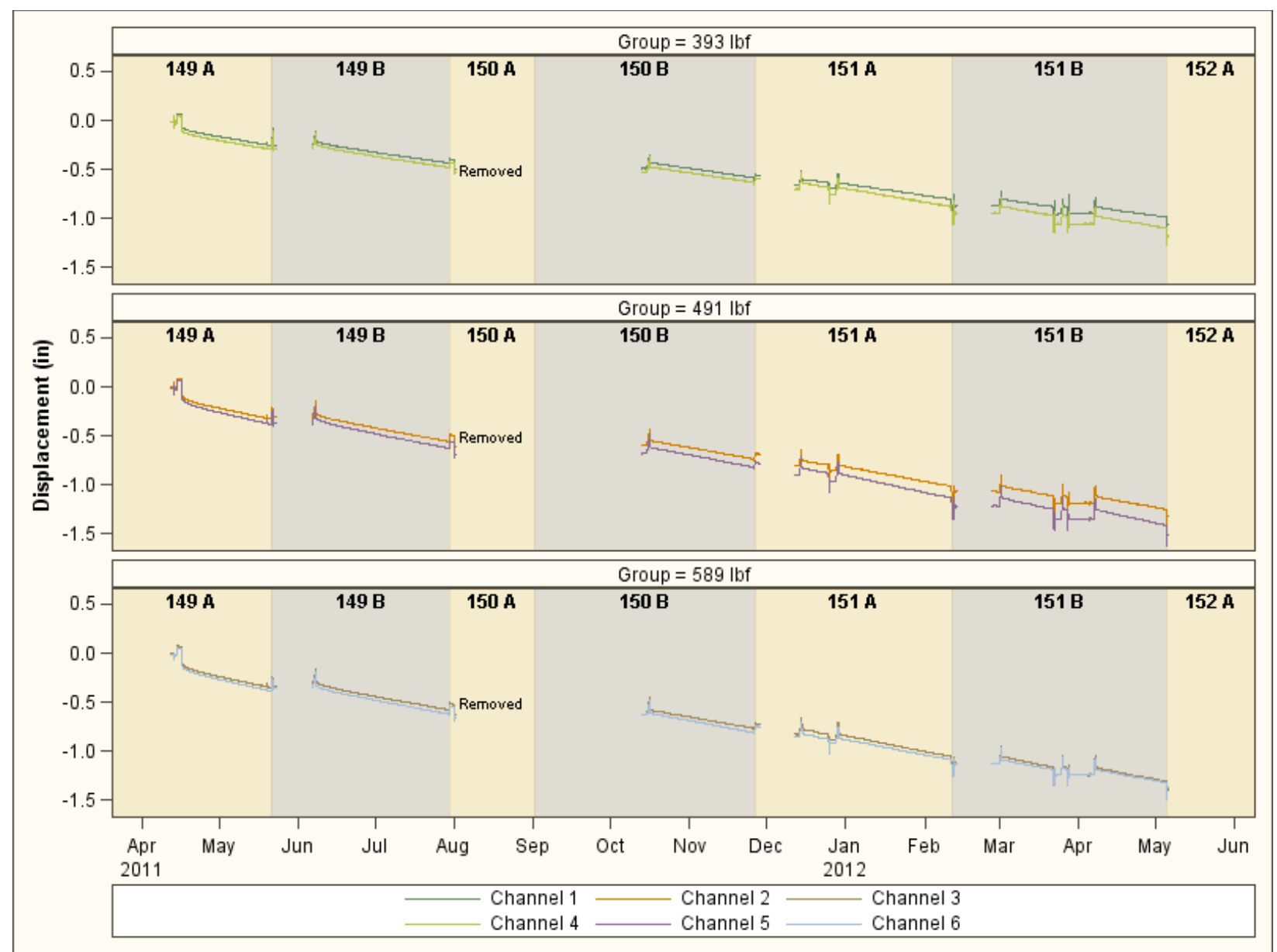

Figure 8. Displacement data.

\subsubsection{Gas Flow}

Argon and helium gas was passed through the AGC-2 capsule to control the temperature by altering the thermal conductivity. Two gas feeds were supplied to provide a redundant supply of temperature control gas. Both gas feeds are routed to both the inside and outside of the heat shield. The helium/argon ratio was similar in both gas streams. Helium dominated the gas composition as shown in Figure 9. During reactor shutdowns, helium flow was increased to $100 \mathrm{sccm}$. All gas flow data are consistent with planned gas flow conditions and expected values. 


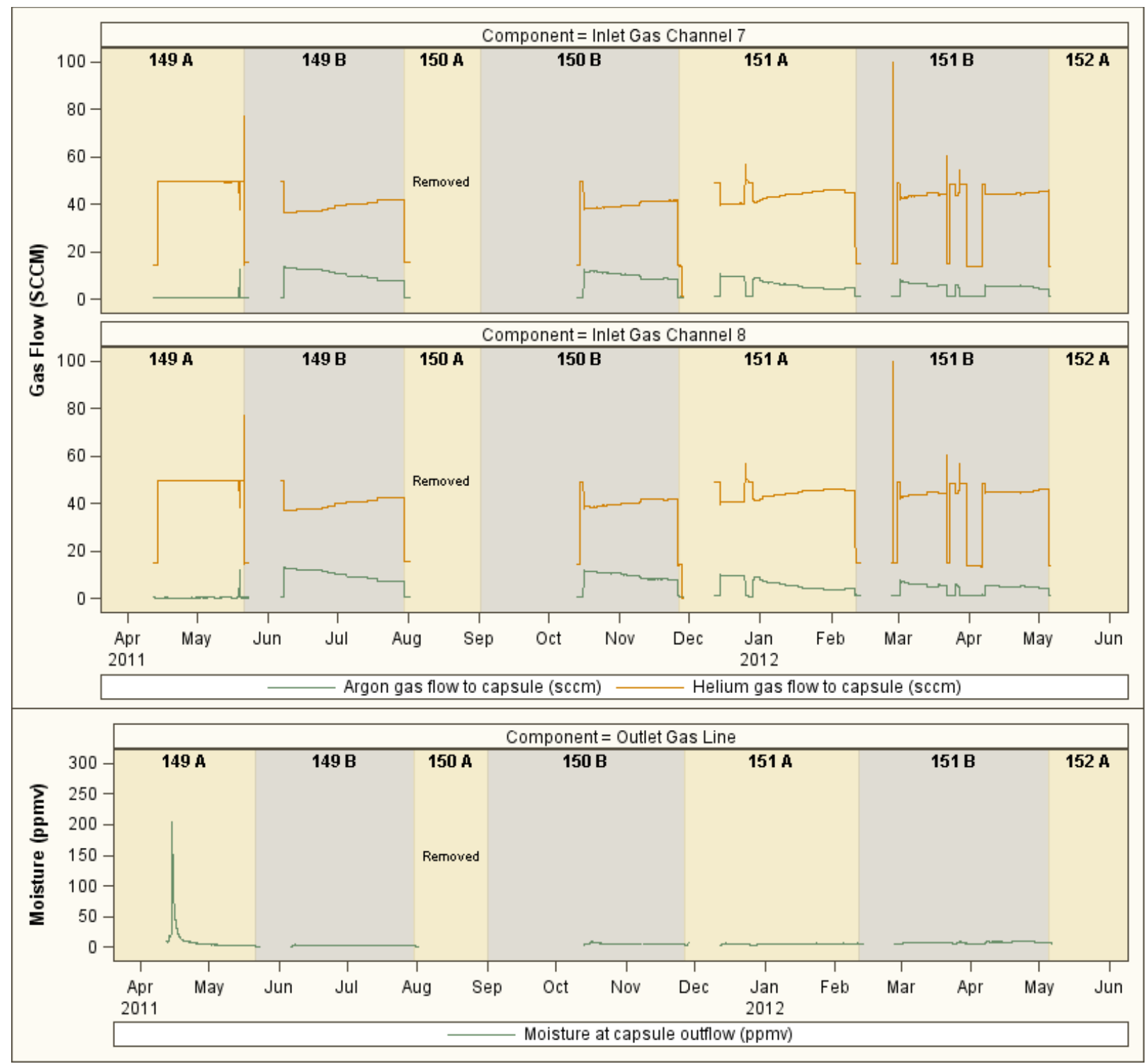

Figure 9. Composition of gas flow. The top two plots show the argon and helium flows from the two gas feed systems. The bottom plot shows the moisture in the gas outflow from the capsule.

\subsubsection{Gas Pressure}

Gas pressures increased gradually throughout the experiment to maintain gas-flow setpoints. Gas pressure values are within expected ranges as shown in Figure 10. 


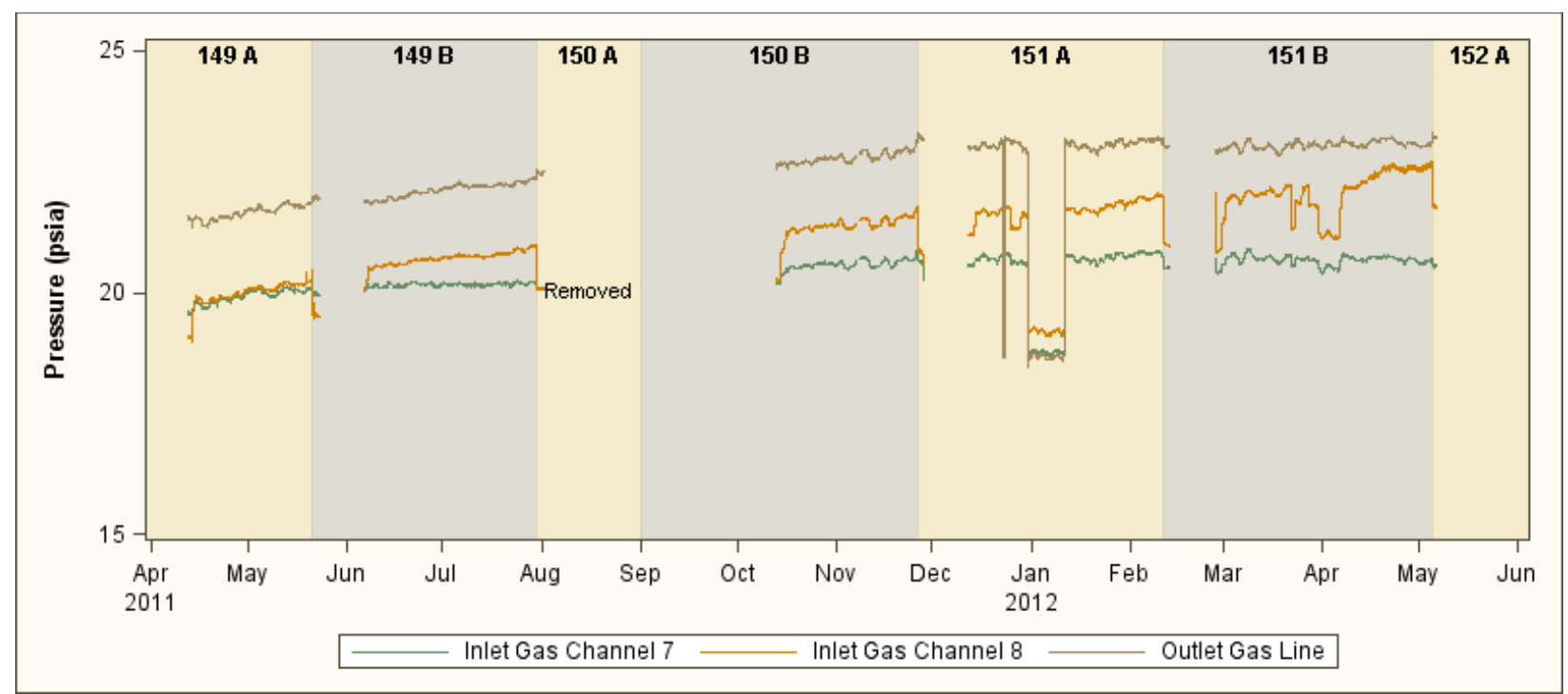

Figure 10. Gas pressure.

\subsubsection{Stack Raise Pressure}

During reactor outages, the stacks of stressed graphite specimens were raised from below to make sure that the specimens were not wedged into the channels. The procedure was to apply an upper ram pressure of $50 \mathrm{psi}$ to all stacks, then apply pressure to each individual stack from below while the compression ram pressure was reduced to zero. Each stack was raised individually, thus making sure the stack was free to move. This activity was conducted when the capsule was first installed during the outage at the beginning of Cycle 149A as shown in Figures 11 and 12. The pressure on the lower rams is not differentiated by channel so only total raise pressure is recorded. As can be seen in the figures, as the ram gas pressure was removed from each channel, the corresponding stack was raised by about 0.1 to 0.4 in. Each stack raised when pressure was applied, indicating that the stacks were not stuck in the channel.

Stacks were raised again at the beginning of Cycle 149B as shown in Figure 13 and Cycle 150A as shown in Figure 14 to show that the specimens were free during the previous cycle. The capsule was removed from the reactor during Cycle 150A, so there is no stack raising for the Cycle 150B outage. Stacks were again raised during the Cycle 151A outage as shown in Figure 15 and during the Cycle 151B outage as shown in Figures 16, 17, and 18. Stacks were raised at the end of the AGC-2 experiment to demonstrate that the specimens remained free during the final cycle as shown in Figure 19. All stack raising episodes showed the stacks to be free within the channels. All load data are therefore considered to be representative of the compressive load applied to the specimens. 


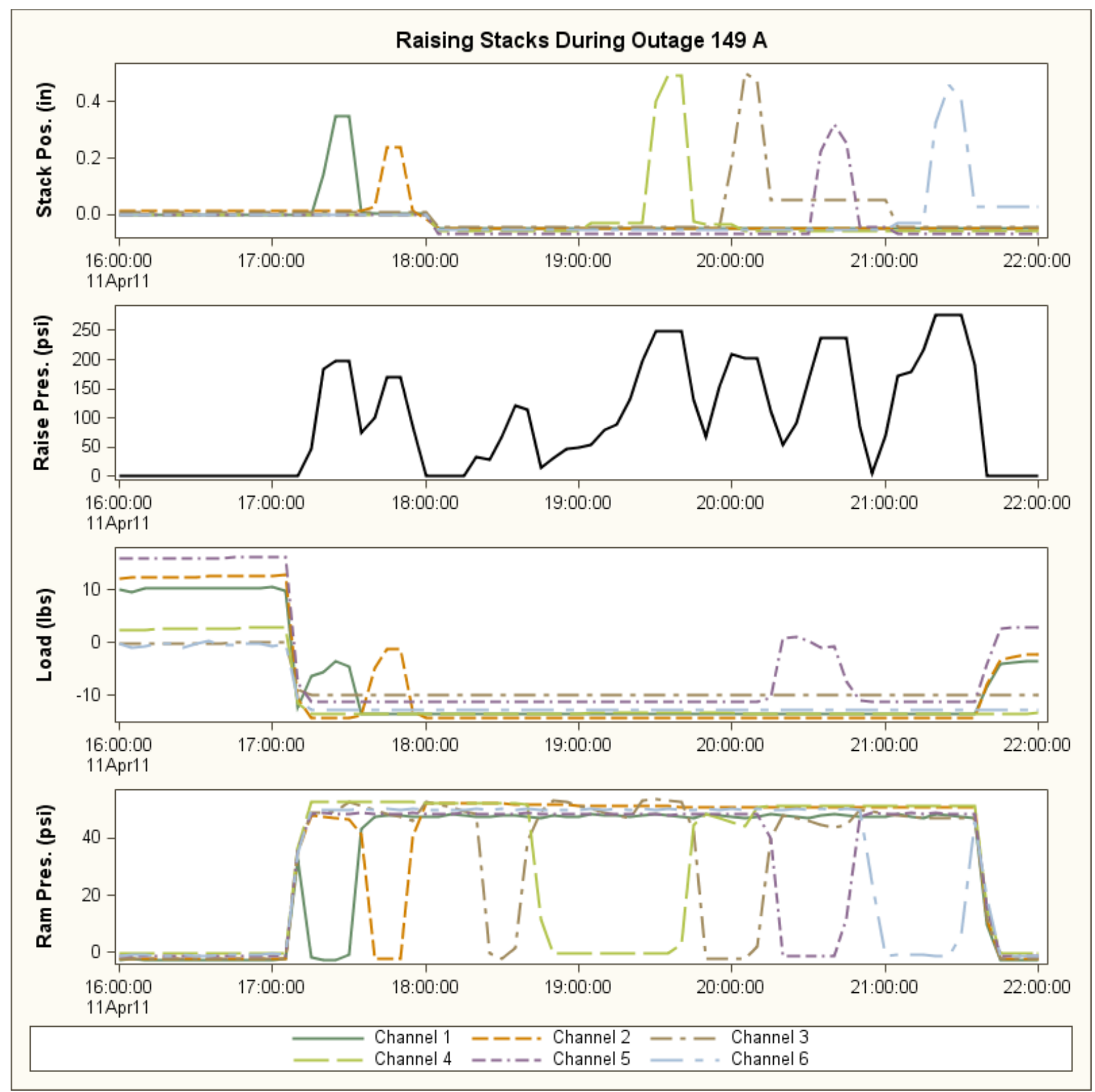

Figure 11. Change in stack position, raise pressure, stack load, and ram gas pressure for stack raising prior to Cycle 149A, immediately after installation of the AGC-2 capsule in the reactor and before irradiation. 


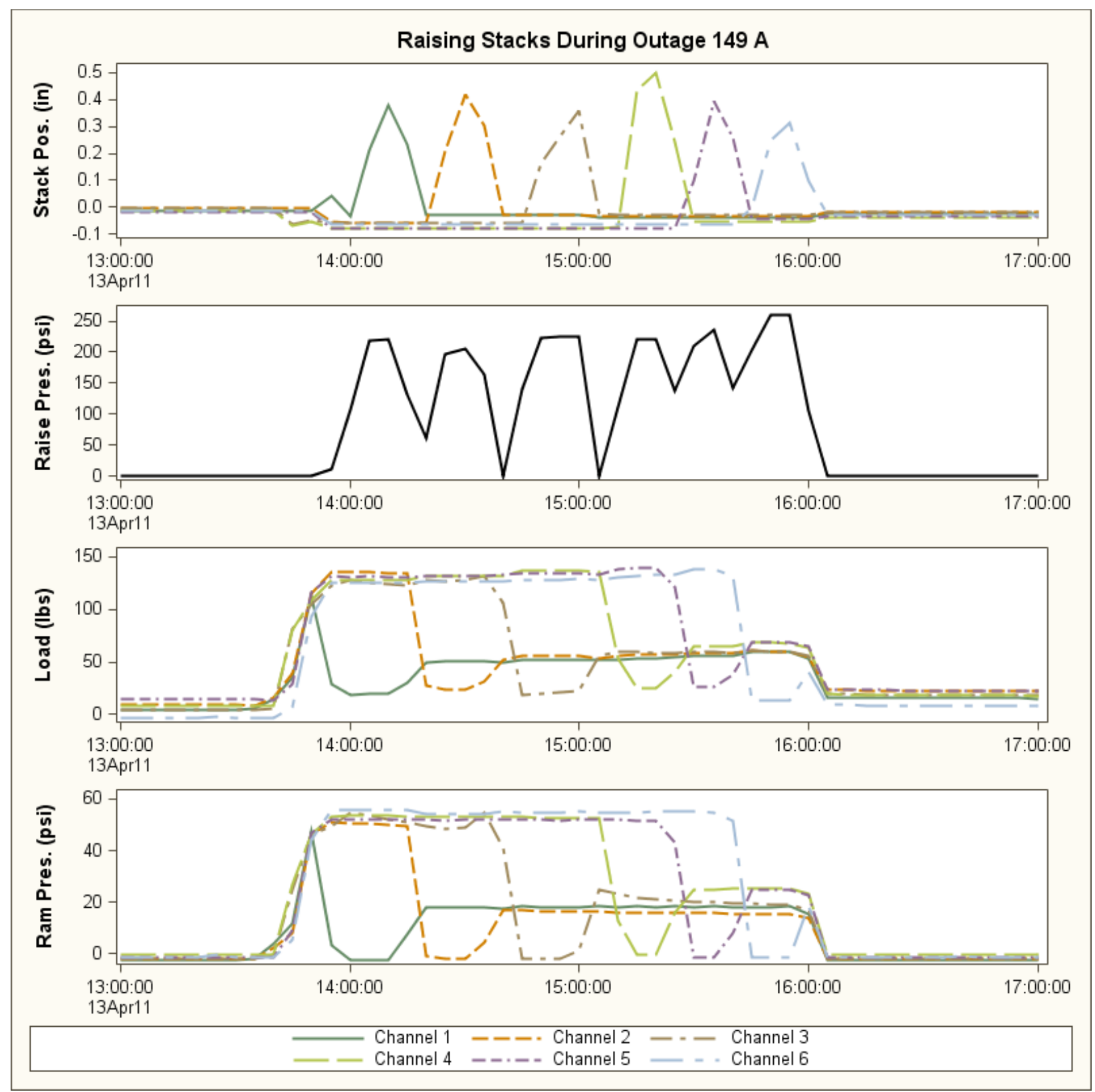

Figure 12. Change in stack position, raise pressure, stack load, and ram gas pressure for stack raising prior to Cycle 149A. This is a second round of stack raising prior to irradiation. 


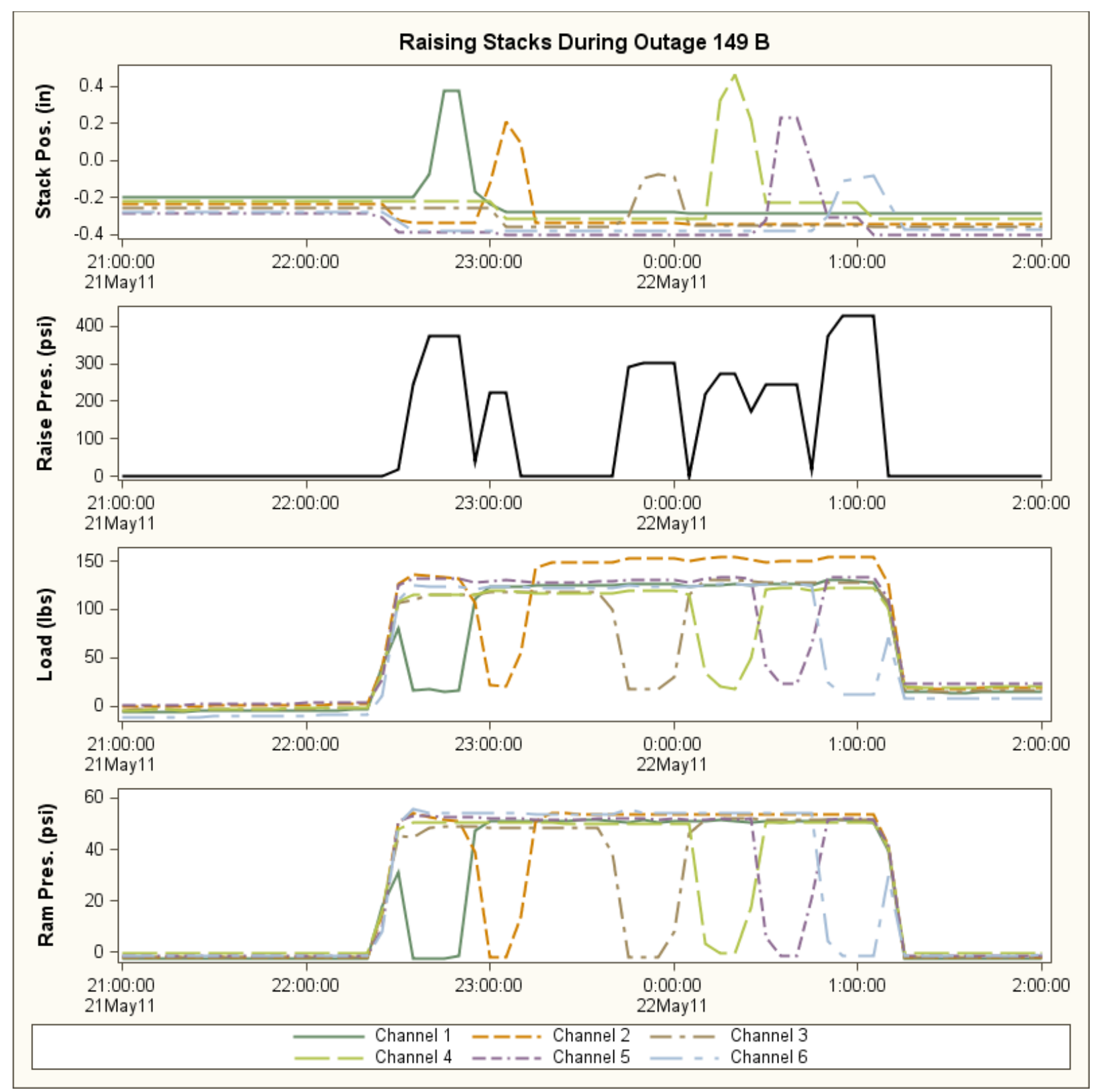

Figure 13. Change in stack position, raise pressure, stack load, and ram gas pressure for stack raising prior to Cycle 149B. 


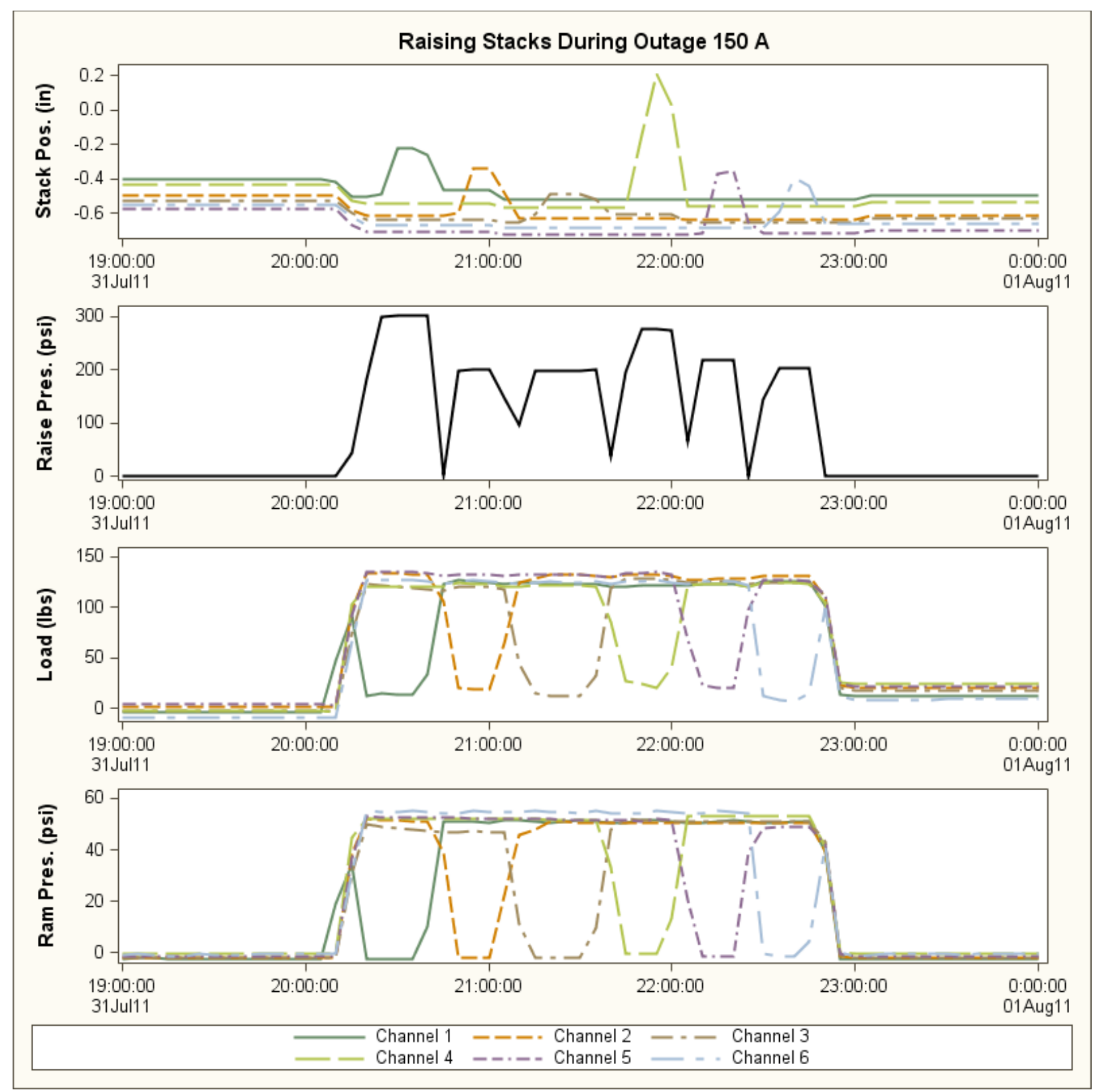

Figure 14. Change in stack position, raise pressure, stack load, and ram gas pressure for stack raising prior to Cycle 150A. This demonstrates that graphite specimens were free prior to the capsule being removed for the high-power Cycle 150A. 


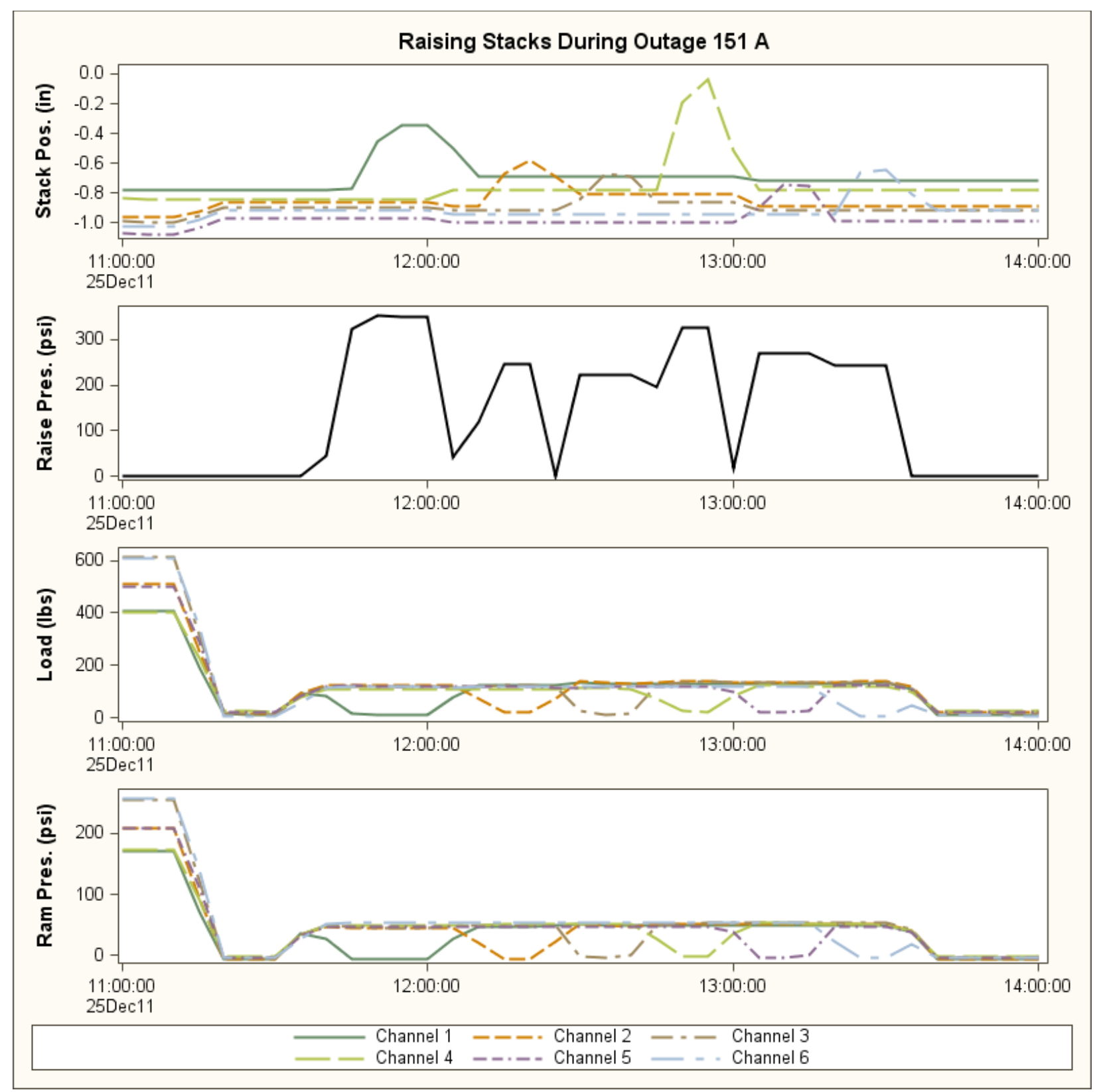

Figure 15. Change in stack position, raise pressure, stack load, and ram gas pressure for stack raising prior to Cycle 151A. 


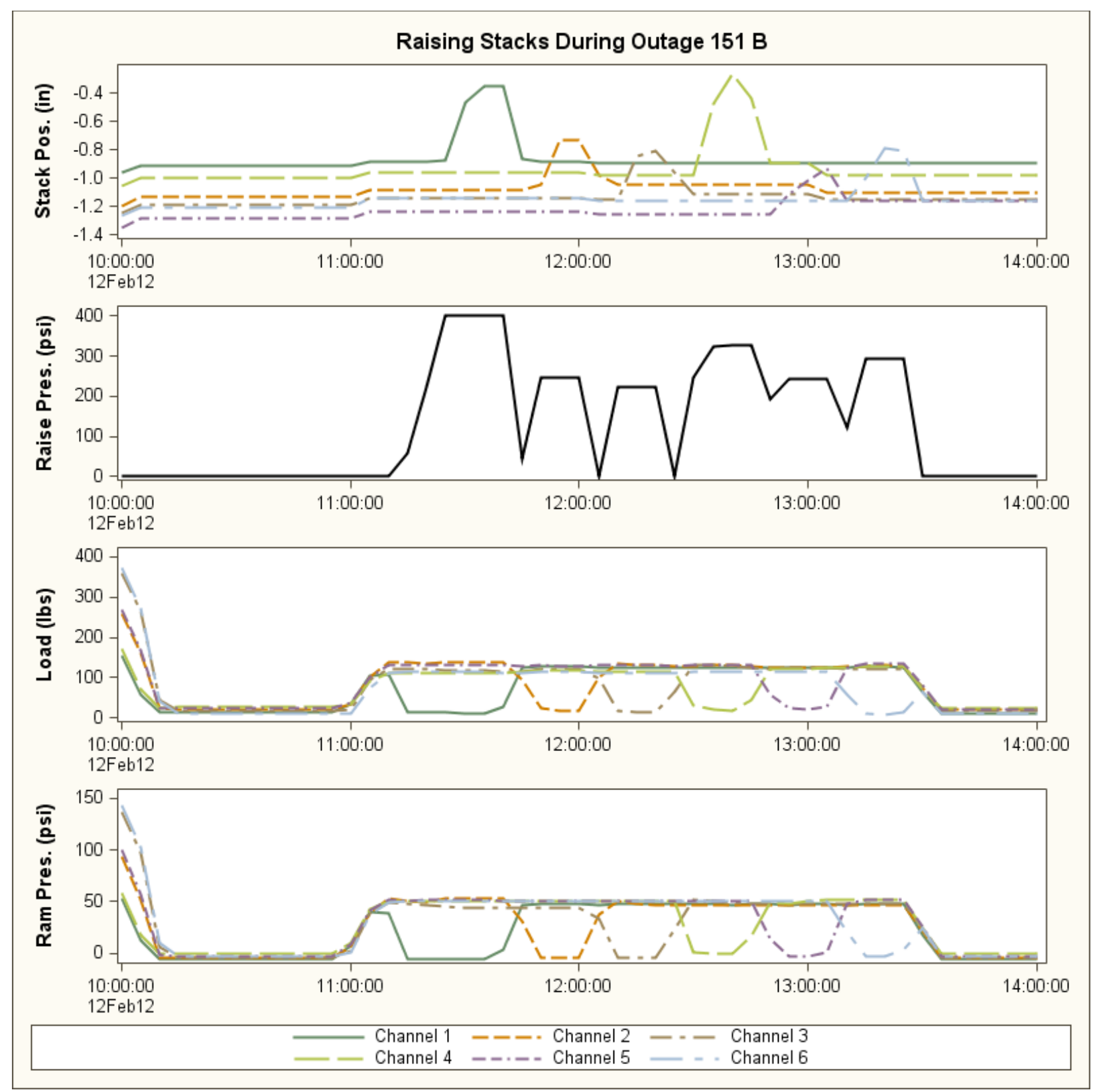

Figure 16. Change in stack position, raise pressure, stack load, and ram gas pressure for stack raising on February 12, 2012, prior to Cycle 151B. 


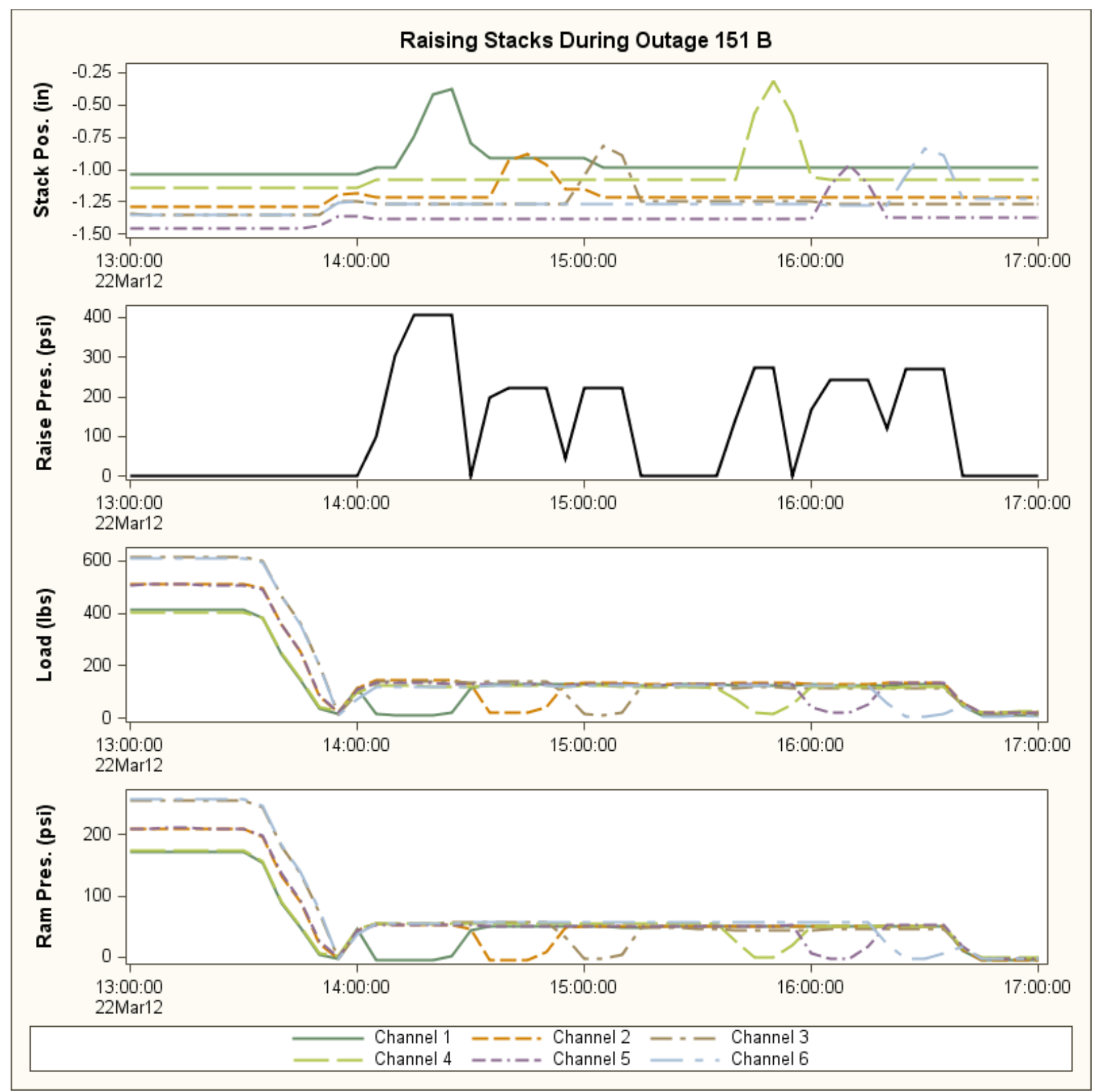

Figure 17. Change in stack position, raise pressure, stack load, and ram gas pressure for stack raising on March 22, 2012, prior to Cycle 151B. 


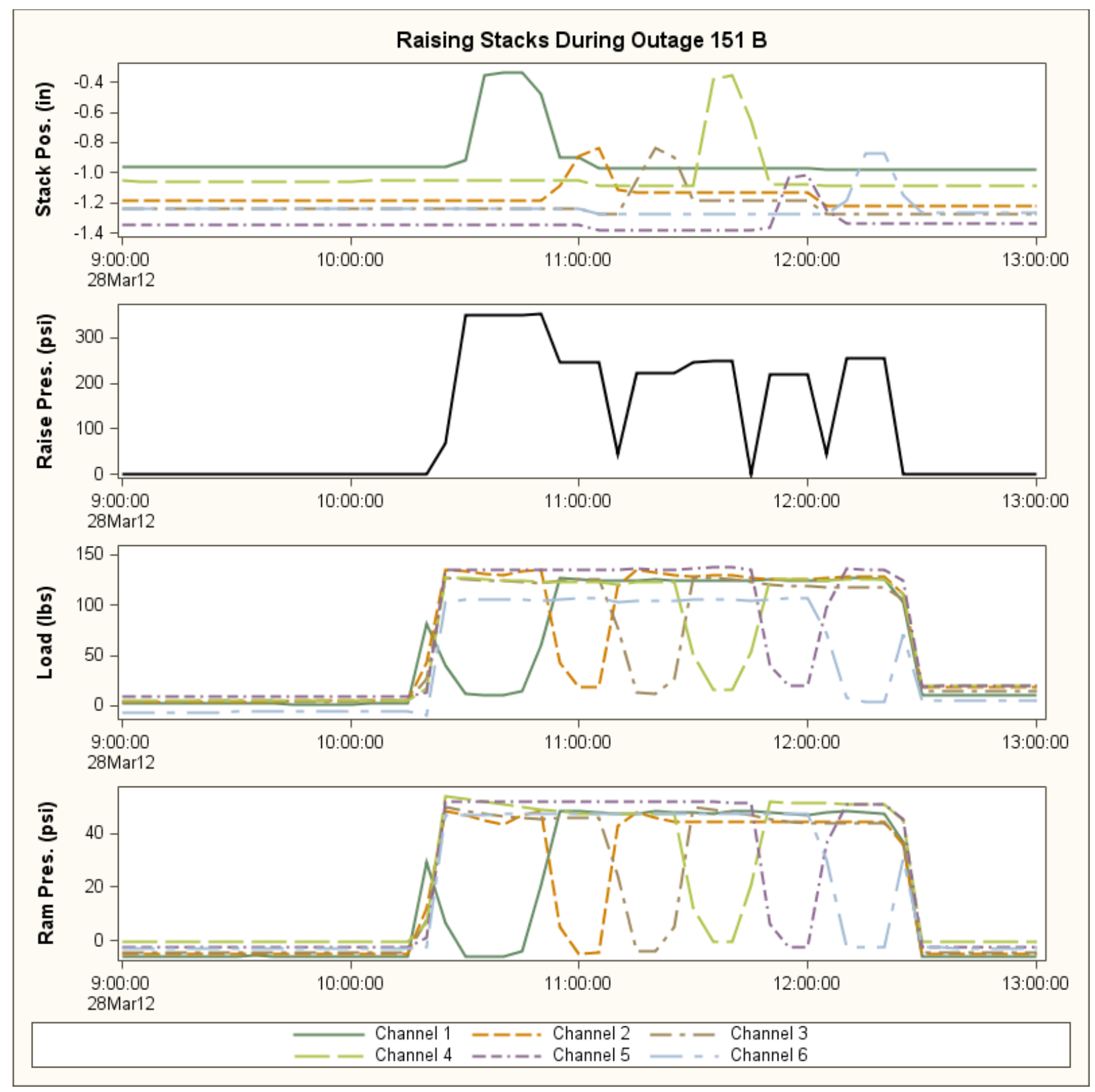

Figure 18. Change in stack position, raise pressure, stack load, and ram gas pressure for stack raising on March 28, 2012, prior to Cycle 151B. 


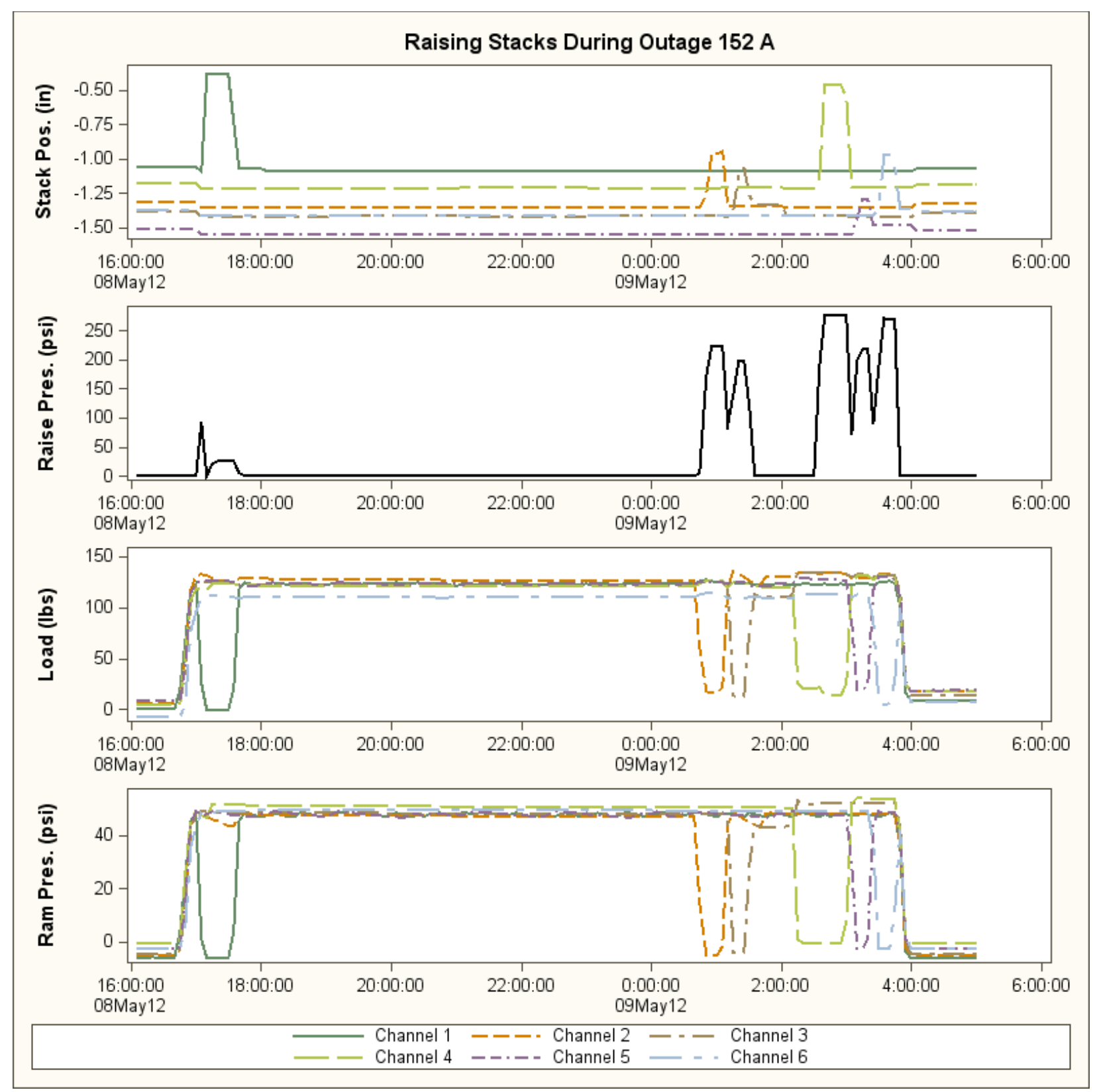

Figure 19. Change in stack position, raise pressure, stack load, and ram gas pressure for stack raising on May 8 and 9, 2012, prior to Cycle 152A at the end of the AGC-2 experiment.

\subsubsection{TC Correlation Analysis}

During the first Advanced Gas Reactor (AGR) experiment (AGR-1), a number of the TCs formed virtual junctions outside the capsule in which they were installed, causing them to give erroneous readings (Pope 2010). One way this was detected was when the TC switched from being highly correlated to other TCs in the capsule where it was installed, to being highly correlated to TCs in another capsule. The basis of this test is that temperatures measured at a TC will be more highly correlated to TCs installed at the same elevation, or at immediately adjacent elevations, than to TCs installed at other elevations. This test is applied to the TCs installed in the AGC-2 capsule. While there is only one AGC-2 capsule, as opposed to six AGR-1 capsules, TCs should be most highly correlated to the nearest TCs. 
A correlation was calculated on a daily basis for each TC with all other TCs. The highest correlation coefficient was selected for each day and plotted on the graphs shown in Figures 20-31. Each graph shows the vertical position of the base TC as a solid line and the daily maximum correlations to other TCs as circles. Using Figure 20 as an example, TC01 is installed at a height of $45.7 \mathrm{~cm}$ above the centerline of the reactor core at Level 8. TC01 is most highly correlated with TCs installed at Level 7 in the core. This behavior is fairly consistent throughout the AGC-2 irradiation experiment. Therefore, there is no evidence that TC01 has formed a virtual junction at a different position within the capsule.

Reviewing the other figures, the TCs where two TCs are installed at the same level in the capsule are most highly correlated to each other (TC02 with TC03 at Level 7, TC04 with TC05 at Level 6, TC07 with TC08 at Level 4, TC09 with TC12 at Level 3, and TC10 with TC11 at Level 2). Where only one TC is installed at a given level, the TC is most closely correlated to a TC immediately adjacent to (either above or below) that TC. There does not appear to be any evidence of formation of virtual junctions in the AGC-2 capsule.

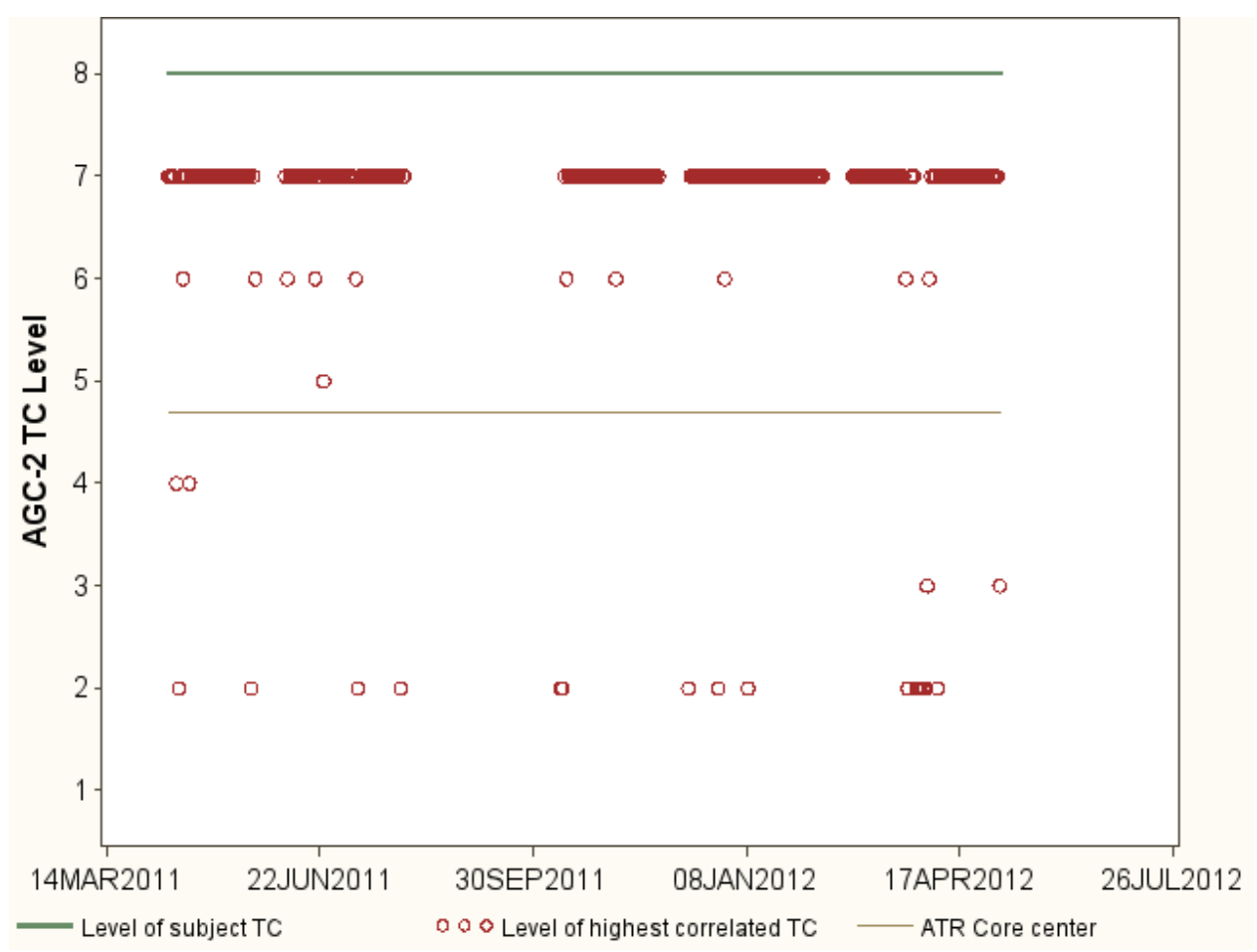

Figure 20. The level of the TC with the highest correlation to TC01 at Level $8(45.7 \mathrm{~cm})$. 


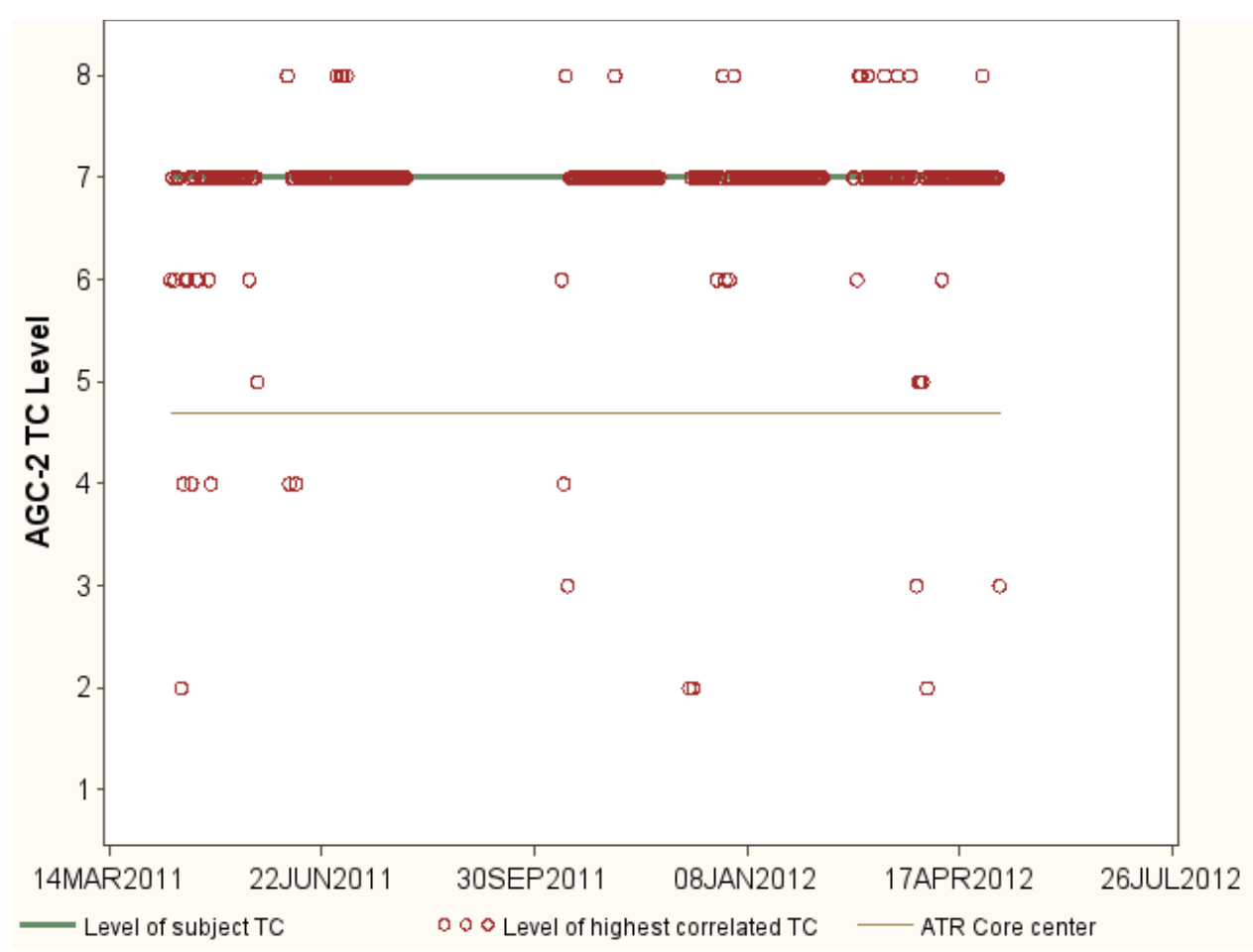

Figure 21. The level of the TC with the highest correlation to TC02 at Level $7(33 \mathrm{~cm})$.

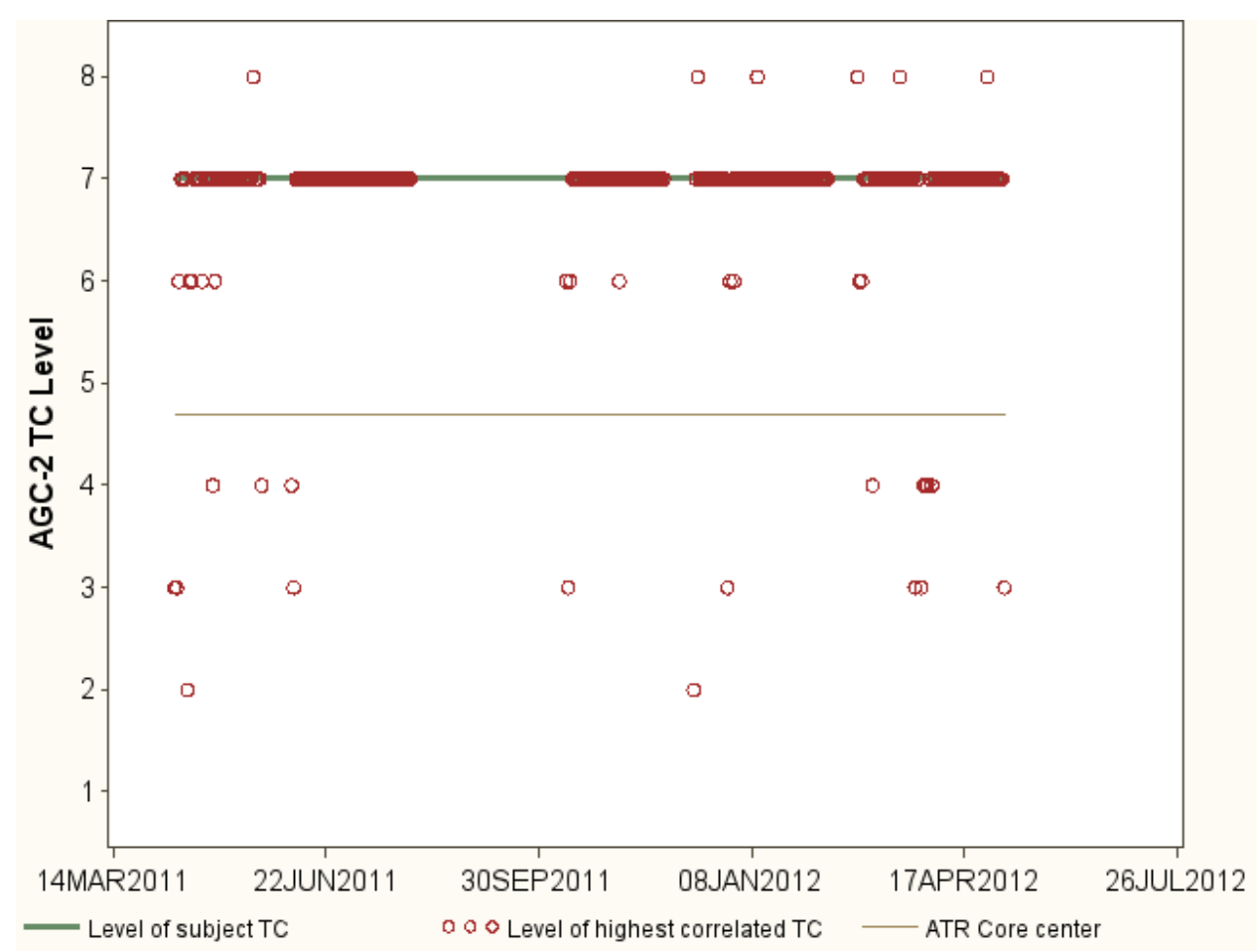

Figure 22. The level of the TC with the highest correlation to TC03 at Level $7(33 \mathrm{~cm})$. 


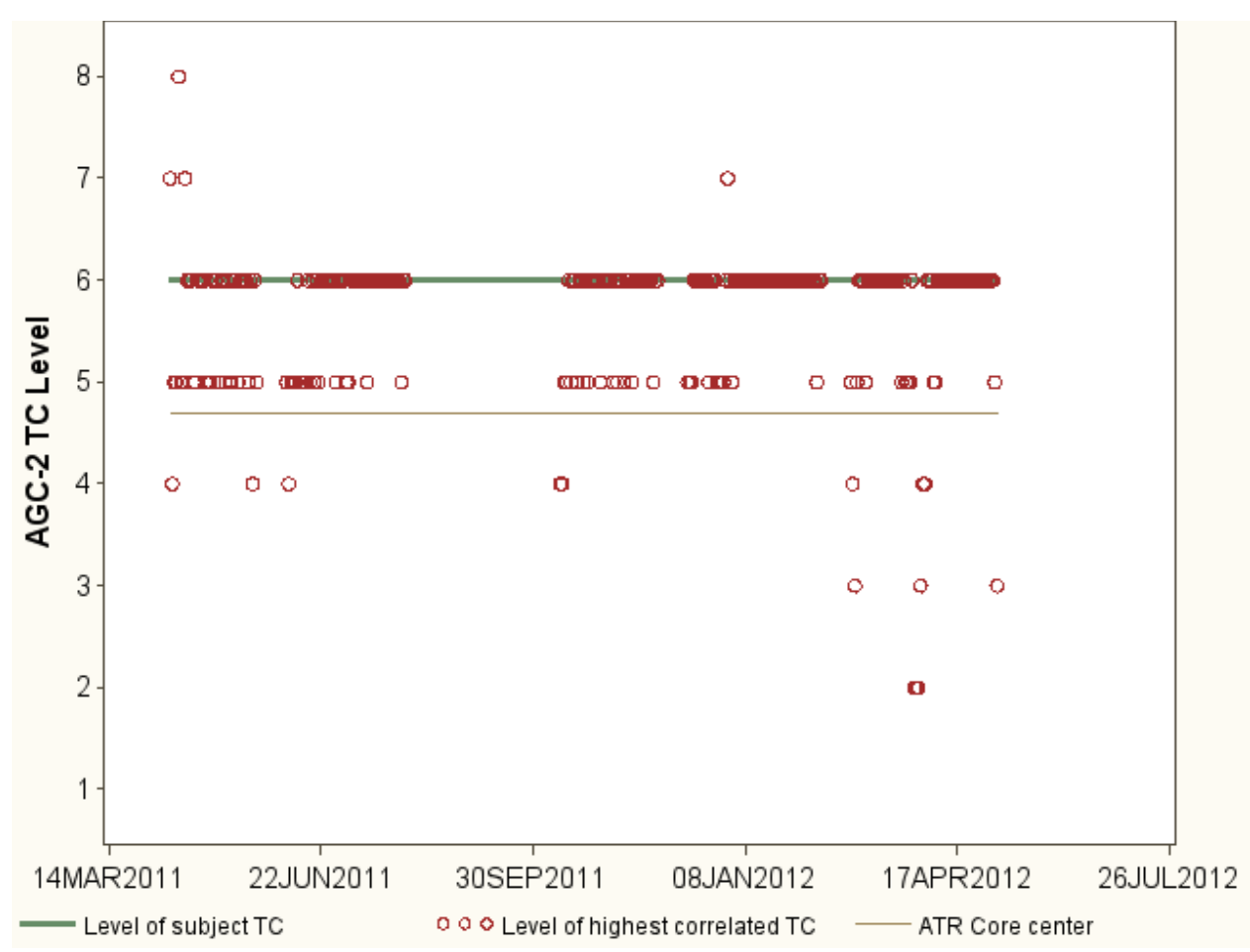

Figure 23. The level of the TC with the highest correlation to TC04 at Level $6(15.2 \mathrm{~cm})$.

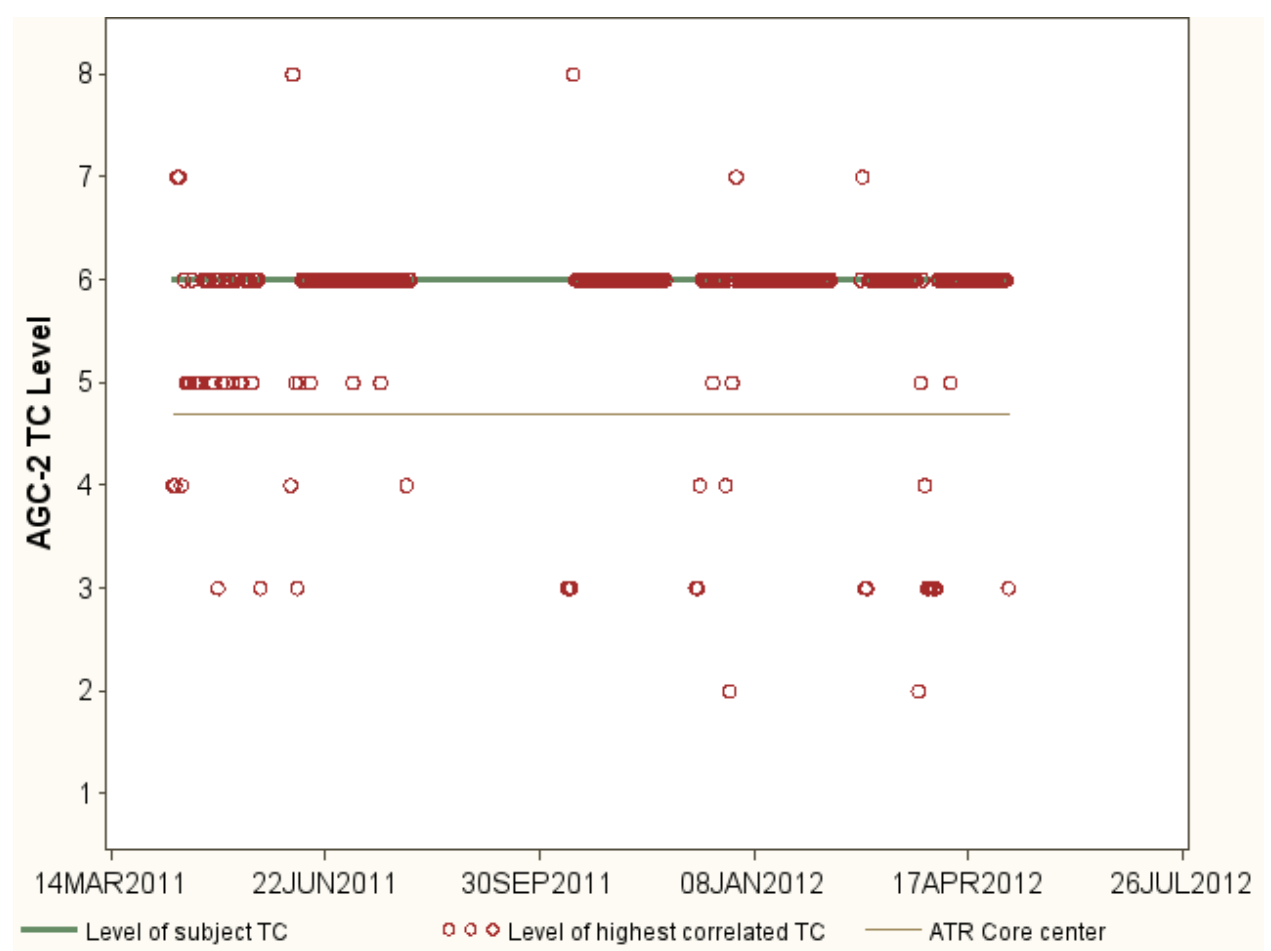

Figure 24. The level of the TC with the highest correlation to TC05 at Level $6(15.2 \mathrm{~cm})$. 


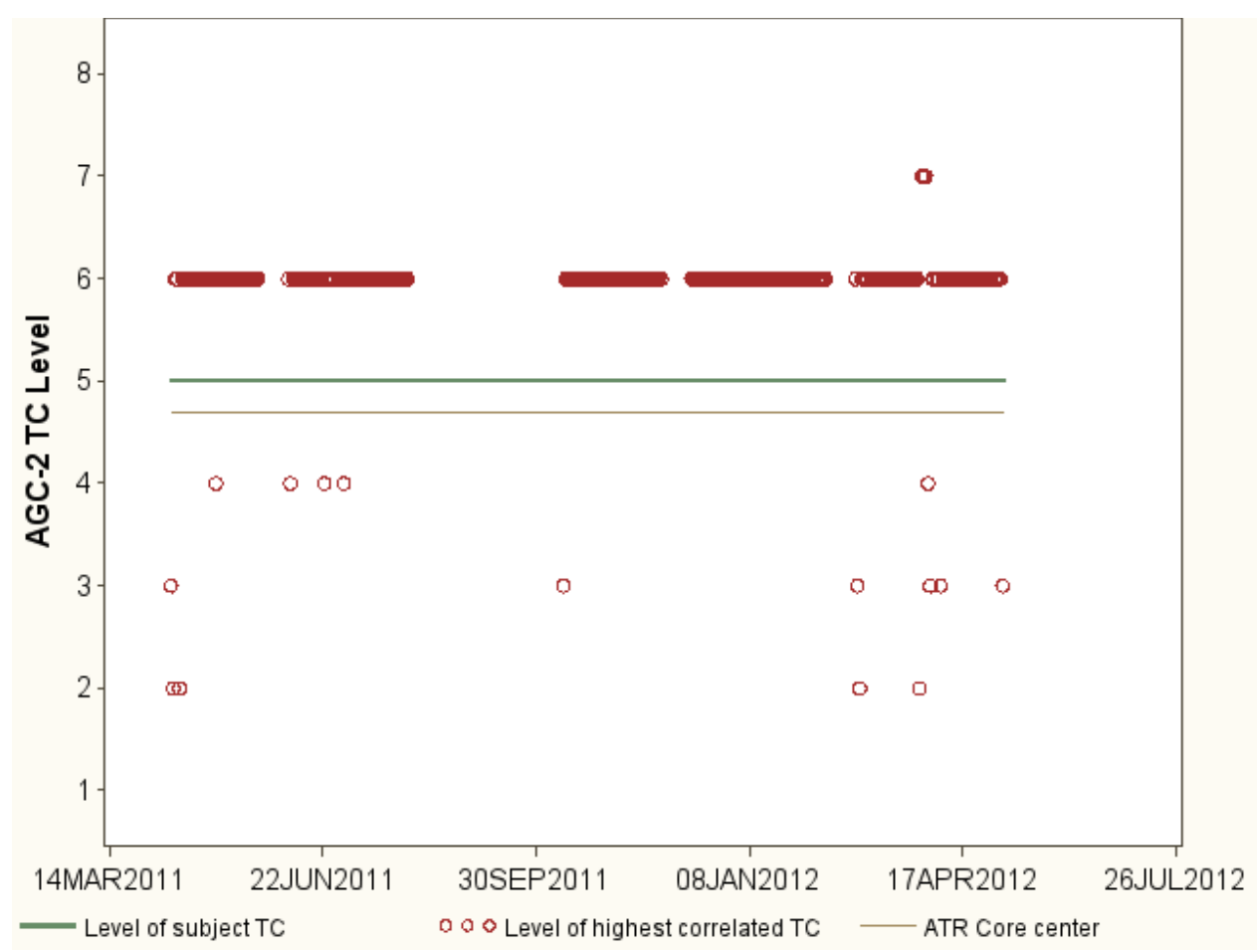

Figure 25. The level of the TC with the highest correlation to TC06 at Level $5(5.1 \mathrm{~cm})$.

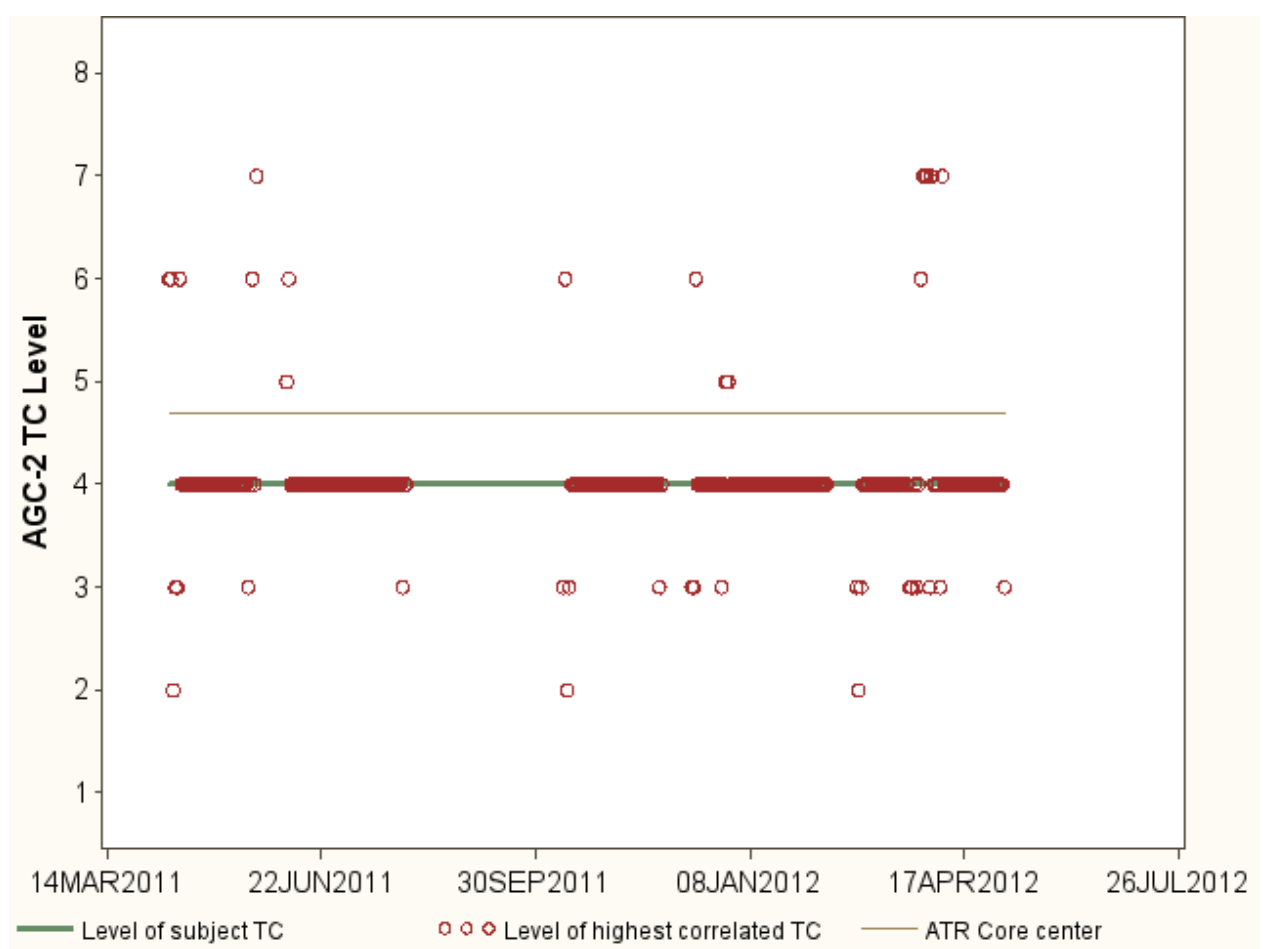

Figure 26. The level of the TC with the highest correlation to TC07 at Level $4(-15.2 \mathrm{~cm})$. 


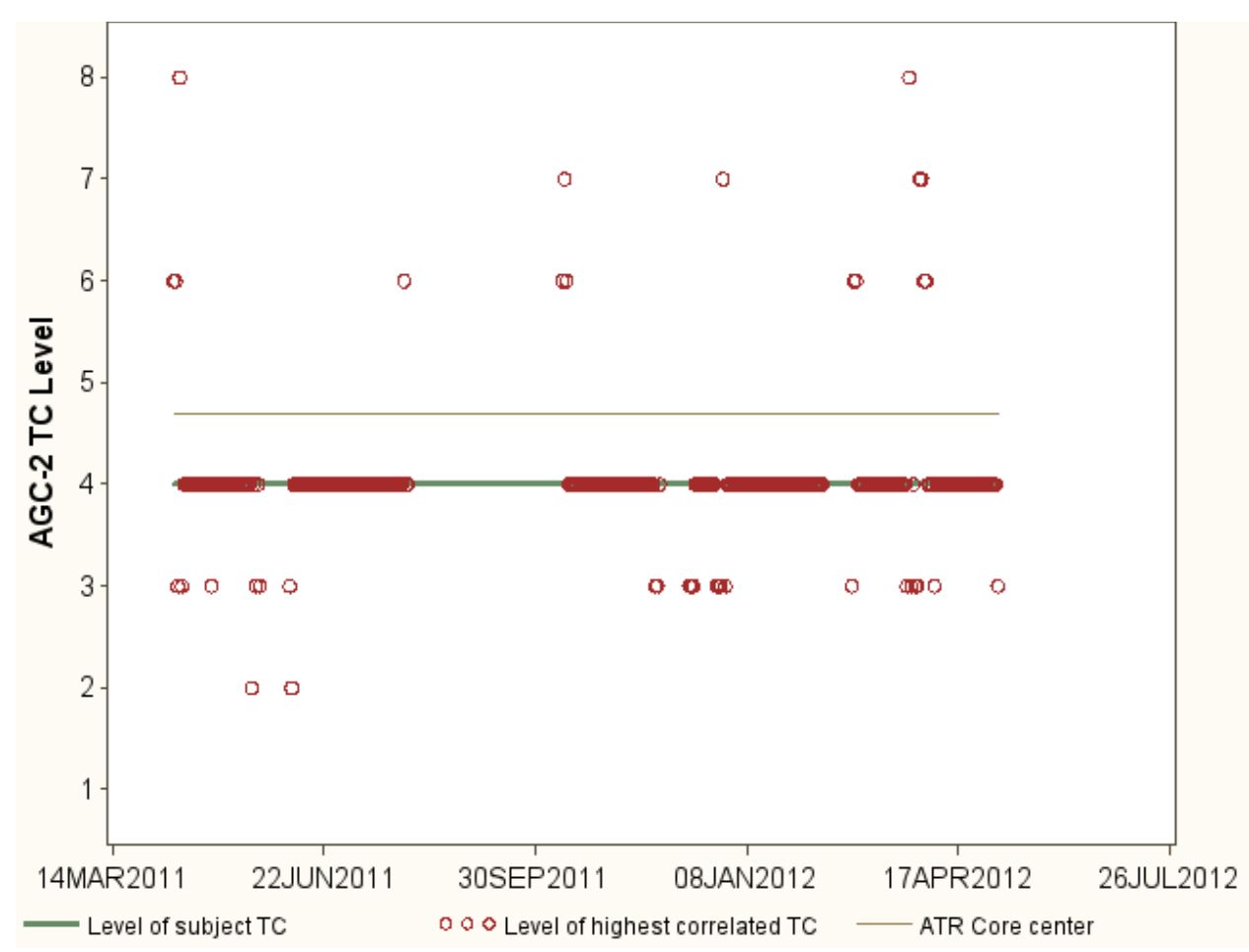

Figure 27. The level of the TC with the highest correlation to TC08 at Level $4(-15.2 \mathrm{~cm})$.

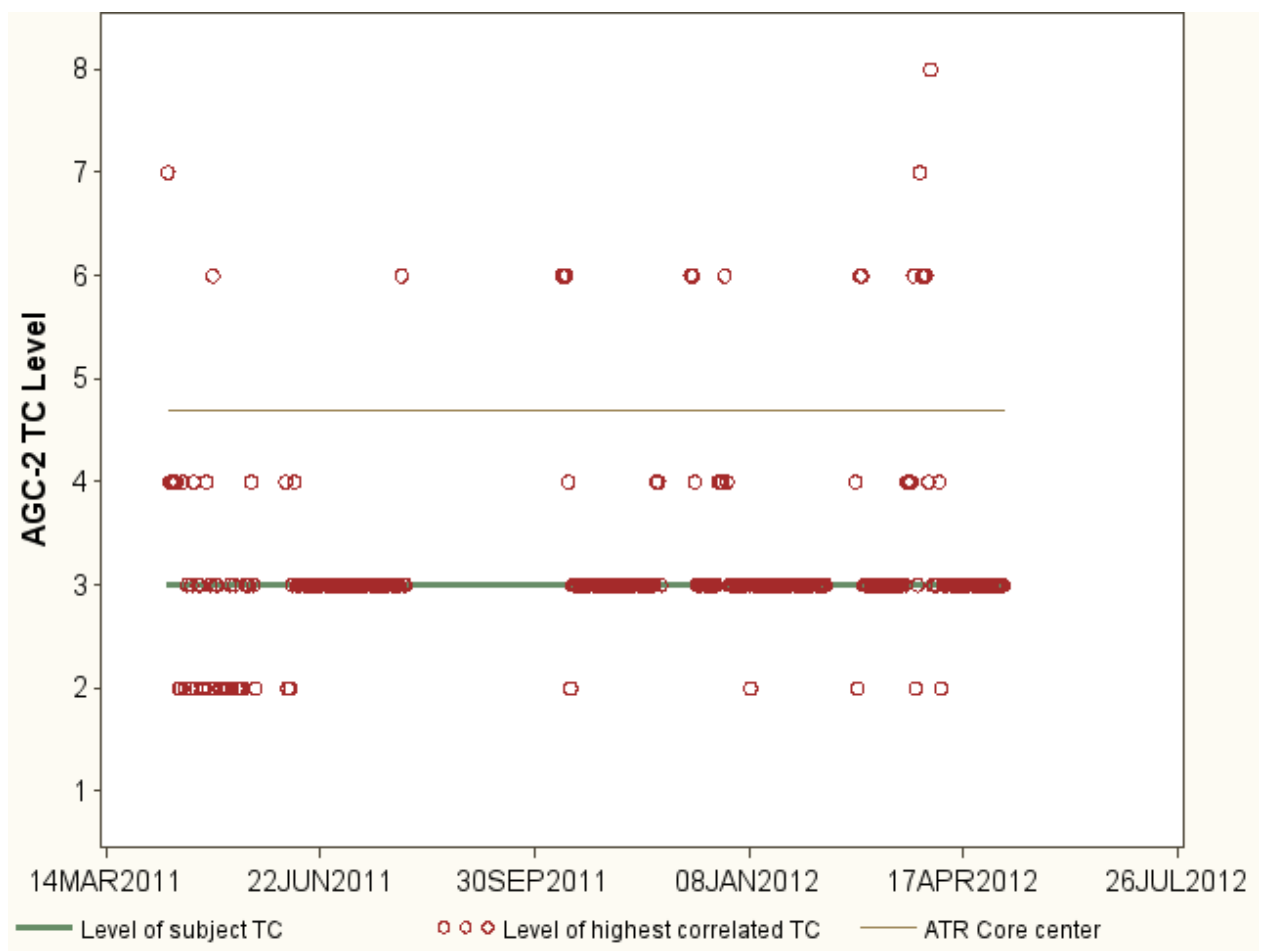

Figure 28. The level of the TC with the highest correlation to TC09 at Level $3(-28.6 \mathrm{~cm})$. 


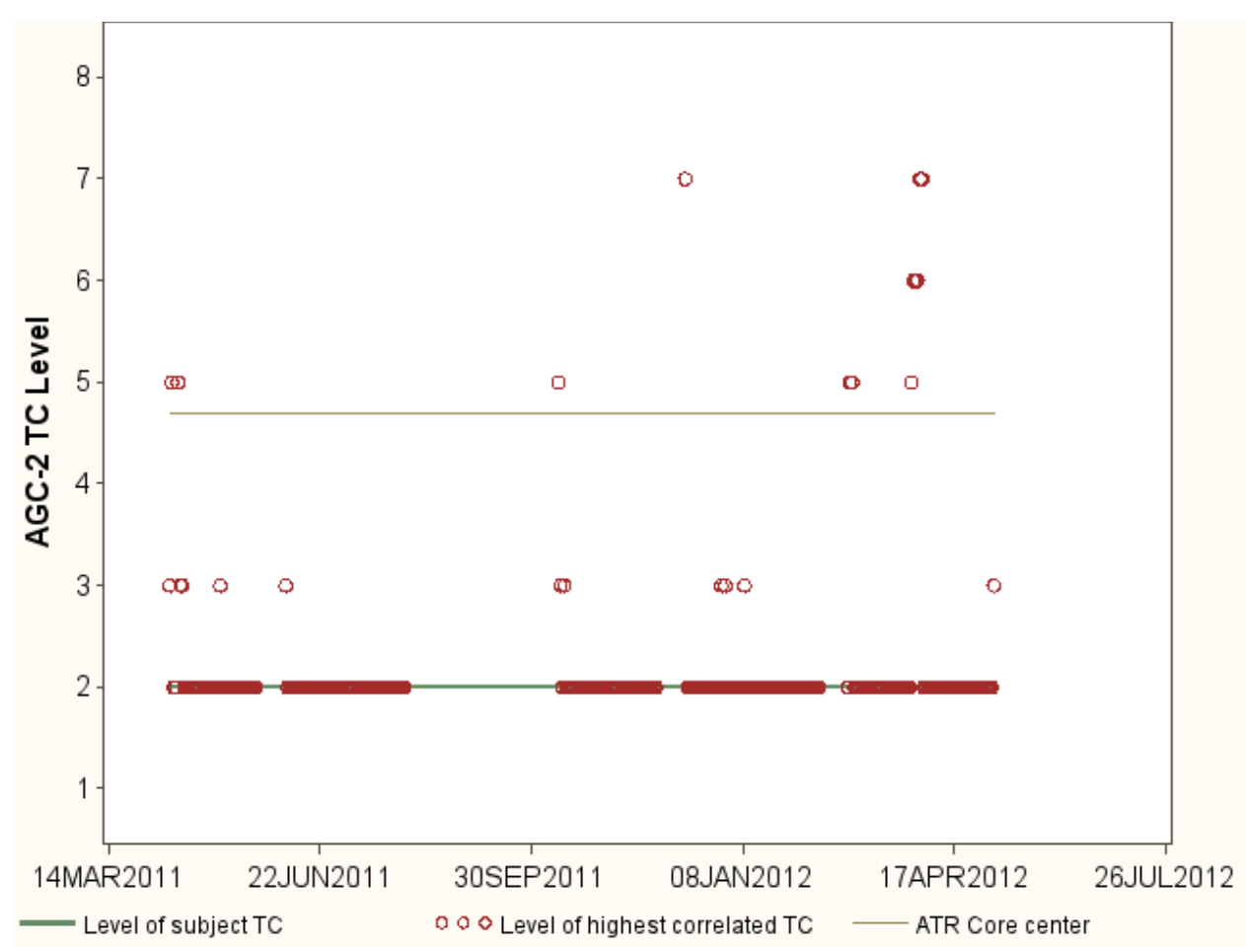

Figure 29. The level of the TC with the highest correlation to TC10 at Level $2(-45.7 \mathrm{~cm})$.

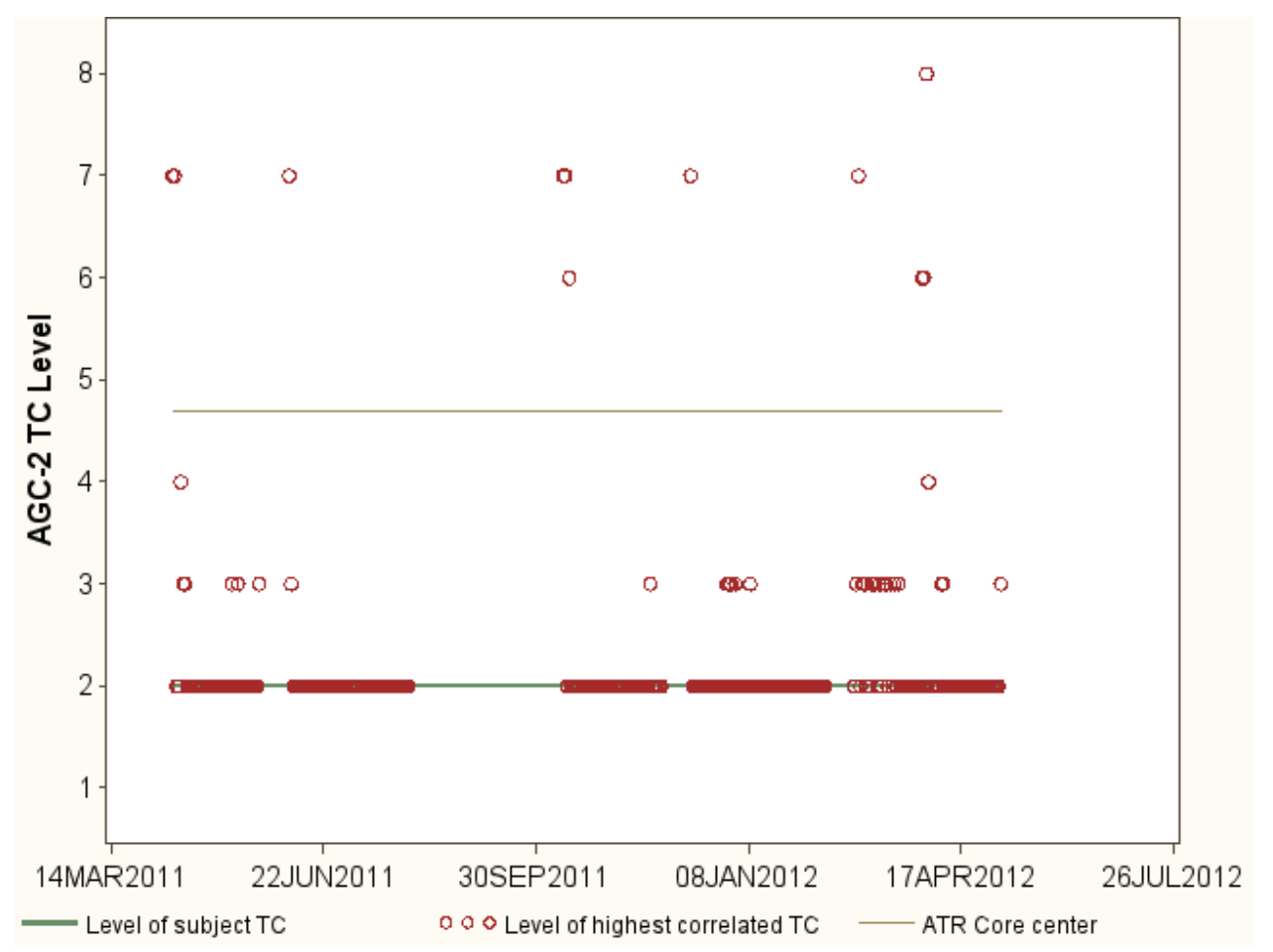

Figure 30. The level of the TC with the highest correlation to TC11 at Level $2(-45.7 \mathrm{~cm})$. 


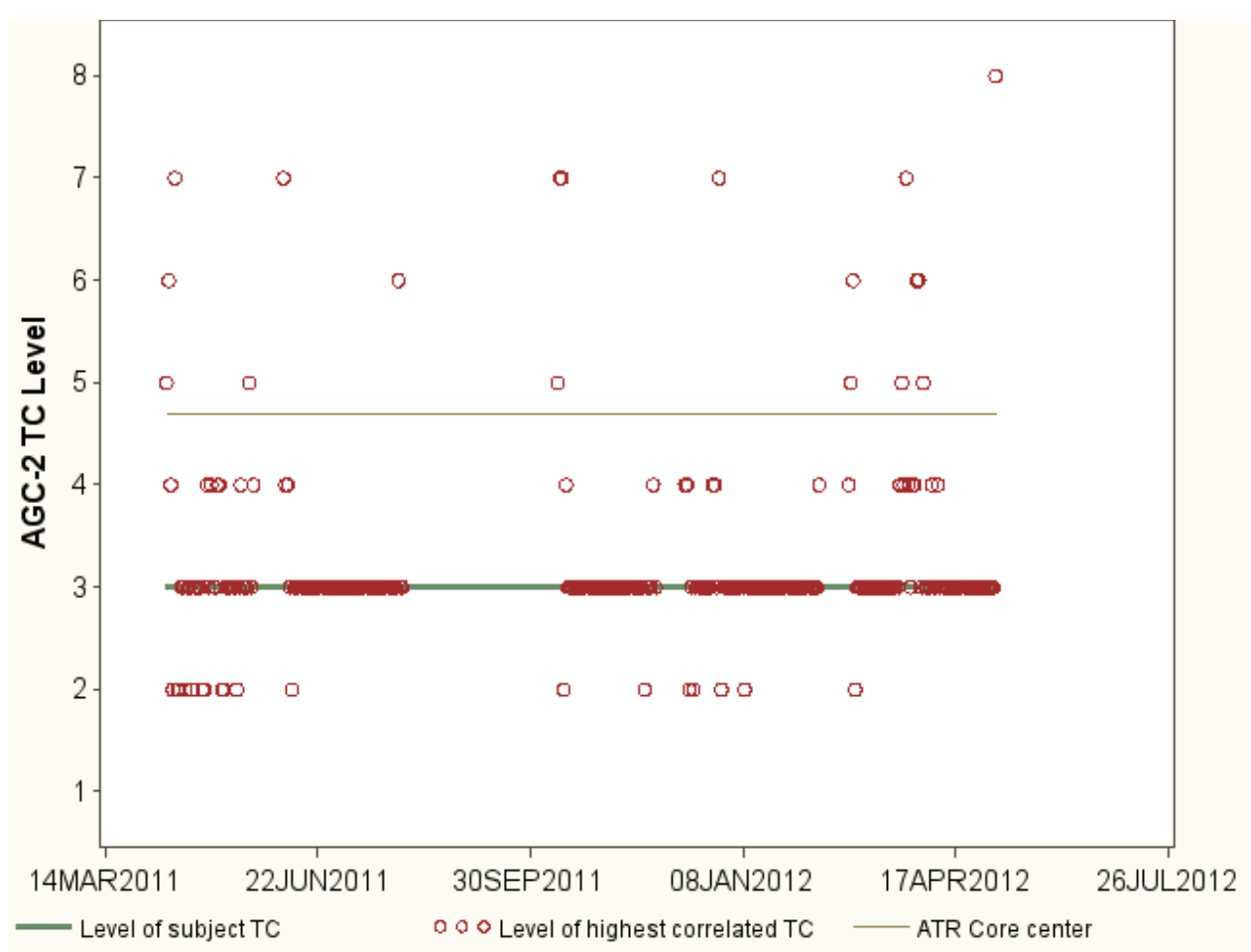

Figure 31. The level of the TC with the highest correlation to TC12 at Level $3(-28.6 \mathrm{~cm})$.

\subsubsection{Control Charts}

The purpose of control charts is to allow simple detection of events that are indicative of actual process change. This simple decision can be difficult where the process characteristic is continuously varying. The control chart provides statistically objective criteria for detecting change. When change is detected and considered valid, its cause should be identified. Instruments installed in the AGC-2 capsule (TCs and load cells) are subject to radiation fields and could degrade or fail during the experiment. A method is needed to make objective decisions about when instruments fail or start to produce untrustworthy data. Control charts provide such a tool to evaluate TCs and load cells for drifting or failure because of radiation damage.

\subsubsection{Control Chart Basics}

To construct a control chart, a baseline period is selected. Data collected during the baseline period are used to define the expected performance of the data time series. The mean of the response value in the baseline period is calculated using all observations. This mean is used to draw the center line of the control chart. The standard deviation of the observations is calculated and used to draw the upper and lower control limits at three standard deviations above and below the mean. If the time series has a constant mean and standard deviation, $99.7 \%$ of future points will plot between the upper and lower control limits. In addition to data falling outside the control limits, patterns of data within the control limits can also indicate a change in the process generating the data. The three rules used to apply control charts to the AGC-2 monitoring data are as follows (Duncan 1965; StatSoft Inc. 2010):

1. Out-of-control rule:

a. Out of control: $>10 \%$ of days in the monitoring period have differences greater than baseline mean value \pm 3 standard deviations. 
b. Out of control warning: $>30 \%$ of days in monitoring period have difference greater than baseline mean value \pm 2 standard deviations.

c. Otherwise under control.

2. Prolong bias rule:

a. Bias up: $>75 \%$ of days in monitoring period have differences greater than baseline mean value.

d. Bias down: $>75 \%$ of days in monitoring period have differences less than baseline mean value.

e. Otherwise no bias.

3. Time trend rule:

a. Strong trend: the correlation between differences and run time is $>0.8$ or $<-0.8$.

f. Moderate trend: the correlation between differences and run time is between 0.6 and 0.8 or between -0.6 and -0.8 .

g. Otherwise no time trend.

Control charts are based on the assumption that the mean and standard deviation of the process are constant between the baseline period and the monitoring period. If such an assumption is violated, the control chart cannot be interpreted strictly by the above rules. For AGC-2, the capsule was removed from the reactor during Cycle 150A, and rotated 180 degrees between Cycles 150B and 151A. These two activities may have voided the assumption that the mean of the process was constant throughout the experiment. In particular, rotating the capsule changes the distance from a TC to the reactor core, thus making a change in mean temperature likely. The rules are therefore applied as guidelines to aid in reviewing the temperature and load cell data. Professional judgment is applied to making the decision about whether data from TCs and load cells are still valid.

\subsubsection{TC Control Charts}

The AGC-2 experiment covered five ATR reactor cycles over a 13-month period. The capsule was removed from the reactor during Cycle 150A. All of the data are being qualified at once, so there are no qualified data to serve as a baseline. The two cycles before the capsule was removed were arbitrarily identified as the baseline period. The three cycles after Cycle 150A were then used as the monitoring period. Rotation of the capsule occurred in the middle of the monitoring period.

The TC temperature differences depend on capsule thermal condition parameters such as heat sources and gas mixture, which define the graphite temperature and graphite thermal conductivity. Stable temperature differences will be achieved only when the capsule is in steady-state thermal conditions at full power operation. Data used to build the control charts was filtered to limit the data to periods when effective reactor power exceeded $20 \mathrm{MW}$. Limiting temperature data to this experiment condition narrows the control limits and makes it easier to identify whether the TC failure causes their difference to be outside of control limits.

The pattern exhibited by a failing TC that was starting to drift is that the difference between that TC and all other TCs would get larger over time. There is no TC that shows a trend relative to all other TCs. The changes displayed in the control charts are more aligned with location in the capsule and rotation of the capsule between Cycles 150B and 151A. The TCs most likely to show changes because of the rotation of the capsule are TC03 and TC10 on the north side of the capsule and TC05 and TC08 on the south side of the capsule. Of all the control charts for the paired TCs, there are 27 that show a significant percent of measurements out of control. Of these 27 pairs, 21 involve one or both of the above listed TCs. Looking at the pattern of the changes in the figures, most of the out-of-control temperature differences occurred 
during the last two cycles, after the capsule was rotated. The other clustering of out-of-control TC pairs involve TC10 and TC11, located at the bottom of the capsule.

For each TC, the control chart that had the highest percent of out-of-control measurements during the monitoring period is displayed. The greatest percent of out-of-control values for TC01 is for differences with TC11. TC01 and TC11 are on opposite ends of the capsule. Figure 32 shows that these differences occur after the capsule was rotated. TC11 also shows the most out of control differences for TC02 (see Figure 33). These out of control differences mainly occur after the capsule was rotated. TC03 and TC05 are on opposite sides of the capsule, and there is a significant change in the temperature differences between these TCs when the capsule is rotated (see Figure 34). Other TC pairs that show a significant change in temperature difference associated with rotation of the capsule are TC04-TC11 (see Figure 35), TC05-TC09 (see Figure 36), TC06-TC11 (see Figure 37), and TC09-TC10 (see Figure 40). TC08 indicated a lack of control with respect to TC12 (see Figure 39). The three TCs at the bottom of the capsule (TC10, TC11, and TC12) showed no out-of-control values among their differences as shown in Figures 41 and 42.

There is no evidence of any failing TCs. The changes in the control charts are mainly related to rotation of the capsule.

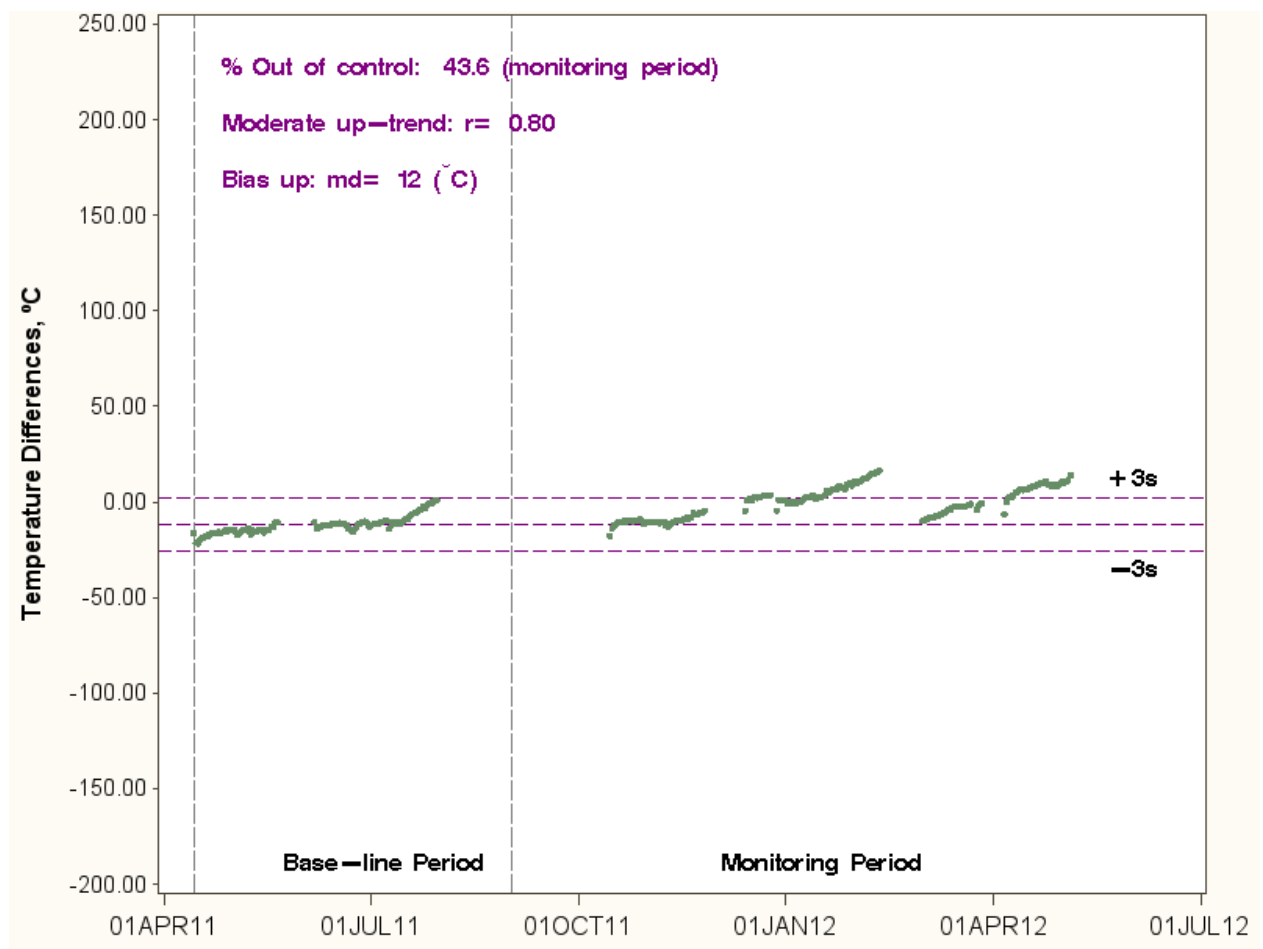

Figure 32. Difference TC01-TC011 has the greatest percent of out-of-control values in the monitoring period for TC01 along with a moderate upward trend and bias. 


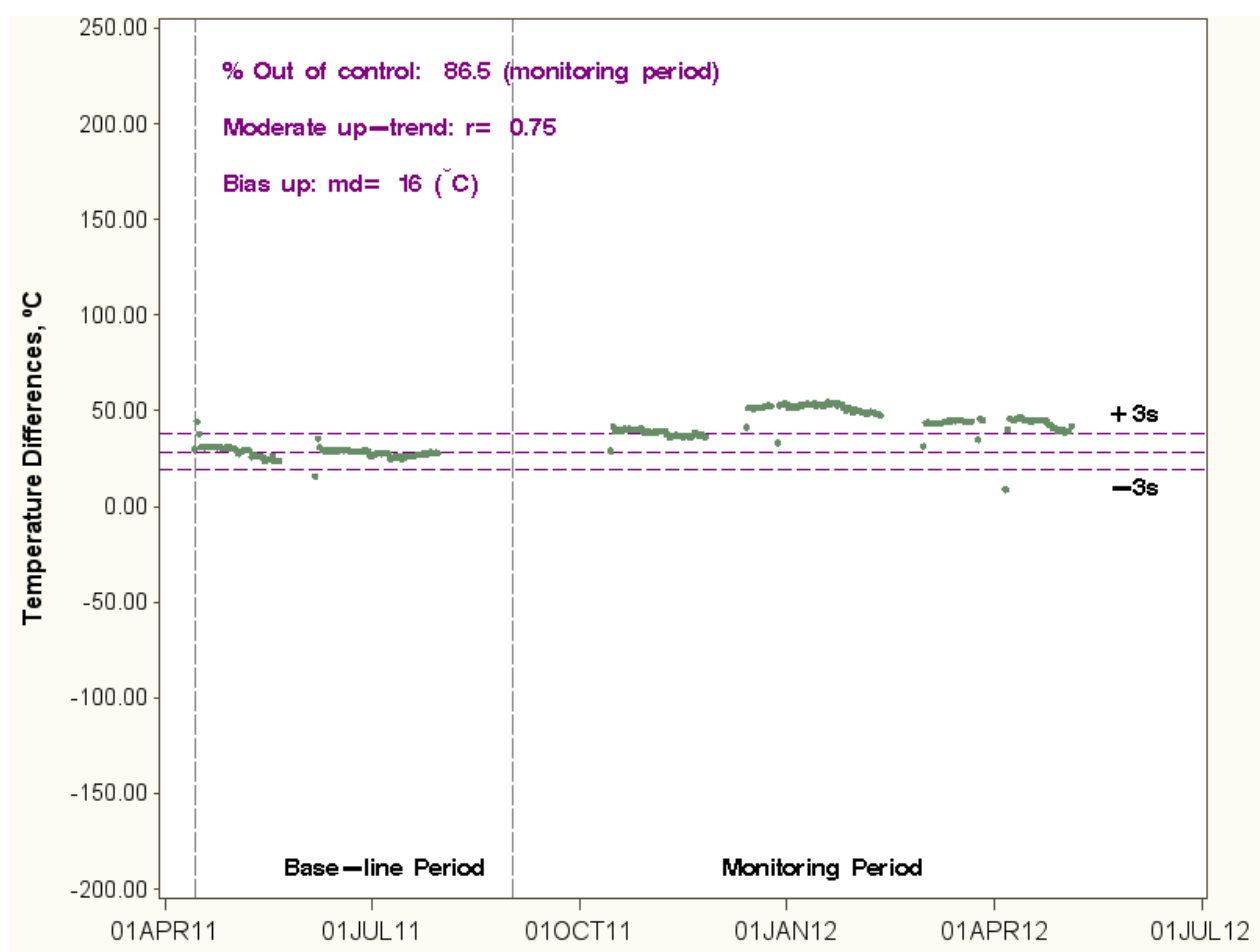

Figure 33. Difference TC02-TC11 has the greatest percent of out-of-control values in the monitoring period for TCO2 along with moderate upward trend and bias.

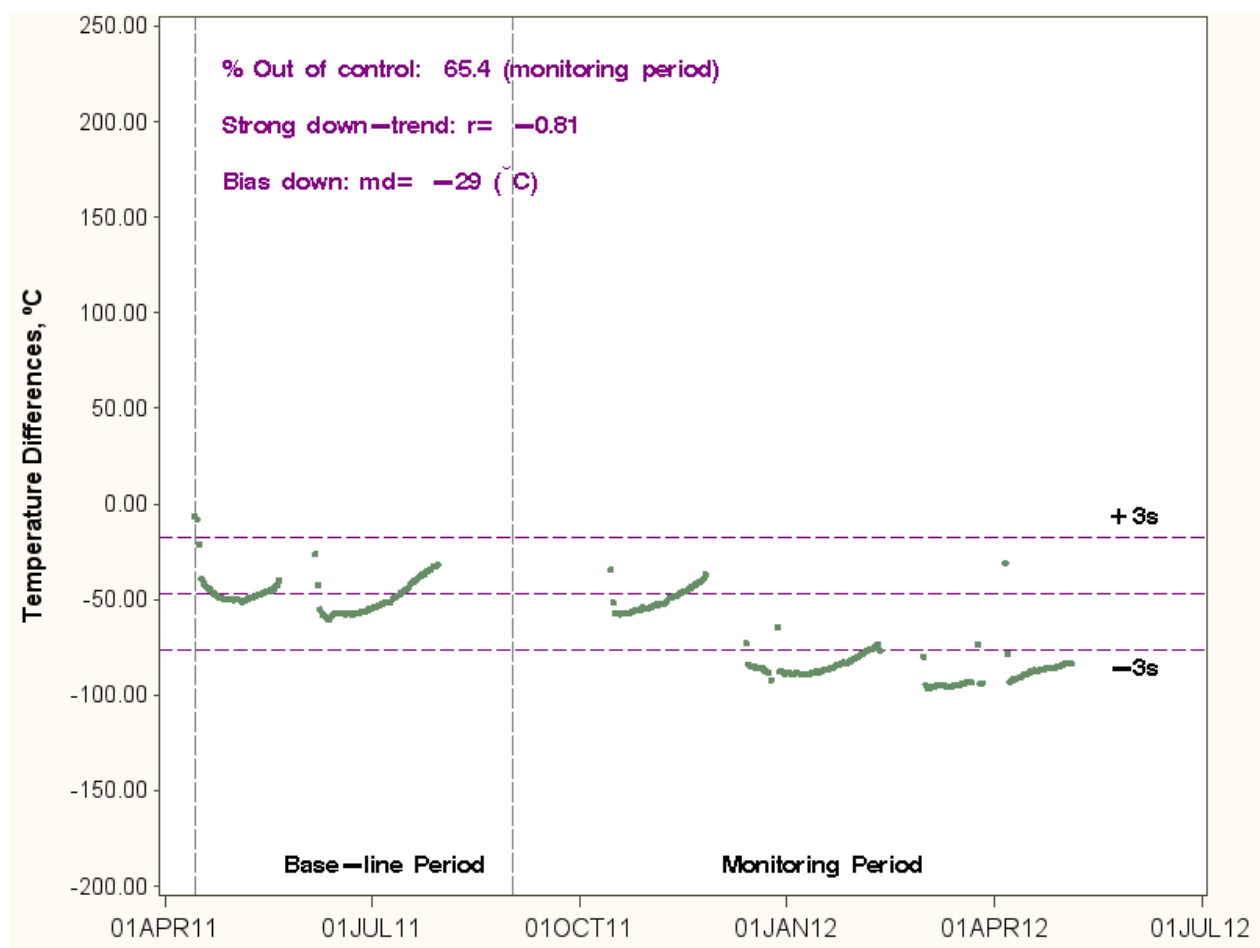

Figure 34. Difference TC03-TC05 has the greatest percent of out-of-control values in the monitoring period for TCO3 along with a strong downward trend and bias downward. 


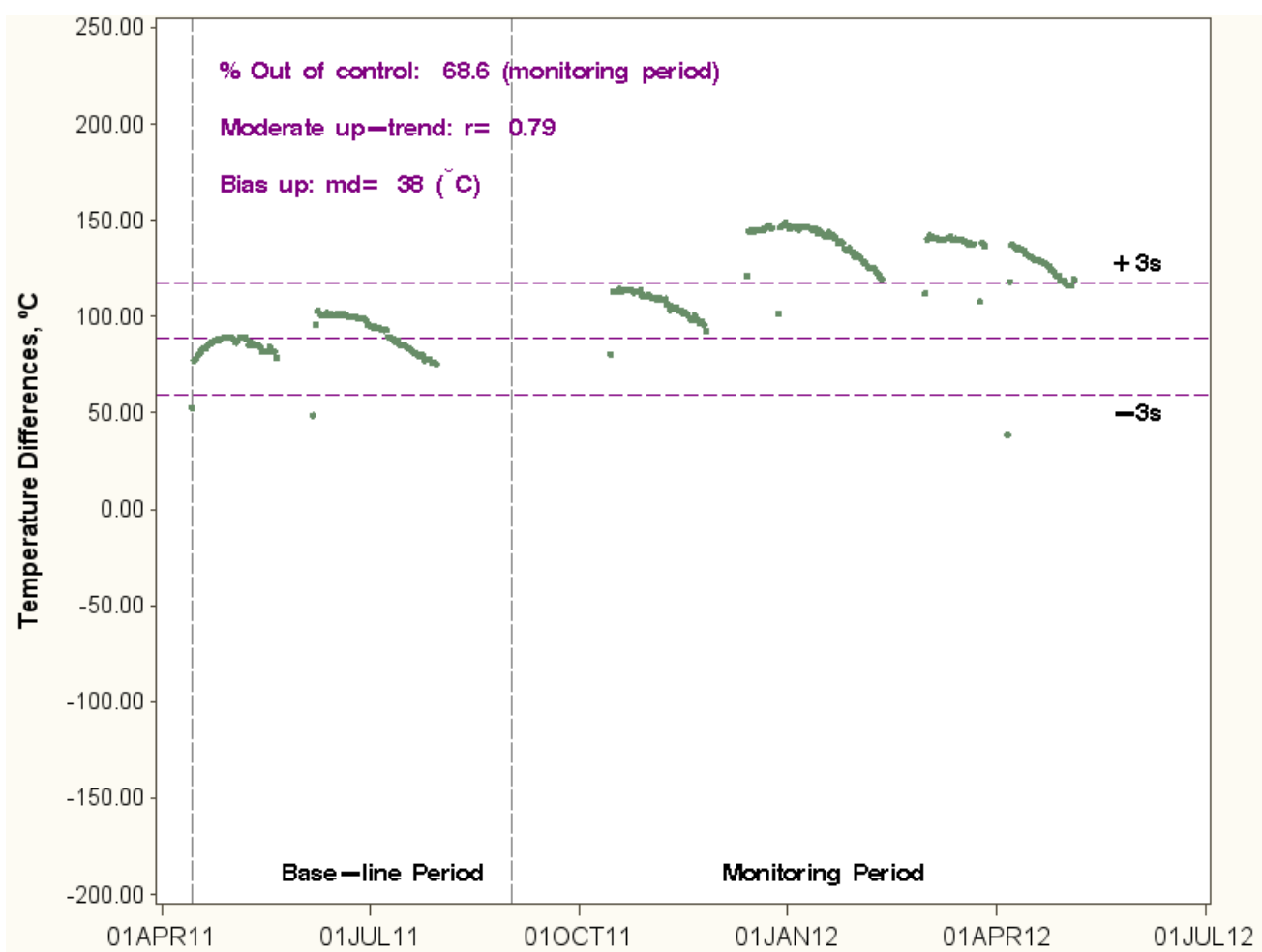

Figure 35. Difference TC04-TC11 has the greatest percent of out-of-control values in the monitoring period for TC14 along with a moderate upward trend and bias.

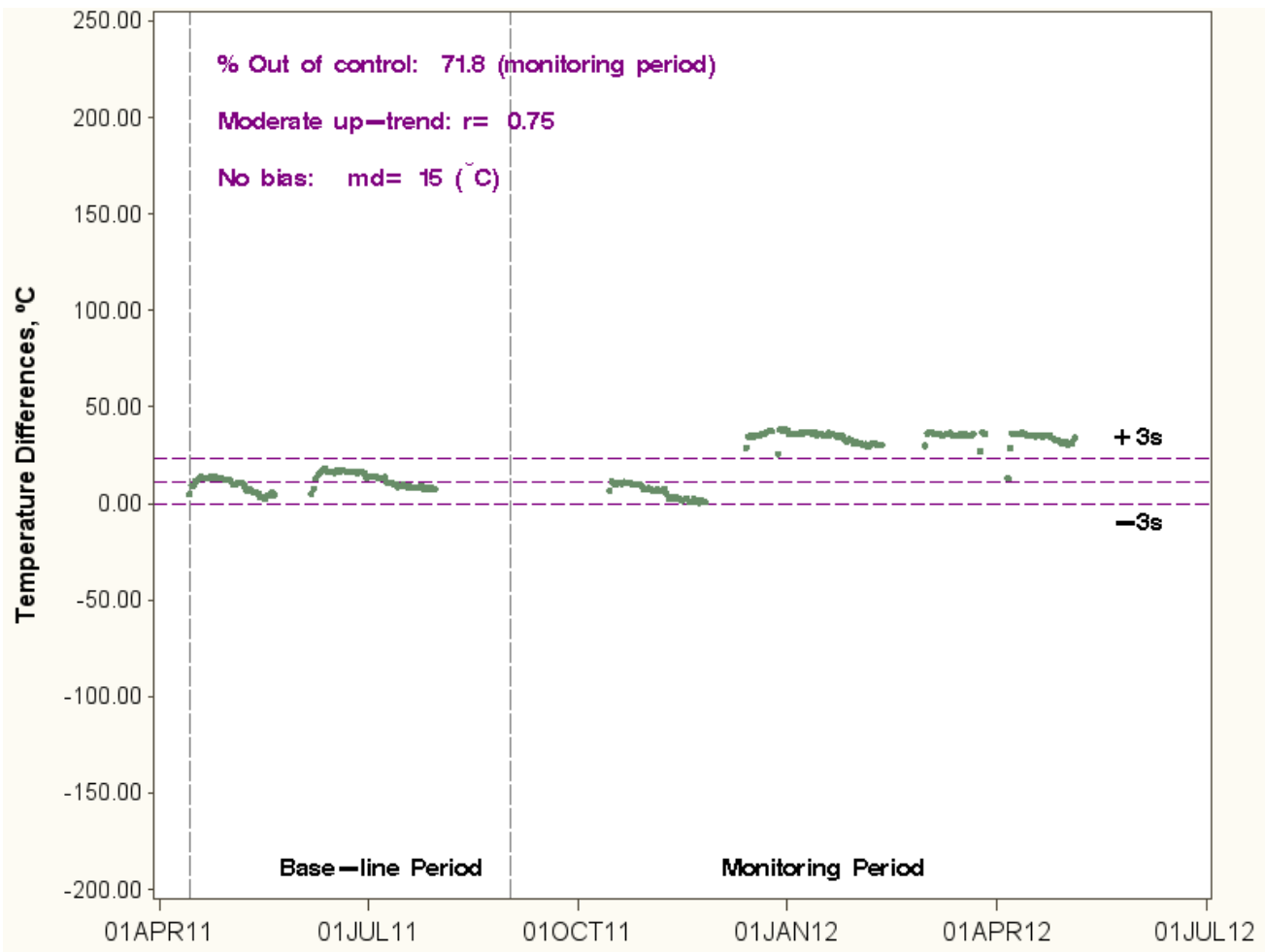

Figure 36. Difference TC05-TC09 has the greatest percent of out-of-control values in the monitoring period for $\mathrm{TC} 05$ with a moderate upward trend but not a significant bias. 


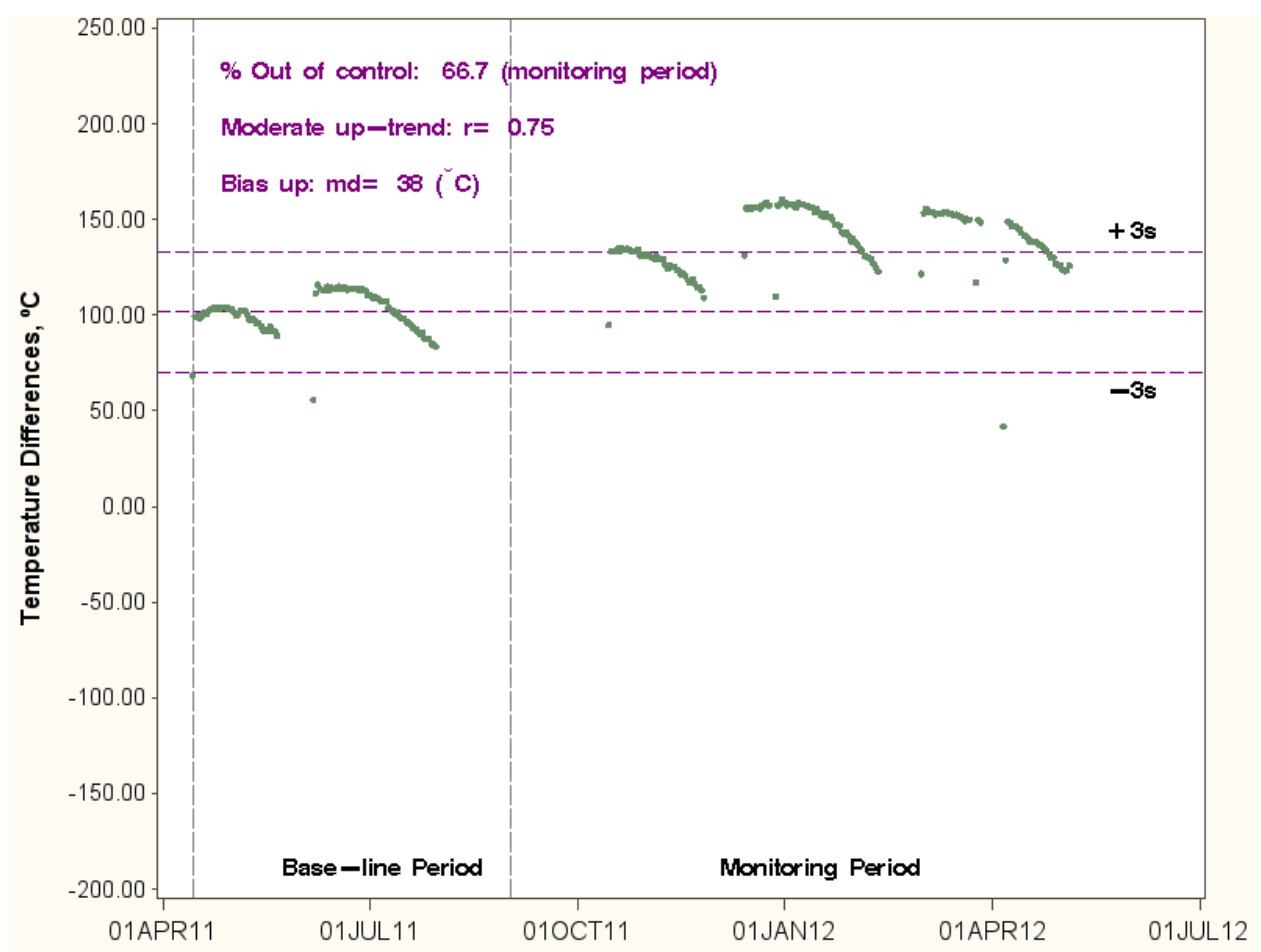

Figure 37. Difference TC06-TC11 has the greatest percent of out-of-control values in the monitoring period for TCO5 with a moderate upward trend and bias.

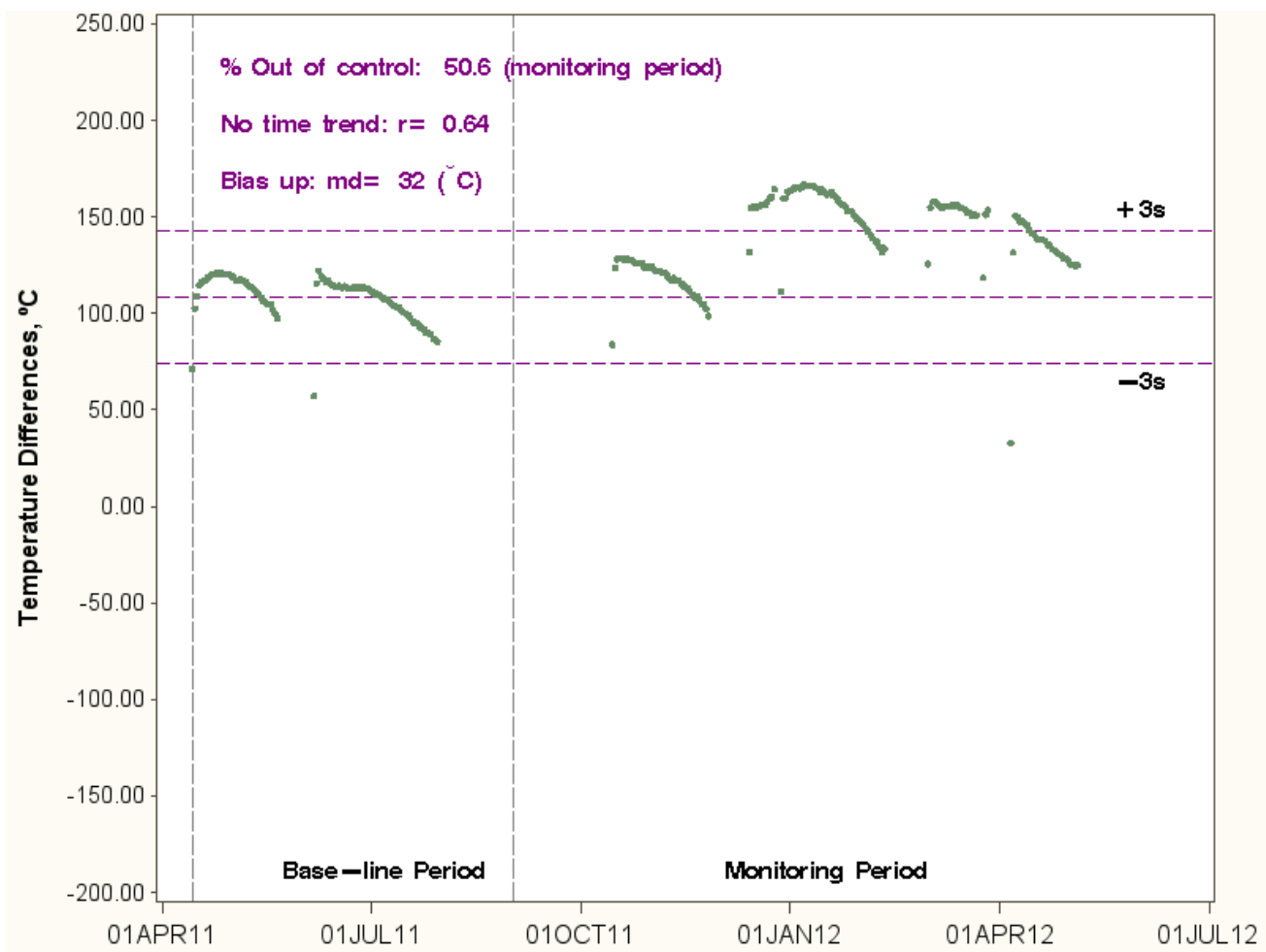

Figure 38. Difference TC07-TC10 has the greatest percent of out-of-control values in the monitoring period for $\mathrm{TC} 07$ with a positive bias but no trend. 


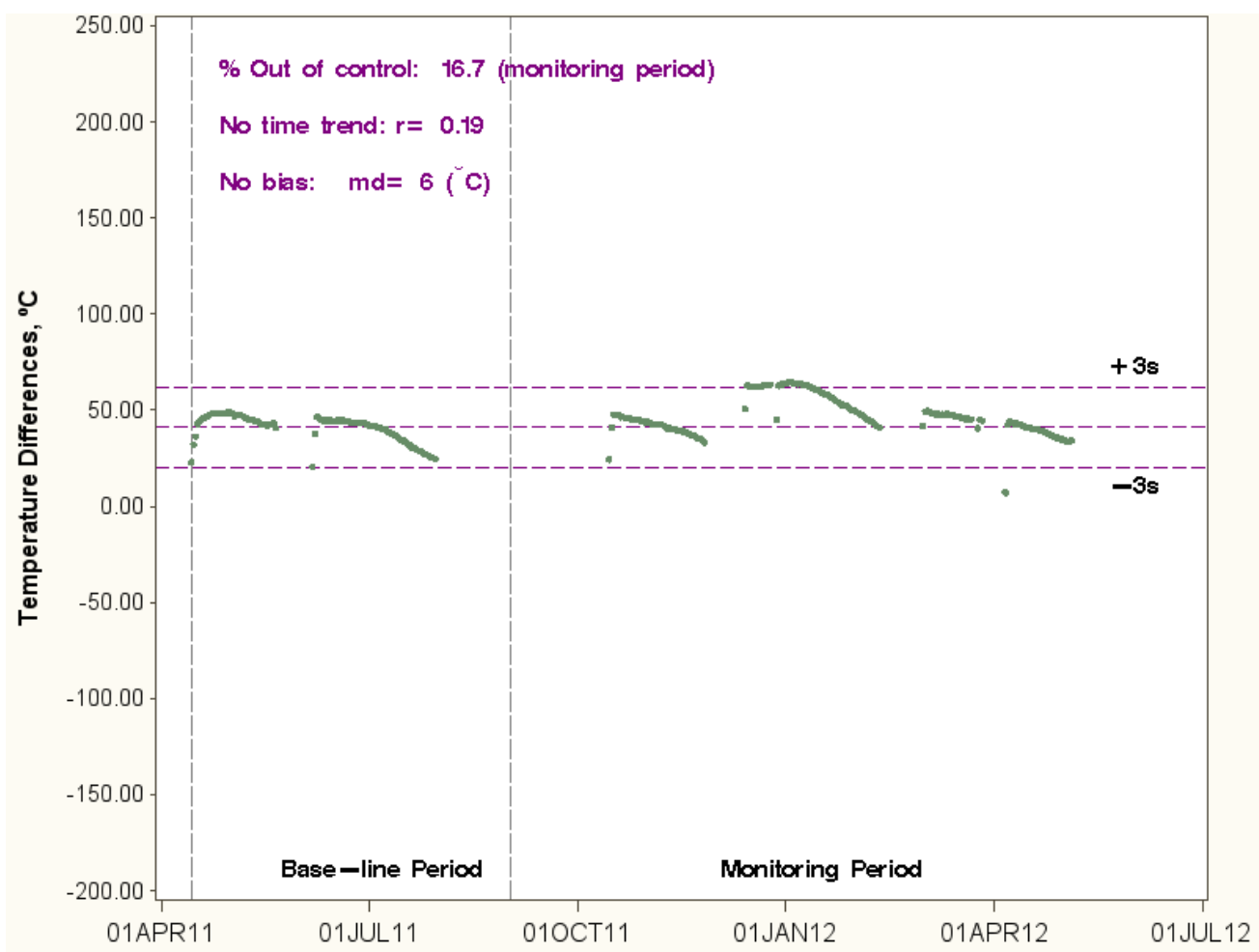

Figure 39. Difference TC08-TC12 has the greatest percent of out-of-control values in the monitoring period for TC08 with no trend and no bias.

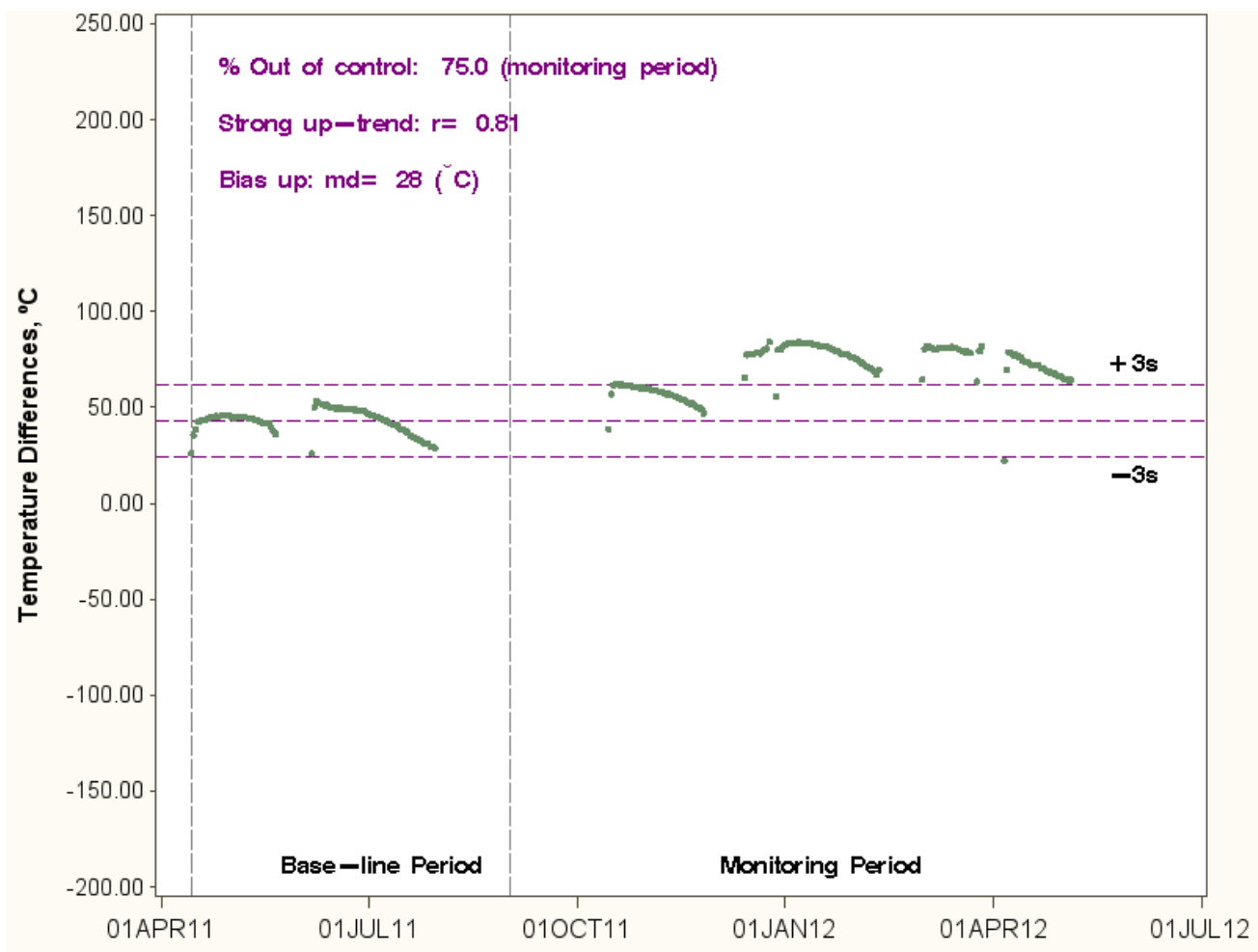

Figure 40. Difference TC09-TC10 shows a strong upward trend and bias with a significant fraction of values out of control. 


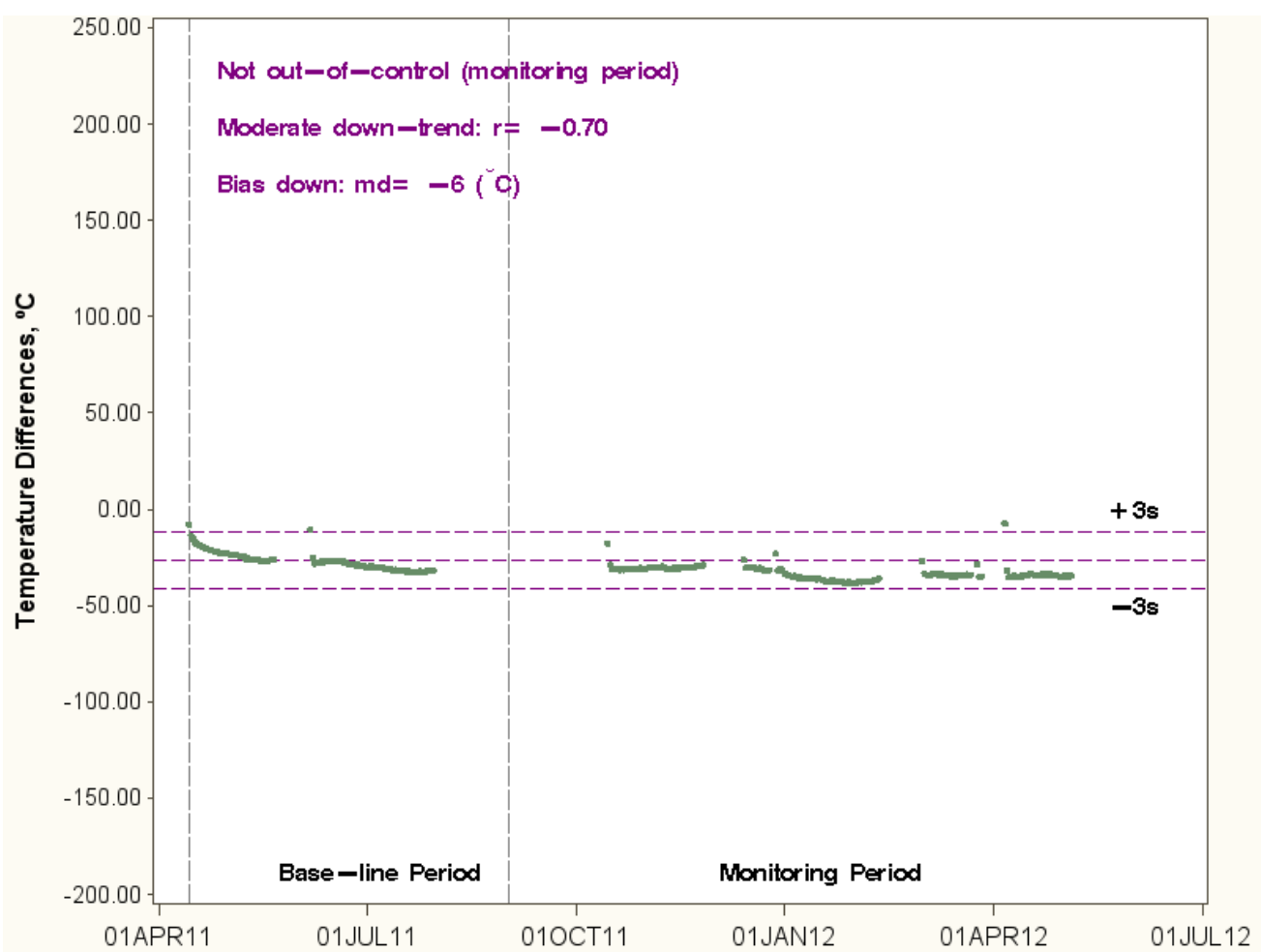

Figure 41. Difference TC10-TC11 has no out-of-control measurements, but shows a moderate downward trend and bias.

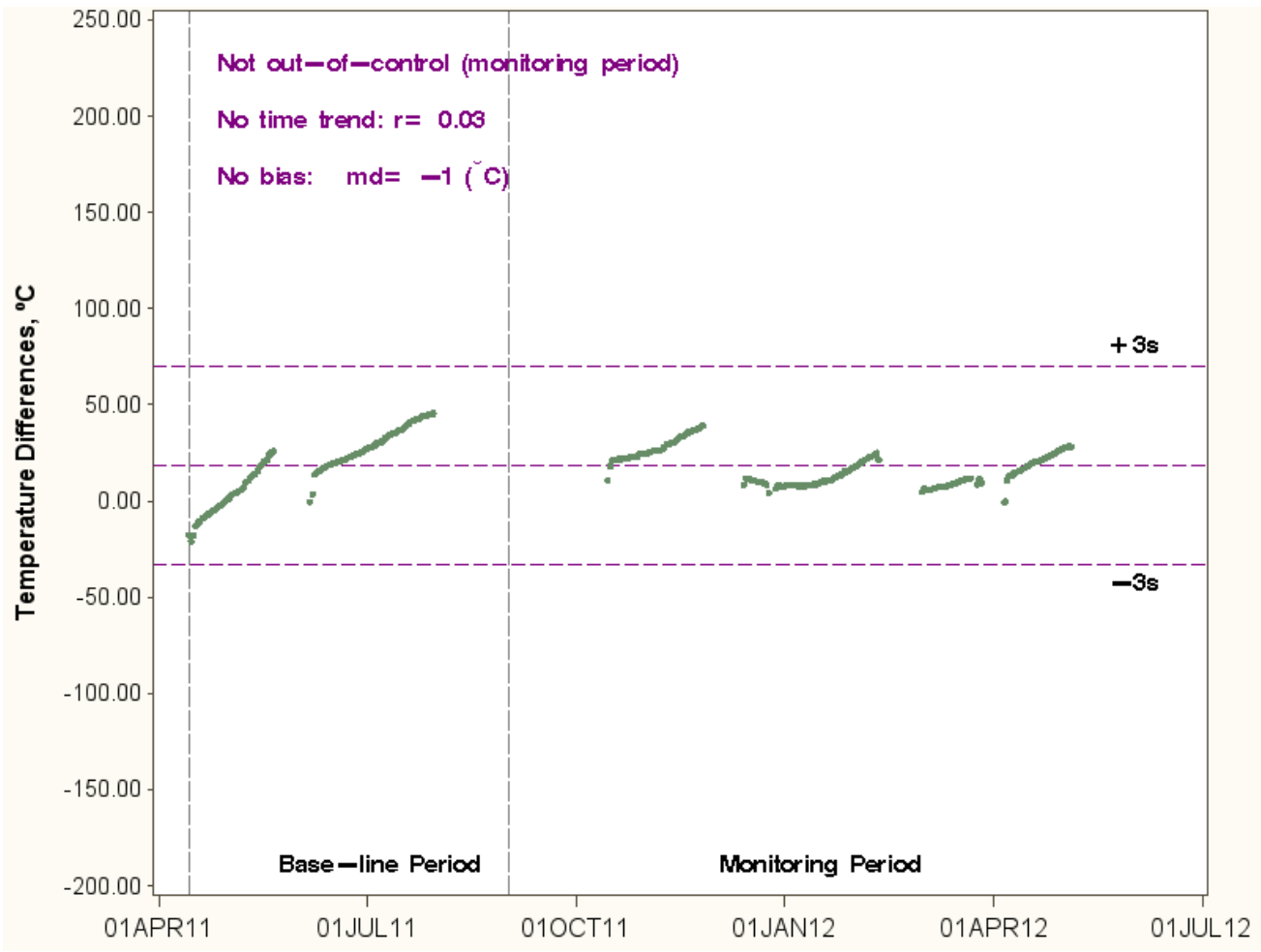

Figure 42. Difference TC11-TC12 has no out-of-control measurements with no trend and no bias. 


\subsubsection{Load Cell Control Charts}

Load cells monitor the stress applied to graphite specimens in the upper portion of Channels $1-6$. The load cells are subject to elevated radiation fields, and there is a possibility that some of the load cells will fail during the experiment. Control charts are used to evaluate load cells for drifting or failure caused by radiation damage. The baseline period was kept the same as the baseline period used for the TC analysis. As noted in the time series plots discussed in Section 3.3.3.2, the paired load cells showed greater differences during the final two cycles of the experiment. This difference is also apparent in the control charts, with the last two cycles showing a large number of differences outside of tolerance limits. This change coincides with the rotation of the capsule. It does not seem that proximity to the core would be an issue for the load cells as it is for the TCs. It may be that the system was not reset in exactly the same way after the rotation. However, all loads remained within specifications.

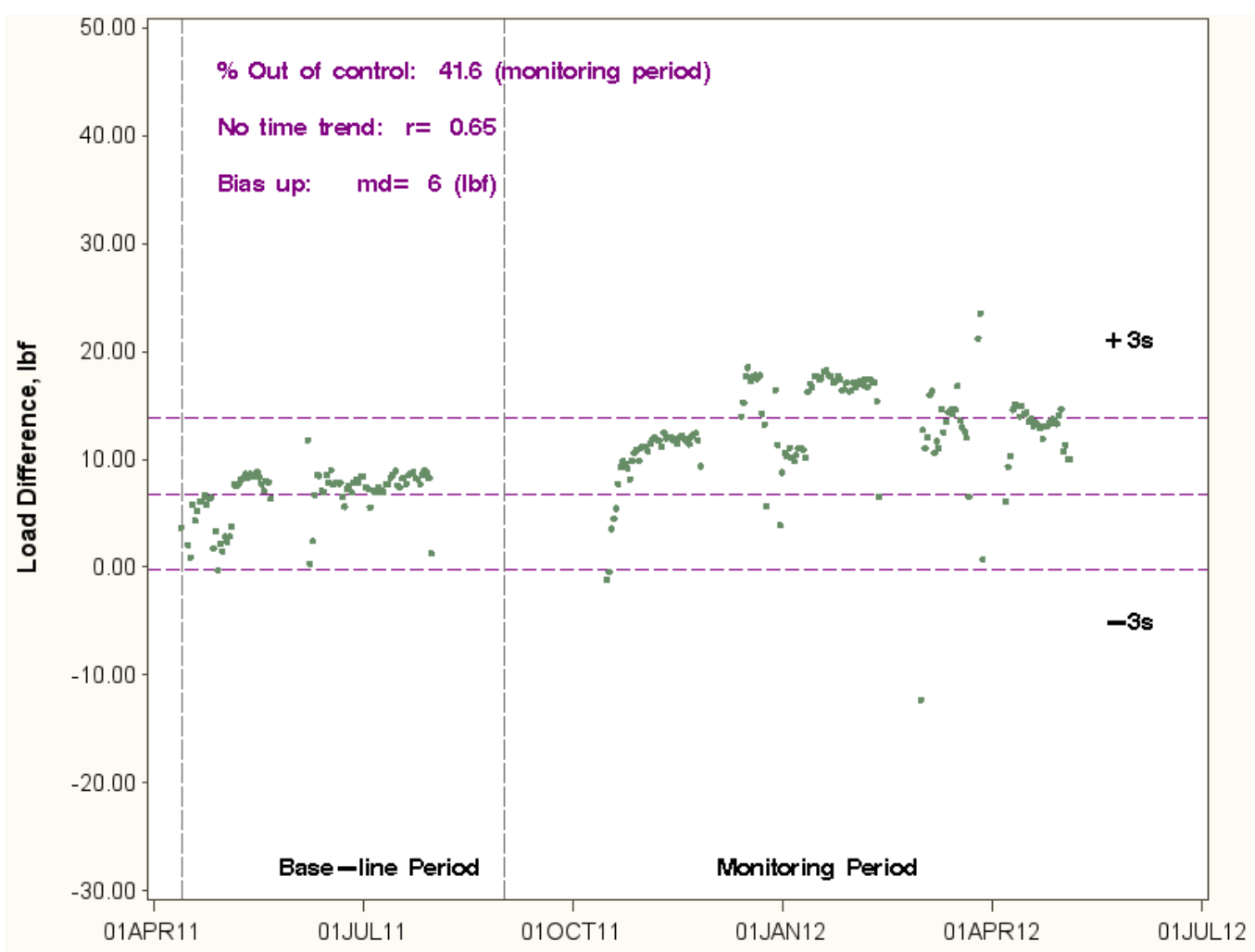

Figure 43. Control chart for differences between load cell pair LC01-LC04. 


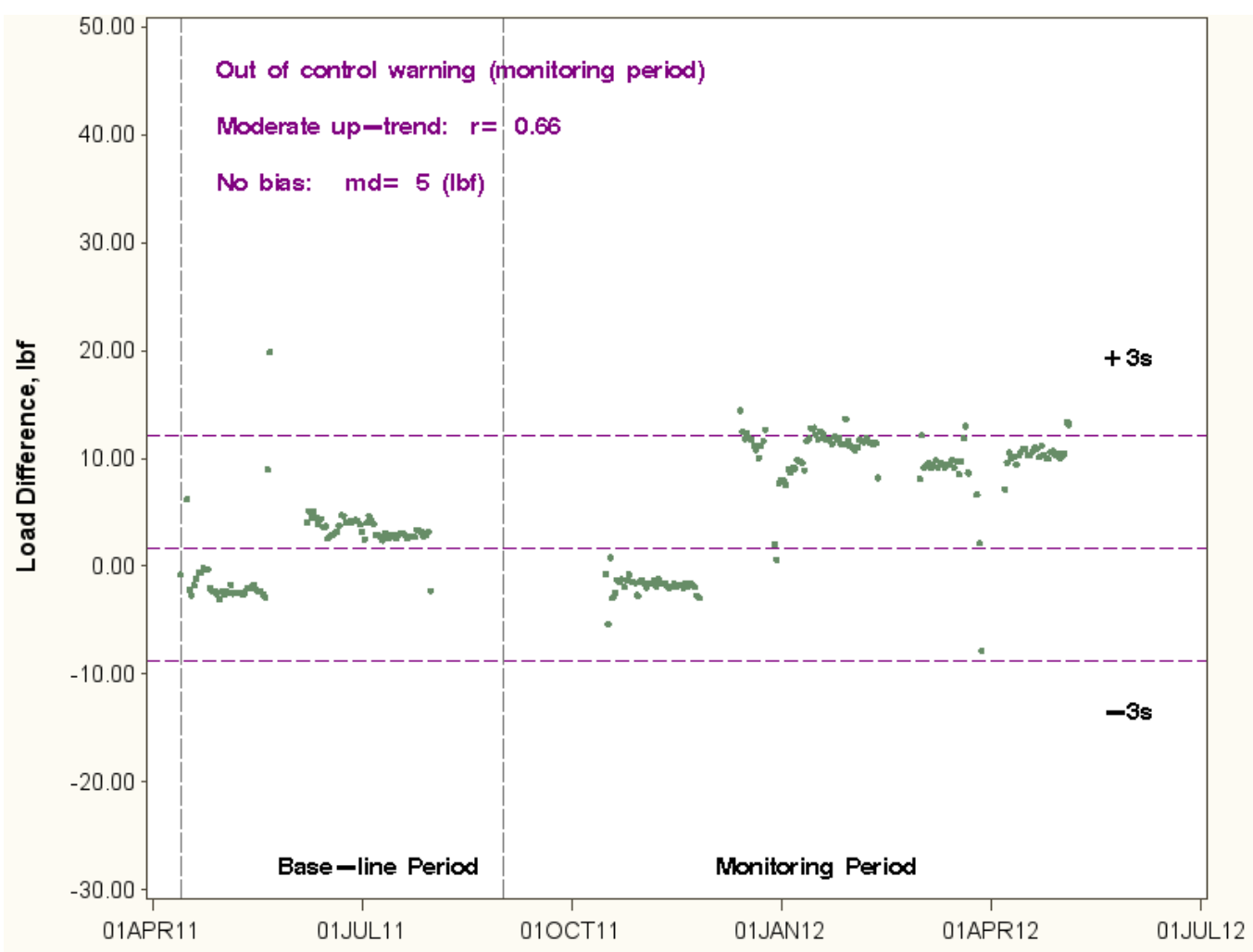

Figure 44. Control chart for differences between load cell pair LC02-LC05.

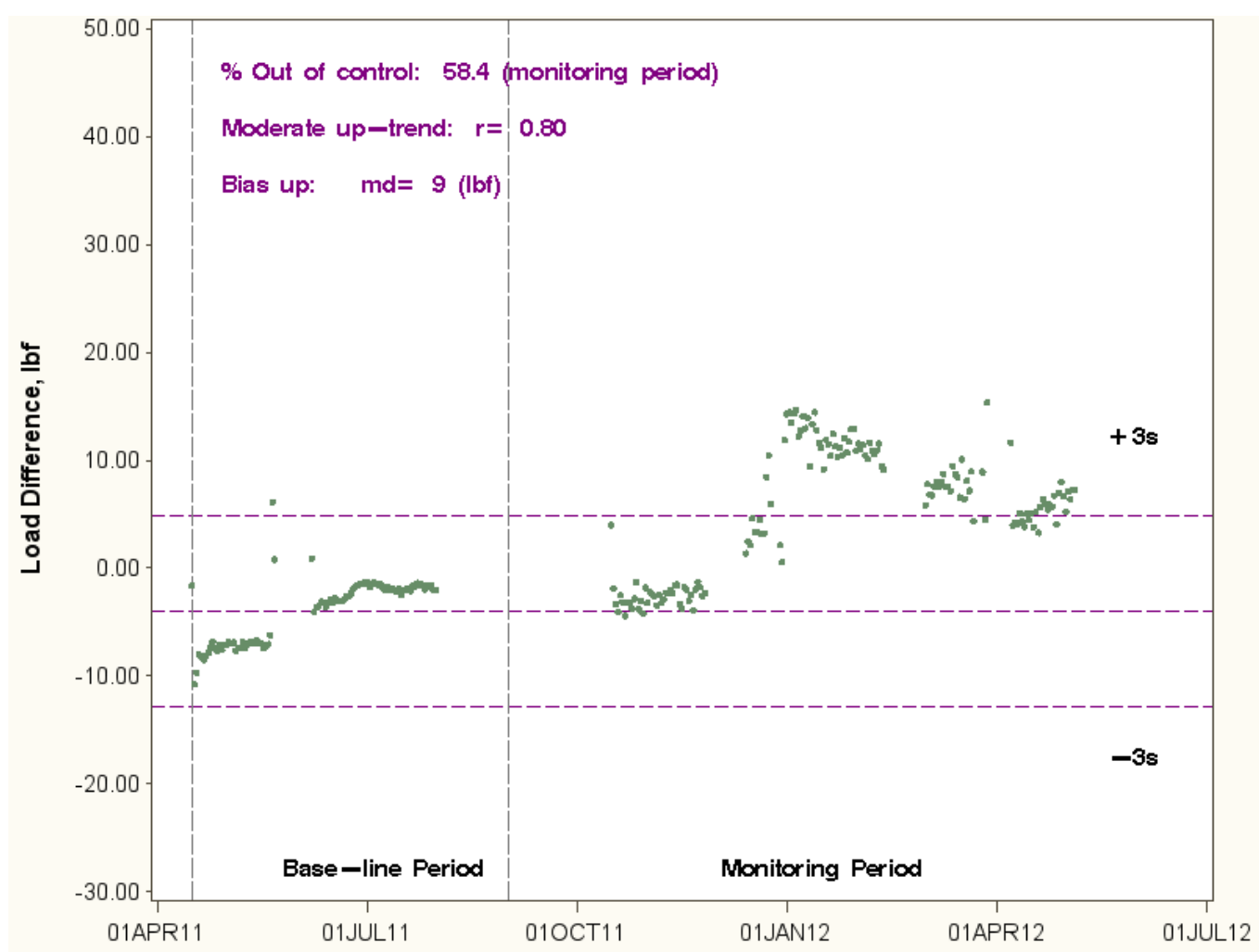

Figure 45. Control chart for differences between load cell pair LC03-LC06. 


\section{DATA QUALIFICATION}

Data qualification refers to the multistep process of verifying that the data meet the requirements for the intended use. All Type $A$ and Type $C$ data are qualified for use. This section discusses the results of data qualification for AGC-2 irradiation monitoring data. Data that have been captured into NDMAS but have not yet been through the qualification process are identified as In Process. The result of the data qualification process is the assignment of a data element to one of three categories:

- Qualified. Independent verification documents that the data meet the requirements for a specific end use as defined in a data collection plan and that data were collected within an NQA-1 or equivalent QA program. Any nonconformance concluded to not affect the usability of the data.

- Trend. Independent verification identifies minor flaws or gaps in meeting requirements for data use. Even so, the data still provide information that can be used by the program. Data were collected within an NQA-1 or equivalent QA program.

- Failed. Independent verification identifies major flaws in meeting data collection requirements. Data do not provide information about the system or object. Data are not useable by the program.

\subsection{Conformance to an NQA-1 Part I QA Program}

The verification of data with regard to meeting NQA-1, Part 1 requirements involves tracing the documentation trail of the data. The process to collect data involves writing a plan describing how data will be collected and the QA and quality control activities associated with that data. Review of the plan assures that the planned work will generate data of appropriate quality for use in the NQA-1 program. During execution, auditors and line managers evaluate the work and make sure that it is conducted according to the plan. Metadata generated by the initial documentation, audits, and acceptance inspection provide the evidence that data meet the requirements of an NQA-1 data collection program.

Documentation of the QA Program is accomplished by reference to documents. These include plans, audit reports, nonconformance reports, and engineering design files.

The following documents provide the evidence that the AGC-2 experiment data meet the requirements of NQA-1 Part 1:

- VHTR TDO Quality Assurance Project Plan (PLN-2690) — defines an NQA-1 Part 1 compliant QA program.

- Graphite Technology Development Plan (Windes et al. 2007) - overall project plan for the graphite technology research and development area.

- AGC-1 Irradiation Experimental Test Plan (Bratton 2006) - the principal experimental plan covering AGC experiments, including AGC-2.

- Advanced Graphite Capsule AGC-2 Experiment Test Train (TFR-645), Advanced Graphite Capsule Temperature Control System (TFR-509), and Advanced Graphite Capsule Compression Load Control Gas System (TFR-510) — plans that cover the irradiation phase of the experiment.

- Inspection Report IAS121679, which reviewed the ATR Data Source Streams. The inspection determined that the equipment used in the collection of data is calibrated as required by ATR technical specifications and operating requirements, data collection and transfer systems are verified to function through system testing and operational checks, and software systems meet configuration control and testing requirements. 


\subsection{Design and Instrument Specifications}

Project plans and design documents contain requirements for the construction and instrumentation of the AGC-2 capsule. To assure conformance to these requirements, an Engineering Work Instruction is prepared as a detailed checklist. This checklist has signoffs for each step with hold points for QA review and approval. Completion and acceptance of these instructions by management and QA provides independent verification that the requirements for construction and instrumentation were met. This includes verifying calibration of instruments and testing instruments after installation to ensure instruments are functional. The completed Engineering Work Instructions is filed in the INL Electronic Data Management System under the title "Engineering Work Instructions for Assembling the AGC-2 Experiment." All requirements for construction and instrumentation for the AGC-2 capsule were met and are documented in the Engineering Work Instruction.

\subsection{Data Qualification Determination}

This section summarizes the data qualification decisions. Detailed information on the data and the technical basis for the decisions is discussed in Section 3. A total of 3,430,367 response values were recorded from irradiation monitoring of the AGC-2 experiment. Of these data, only one value at TC-13, a temperature measured at 10:55 on May 23, 2011, failed to meet the requirements for data collection and accuracy. All other data are Qualified for use by the VHTR Program.

\subsubsection{Failed Data}

Temperature at TC-13 measured at 10:55 on May 23, 2011, failed to meet the requirements for data collection and accuracy.

\subsubsection{Trend Data}

No data are identified as Trend data in this data set.

\subsubsection{Pending Data}

No data remain in the In Process category.

\subsubsection{Qualified Data}

All other data collected from the AGC-2 irradiation monitoring experiment for the response variables discussed in this report are judged to meet the requirements laid out in data collection plans. The response variables qualified in this report are TC temperatures, pneumatic ram pressures, load cell output, stack position, constituent sweep gas flow rates, gas moisture, and gas pressure.

\subsubsection{Corrective Actions}

No corrective actions were identified in this review. 


\section{DATA ACCESS}

Graphite irradiation monitoring data have been uploaded to the NDMAS webpage for easy access by VHTR TDO program participants. A tab has been created on the webpage dedicated to the graphite irradiation experiment data shown in Figure 46. The graphical summary provides experiment-long figures for temperature, gas flows, and creep specimen loading. There are four links on this page. Three links provide access to temperature, gas flow, and load data that can be downloaded for analysis. The fourth link is to graphs of stack raising.

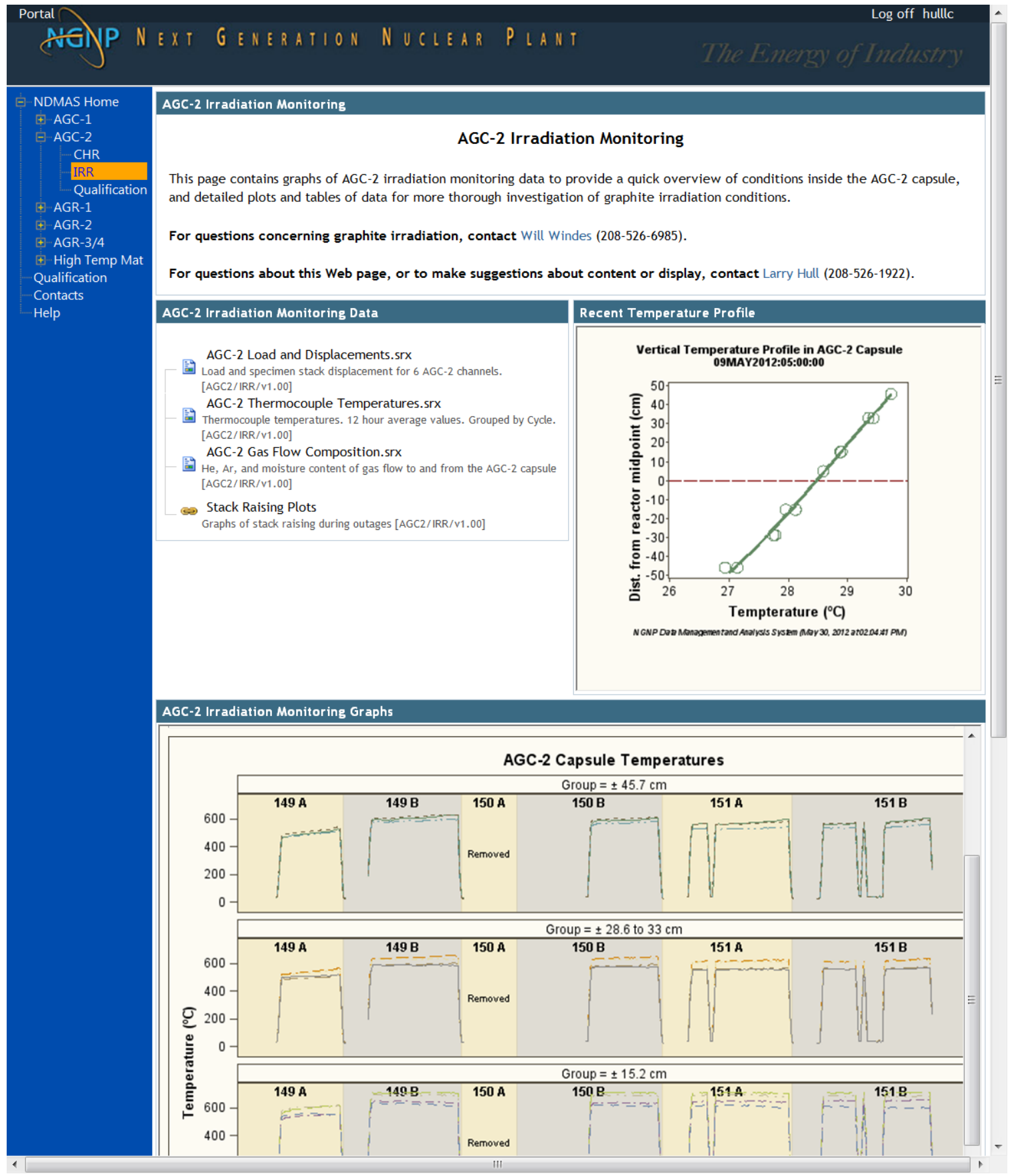

Figure 46. The AGC-2 irradiation monitoring tab (orange highlight) on the NDMAS webpage provides access to a series of reports and graphs. 


\section{QUALITY ASSURANCE}

NDMAS activities are conducted within the requirements of the VHTR TDO QA Program Plan (PLN-2690). Software quality assurance requirements for NDMAS are contained in the VHTR TDO

Software Quality Assurance (MCP-3058). Because graphite will be used as a structural component in the core of a nuclear reactor, the data collection program is being conducted within an NQA-1 Part I QA program. The INL data quality level for graphite data is Quality Level 2. 


\section{REFERENCES}

Bratton, R. L., 2006, AGC-1 Irradiation Experiment Test Plan, INL/EXT-06-11102, Idaho National Laboratory, Idaho Falls, ID.

Burchell, T. D., 2009, A Revised AGC-1 Creep Capsule Layout, ORNL/TM-2009/009, Oak Ridge National Laboratory, Oak Ridge, TN.

Duncan, A. J., 1965, Quality Control and Industrial Statistics, Third Ed., Richard D. Irwin, Inc., Homewood, IL.

MCP-2691, 2011, “Data Qualification,” Rev. 1, Idaho National Laboratory, Idaho Falls, ID.

MCP-3058, 2012, “VHTR TDO Software Quality Assurance,” Rev. 1, Idaho National Laboratory, Idaho Falls, ID.

PLN-2494, 2012, "VHTR Technology Development Office Program Management Plan," Rev. 9, Idaho National Laboratory, Idaho Falls, ID.

PLN-2690, 2011, "Very-High-Temperature-Gas-Reactor Technology Development Office Quality Assurance Program Plan,” Rev. 8., Idaho National Laboratory, Idaho Falls, ID.

PLN-2709, 2011, "Very-High-Temperature-Reactor Program Data Management and Analysis Plan," Rev. 3, Idaho National Laboratory, Idaho Falls, ID.

PLN-3319, 2012, "Records Management Plan for the VHTR Technology Development Office," Rev. 2 , Idaho National Laboratory, Idaho Falls, ID.

Pope, M. A., 2010, “AGR-1 Irradiation Test Final as-Run Report,” INL/EXT-10-18097, Idaho National Laboratory, Idaho Falls, ID.

StatSoft Inc., 2010, Electronic Statistics Textbook, StatSoft, Inc.,

TFR-509, 2011, “Advanced Graphite Capsule Temperature Control System,” Rev. 2, Idaho National Laboratory, Idaho Falls, ID.

TFR-510, 2009, “Advanced Graphite Capsule Compressive Load Control Gas System,” Rev. 2, Idaho National Laboratory, Idaho Falls, ID.

TFR-645, 2010, “Advanced Graphite Capsule AGC-2 Experiment Test Train,” Idaho National Laboratory, Idaho Falls, ID.

Windes, W. E., T. D. Burchell, and R. Bratton, 2007, Graphite Technology Development Plan, INL/EXT-07-13165, Idaho National Laboratory, Idaho Falls, ID. 
Appendix A

\section{Credentials of Technical Reviewers}




\section{Appendix A-Credentials of Technical Reviewers}

\section{Credentials for Scott Barrie}

Scott Barrie has worked full time at the Idaho National Laboratory (INL) since 1991 after graduating from college with a Bachelor's degree in Mechanical Engineering. He worked on various environmental projects including ground water and subsurface gas monitoring at various INL locations. He helped design a device to monitor volatile organic compounds in ground water, which received a patent. While working on the Large Scale Aquifer Pumping and Infiltration Test he obtained a Master's Degree in Mechanical Engineering from the University of Idaho. In 1999 he started working on various projects at the Advanced Test Reactor. He redesigned the Advanced Test Reactor (ATR) bottom-head inpile tube seals installed in the 2004 Core Internals Changeout and designed the cryogenic traps to capture fission gases for the MICE Naval Reactors experiment. He is currently the lead mechanical design engineer for the first, second, and third Advanced Graphite Creep experiments for the Next Generation Nuclear Plant. Scott holds a PE license for Mechanical Engineering in the State of Idaho.

\section{Credentials for Matthew Weseman}

Matthew Weseman has 32 years experience in designing, developing, and producing instrumentation and process control (I\&C) systems. He has supplied project engineering/management duties for numerous I\&C tasks, performing research, analysis, design and testing activities. He has experience with the commercial, military, and nuclear sectors and has extensive involvement in generating project and program proposals involving determining specifications, preliminary design, and presentation to the customer/upper management. He is currently an Advisory Engineer for the Defense Systems and Technologies (Process Instrumentation \& Controls subsection) of Battelle Energy Alliance, LLC (Idaho National Laboratory prime contractor) where he performs project engineering, design, installation, and operation of various process control and instrumentation systems, including: data acquisition, control, instrumentation, communication (wireless), networked, programmable logic controllers, and manmachine interface systems. Responsibilities include system requirements, design, hardware installation, maintenance, software verification, documentation, and design verification and qualification testing and modifications. Matt coordinates electronic, electrical, mechanical, and pneumatic instrumentation and control systems and is a project engineer/manager of new experiments and control system integration and installation. Matt is a registered Professional Engineer in Idaho. 